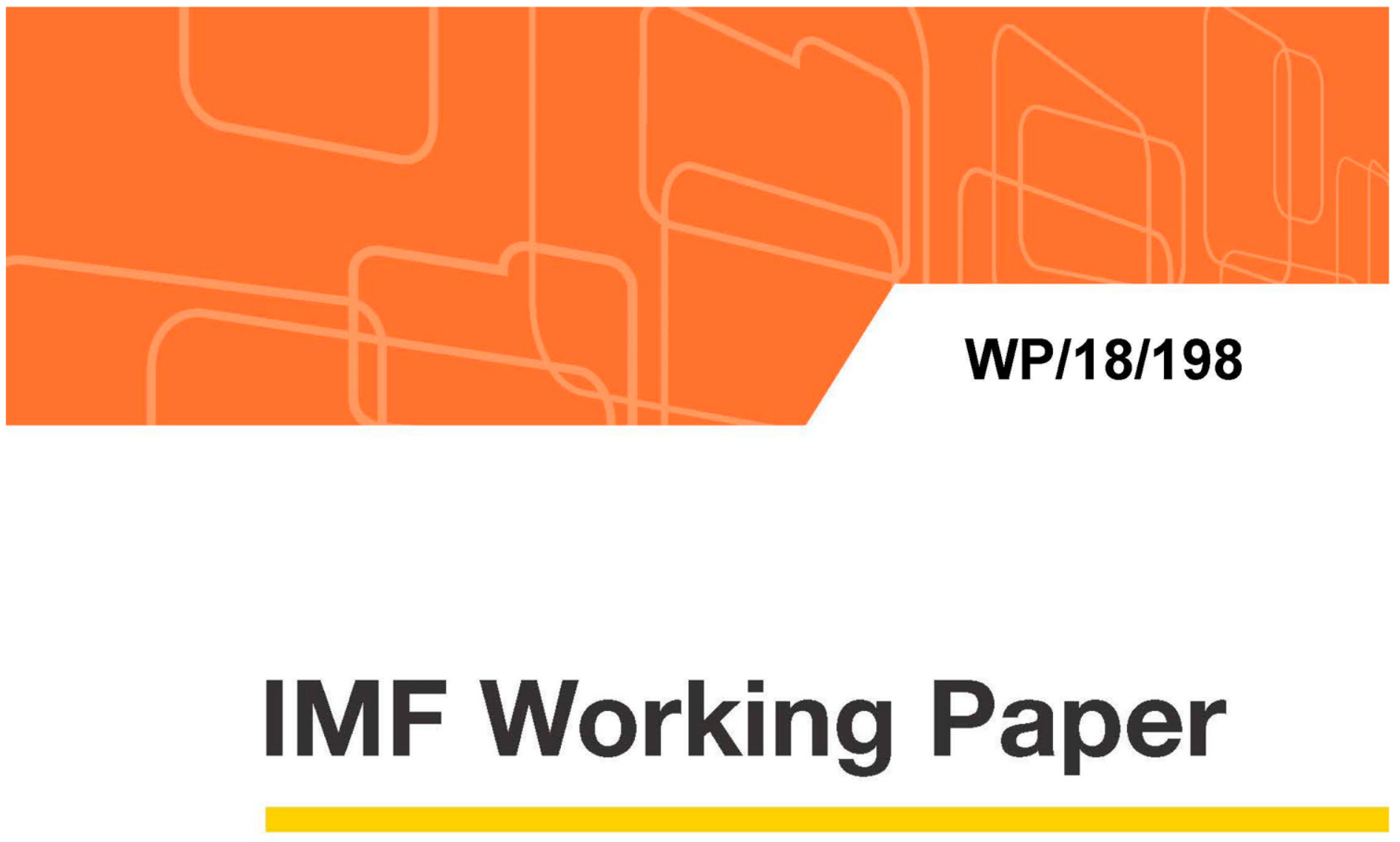

\title{
Managing Reductions in Aid Inflows: Assessing Policy Choices in Haiti
}

by loana Moldovan, Marina Rousset, and Chris Walker

IMF Working Papers describe research in progress by the author(s) and are published to elicit comments and to encourage debate. The views expressed in IMF Working Papers are those of the author(s) and do not necessarily represent the views of the IMF, its Executive Board, or IMF management. 


\section{WP/18/198}

\section{IMF Working Paper}

\section{Managing Reductions in Aid Inflows: Assessing Policy Choices in Haiti}

by loana Moldovan, Marina Rousset, and Chris Walker

IMF Working Papers describe research in progress by the author(s) and are published to elicit comments and to encourage debate. The views expressed in IMF Working Papers are those of the author(s) and do not necessarily represent the views of the IMF, its Executive Board, or IMF management. 


\title{
IMF Working Paper
}

Western Hemisphere Department

\author{
Managing Reductions in Aid Inflows: Assessing Policy Choices in Haiti \\ Prepared by Ioana Moldovan, Marina Rousset, and Chris Walker*
}

Authorized for distribution by Alejandro Santos

September 2018

\begin{abstract}
IMF Working Papers describe research in progress by the author(s) and are published to elicit comments and to encourage debate. The views expressed in IMF Working Papers are those of the author(s) and do not necessarily represent the views of the IMF, its Executive Board, or IMF management.
\end{abstract}

\begin{abstract}
A low-income country such as Haiti that confronts an environment of diminishing aid inflows must assess tradeoffs among the available policy options: spending cuts, monetization, sales of debt, or use of foreign reserves. To provide the analytical tools for this task, the paper draws from a set of DSGE models recently developed to evaluate policy choices in low-income countries for which external aid flows represent an important revenue source. Two simplified stylized variations of the main model are used to gain intuition and initially assess the trdeaoffs. Subsequenctly a full-scale small open economy DSGE model, calibrated to match conditions in Haiti and in similar low-income countries, is employed. Several key results are common to all model versions. While sales of foreign exchange reserves can compensate for the loss of aid inflows, this strategy is not sustainable. The remaining policy choices entail larger welfare costs, involving lower consumption levels and real depreciation. The results suggest that a mixture of spending cuts and depreciation is the best strategy, when use of foreign reserves is constrained.
\end{abstract}

JEL Classification Numbers: E58, E63, F35, F41, O41, H84

Keywords: Dynamic Stochastic General Equilibrium Model (DSGE); Aid; Fiscal Policy; Monetary Policy; Public Investment; Foreign Reserves; Haiti

Author's E-Mail Address: Ioana.Moldovan@glasgow.ac.uk; MRousset@imf.org; CWalker@,imf.org ${ }^{1}$

\footnotetext{
* The authors are grateful to Felipe Zanna for his extensive comments and helpful suggestions as to seminar participants from the Western Hemisphere Department of the IMF for their interest and input.
} 


\title{
Managing Reductions in Aid Inflows: Assessing Policy Choices in Haiti
}

\author{
Ioana Moldovan, Marina Rousset, and Chris Walker*
}

\begin{abstract}
In a long-run environment of diminishing aid flows, Haiti has faced, and is likely in the future to face again, a difficult set of policy tradeoffs, each entailing some combination of spending reductions, sales of debt, use of foreign reserves, or depreciation through a monetary expansion. Two simplified, stylized, models are used to gain intuition and initially assess the tradeoffs. Subsequently a full-scale, small open economy DSGE model, calibrated to match conditions in Haiti and in similar low income countries, is employed. While sales of foreign exchange reserves can better compensate for the loss of aid inflows, the remaining policy choices entail larger welfare costs. Output and consumption levels are generally lower and the real exchange rate depreciates. The results suggest that a mix of spending cuts and depreciation is a second-best strategy, when use of foreign reserves is constrained.
\end{abstract}

Keywords: Dynamic Stochastic General Equilibrium Model (DSGE); Aid; Fiscal Policy; Monetary Policy, Public Investment; Foreign Reserves; Haiti.

JEL Codes: E58, E63, F35, F41, O41, H84

\section{Introduction}

How should an aid-dependent country respond to a decline in aid flows? Over the long run, it is clear that it must move to reduce its aid dependency, but advancing towards this goal nonetheless requires difficult policy tradeoffs in the short term. This study follows in a recent trend of applying dynamic general equilibrium models to low income countries, in order to assess these choices. It employs an open economy new-Keynesian framework, making use of monopolistic competition, sticky prices, tradable and nontradable sectors, and government and central bank balance sheets, in order to provide a dynamic, detailed, and

*July 17, 2018. Moldovan: Ioana.Moldovan@glasgow.ac.uk, University of Glasgow, Economics; Rousset: MRousset@imf.org, Western Hemisphere Department, the International Monetary Fund; Walker: CWalker@imf.org, Western Hemisphere Department, the International Monetary Fund. The authors are grateful to Felipe Zanna for his extensive comments and helpful suggestions, as to seminar participants from the Western Hemisphere Department of the IMF for their interest and input. 
micro-founded model of the Haitian economy. While it is calibrated as far as possible to match observed features of that economy, a lack of detailed data on certain sectors requires the use of some parameters obtained from similar low-income countries in order to fill in gaps. This means that the model can compensate to some degree for the data gap, by providing model-based projections of policy effects where the historical record does not allow for VAR-based predictions.

There is a substantial literature on the macroeconomic effects of foreign aid, although most studies focus on the impact of aid increases - the opposite of the case studied here. While the two scenarios are not fully symmetric, it is instructive to review the major macroeconomic effects of large aid inflows. The conventional understanding ${ }^{1}$ is that these can lead to an undesired exchange rate appreciation and interest rate increase as the funds are spent domestically - a low-income-country version of Dutch disease. To mitigate the effects of the inflow on the exchange rate, the central bank can refrain from selling, or absorbing, the dollars received. These issues are explored in a line of research followed by Berg et al. ${ }^{2}$ on responses to aid scaling-up, that adapts the dynamic stochastic general equilibrium (DSGE) modeling framework to low-income countries. Employing a New-Keynesian small open economy DSGE model, they show that, for a normal range of parameters applicable to low-income contries such as Uganda, it is optimal to spend most but not all of the incremental aid increase, and to absorb (i.e., not accumulate as reserves) most of the inflows. However, the optimal response varies, depending, among other things, on the import content of government expenditure.

The present study focuses primarily on central bank responses to an aid flow reduction. On the assumption that government spending levels are unaffected over the short run by the aid reduction, and that the government finances the resulting budget shortfall through the central bank, the bank can choose among three options dictated by its balance sheet. It can monetize the incremental increase in its government bond holdings through money creation, it can sell domestic bonds to the private sector, or it can reduce its holdings of foreign reserves. A government spending cut in the face of the aid reduction can ease the tradeoffs faced by the central bank, so that it will also be important to understand the marginal benefit of relaxing this assumption.

To strengthen intuitions regarding the short-term implications of these choices, the paper first introduces a static open-economy model which illustrates the main monetary relationships and allows for analytic solutions. This model is also used to provide quantitative estimates of the effects of policy choices that can be compared with those of the main model. A stripped-down version of the main DSGE model, with a closed capital account and flexible

\footnotetext{
${ }^{1}$ As noted, for example, in Allen (2005).

${ }^{2}$ See, for example, Berg et al. (2010a) and Berg et al. (2015).
} 
prices, is also solved analytically, to provide insight on other, non-monetary, mechanisms driving macroeconomic variables, and to facilitate understanding of the main model.

In the full DSGE model, the incorporation of an open capital account and sticky prices in a two-sector dynamic model permits a careful appraisal of the real effects of monetary policy decisions. Also of particular importance in the low-income country context, the model evaluates the development of stocks of reserves, of foreign and domestic debt, and the trajectory of the exchange rate. The model also includes a large share of liquidity-constrained households, an equally important feature of developing economies such as Haiti. Microfoundations permit outright welfare comparisons among different policy choices, as well as across different types of households. Numerical solutions obtained in the model, while in general consistent with intuitive and model-based priors regarding Haiti's policy choices, also offer some surprises of degree and, in some cases, sign.

The results indicate that, while sales of foreign exchange reserves can potentially fully compensate for the loss of aid inflows, the remaining policy choices entail welfare costs. Output and consumption levels are generally lower, while the real exchange rate depreciates. When the aid reduction is accompanied by an equivalent decrease in government spending, the real interest rate depreciates to maintain external balance with the real depreciation. If the expenditures cuts are in public investment, as assumed in the full DSGE model, the subsequent decrease in the stock of public capital (infrastructure) further reduces production capacity. Aid cuts matched by bond sales to the private sector also lead to a real depreciation of the currency as well as a rise in real interest rates through a standard crowding-out effect. Monetization of the increase in government debt following an aid cut still results in a real interest rate higher than the rate prevailing before the aid reduction. Monetization also triggers a large real depreciation and sharply higher inflation, and thus a large nominal depreciation.

The analysis also highlights the welfare implications of these policy choices. Monetizing the increased deficit has worse welfare outcomes for those households who own assets, as very high inflation erodes the value of these assets, while it is the least costly policy option for households who are liquidity-constrained, as they benefit most from the large real appreciation of foreign remittances. Liquidity-constrained households are however significantly worse off when the policy options are to either reduce government expenditures or increase sales of debt - these policies lead to relatively large reductions in after-tax wages, which directly reduce the consumption of these households. The welfare loss for liquidity-constrained households under these policies is about ten times larger than for households that hold assets and are better able to smooth consumption. These results point to further application of the model in evaluating the likely impact of potential shocks, and in proposing appropriate policy responses to these.

The remainder of this paper is organized as follows. Section 2 describes the role of foreign 
aid in Haiti's public-investment program. Section 3 presents a static model, which provides some analytic insights on the tradeoffs faced by policy makers as aid inflows decline. Section 4 considers a simplified dynamic model where the analytical solutions further expand our understanding of the policy implications on the real economy. Finally, in Section 5, we analyze the policy choices through the lense of the more complex DSGE model. The last section concludes.

\section{Aid Flows to Haiti}

Relative to its output, Haiti is the largest recipient of foreign assistance in the Latin America and Caribbean region. It is the poorest country in the Western Hemisphere and one of the poorest in the world, with annual per-capita income around $\$ 800$. Foreign aid, largely humanitarian assistance, has been linked to natural disasters such as tropical storms, hurricanes, floods, droughts, and earthquakes, to which Haiti is particularly susceptible. Real output growth has average only 1 percent over the past 30 years, insufficient to keep up with population growth. Over this period, Haiti has maintained a floating exchange rate, while fiscal policy has been largely determined by the availability of external financing for the public sector deficit.

\section{... and highly aid-dependent}

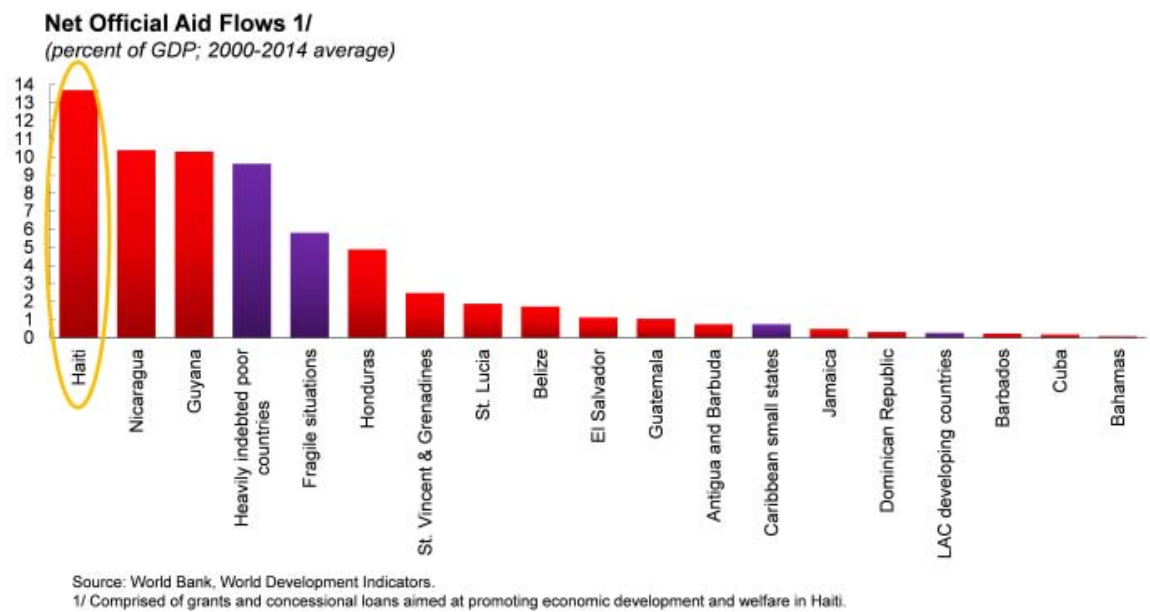

3

Figure 1: Net official aid flows (as percent of GDP), 2000-2014 average.

In January 2010, Haiti suffered a magnitude 7.0 earthquake causing damage equivalent to about 120 percent of GDP. Humanitarian appeals that followed generated an unprecedented aid inflow, yielding over $\$ 8$ billion in grants and loans disbursed over a five-year period. In 
addition, about $\$ 1.9$ billion of Haiti's debt was forgiven or rescheduled after 2010 by official donors (bilateral and multilateral), freeing up government resources for public investment. Foreign aid has been used to finance the reconstruction effort and uphold spending on social services, such as health, education and nutritional assistance. The ratio of grants to domestic revenue averaged over 60 percent in the post-earthquake period.

\section{Development assistance to Haiti}

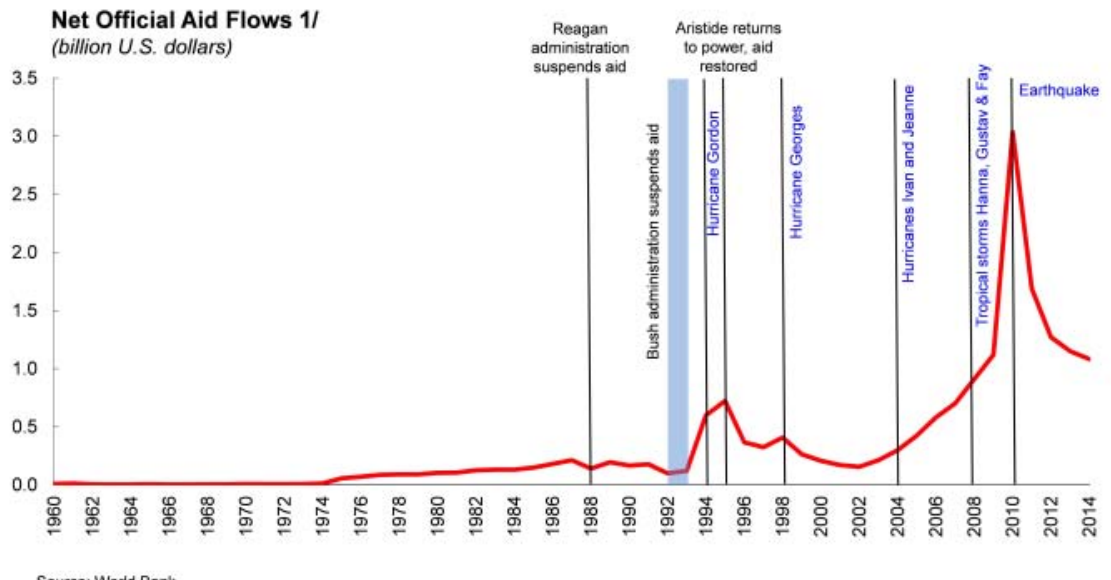

Figure 2: Development assistance to Haiti, 1960-2014.

The level of public spending tracks fairly closely with foreign aid inflows. Foreign aid has been a vital factor buoying public investment in Haiti, but external-aid volatility has contributed to low efficiency of public-investment spending by hampering long-term planning and budgeting. Other factors responsible for low efficiency of public investment are overstated project costs, waste and leakage of resources, and capacity constraints - related not only to project implementation, but its appraisal, selection and evaluation. ${ }^{3}$ Due to these shortcomings, the rise in public investment, especially in the post-earthquake period, has not translated into robust economic growth, but has nonetheless been important to reduce certain infrastructure bottlenecks and sustain the reconstruction effort.

The post-earthquake inflow of external grants and budget support peaked in 2012, declining gradually thereafter as relief efforts wound down. The slowdown of aid flows reflects a large base effect - the scale of donor support following the 2010 earthquake was far above trend (see Figure 4) as many contributions came from bilateral donors on a one-time basis. However, it also reflects broader concerns about domestic policy in Haiti, as well as a global

\footnotetext{
${ }^{3}$ In particular, Dabla-Norris et al. (2012) assign a score of zero to Haiti's investment-project appraisal capacity.
} 


\section{Shrinking public investment}

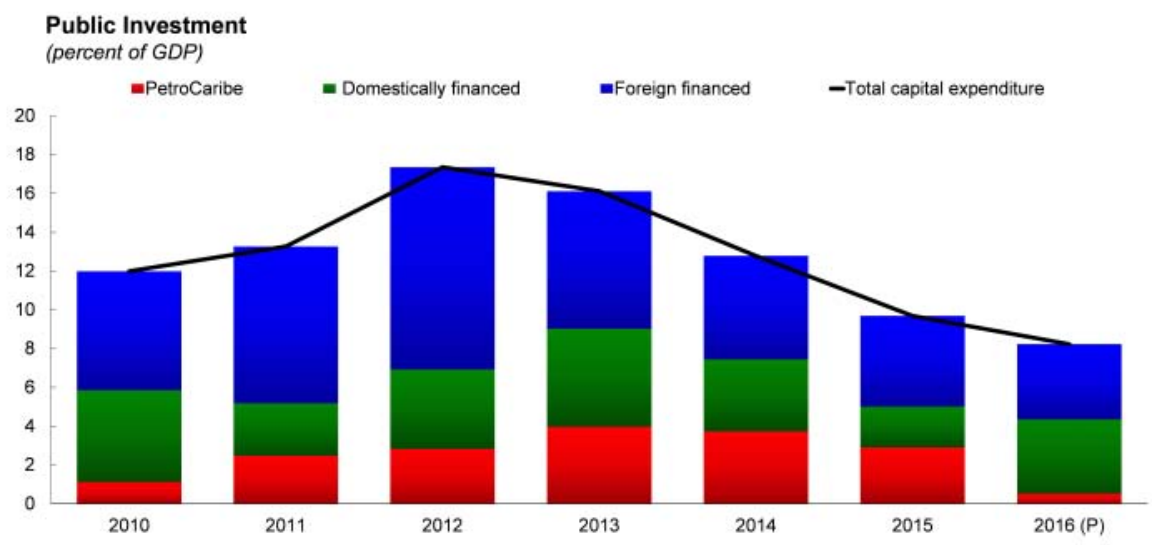

Sources: Ministry of Finance, Haitian Institute of Statistics.

Figure 3: Public investment in Haiti (percent of GDP), 2010-2016.

phenomenon of donor fatigue. In addition, as oil prices collapsed by over 70 percent between June 2014 and January 2016, concessional loans from Venezuela's Petrocaribe program Haiti's main source of non-grant external finance - declined by 80 percent between fiscal years 2014/15 and 2015/16.

\section{Scaling down of aid (cont.)}

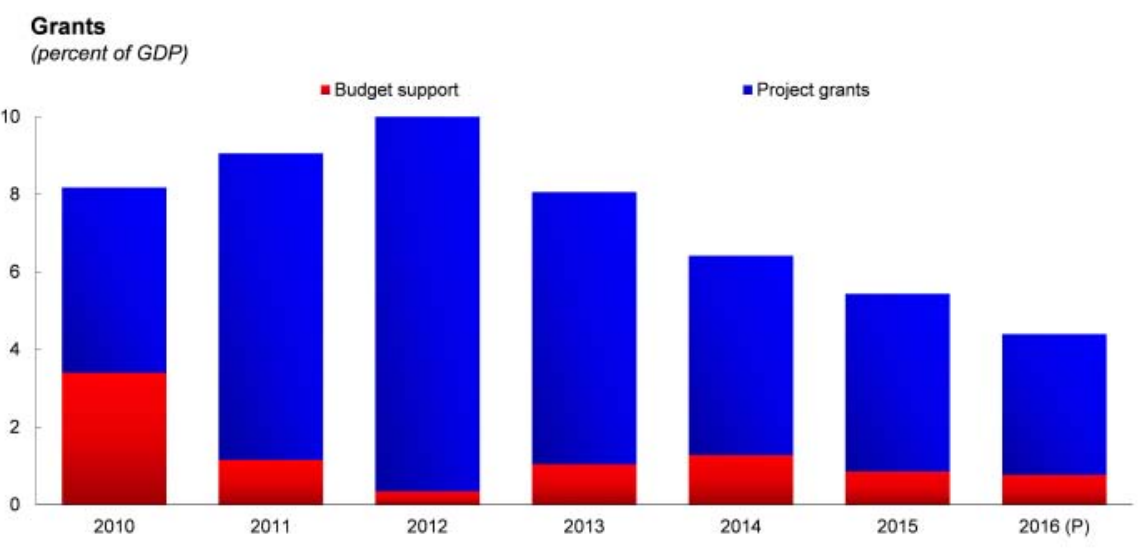

Sources: Ministry of Finance, Haitian Institute of Statistics

Figure 4: Scaling down of aid in Haiti. 


\section{A Simple Static Model of Monetary Policy in Response to Aid Reductions}

A static model suitable for analyzing the policy choices facing the Haitian authorities in the wake of a external aid shock is constructed. Calibration with plausible parameters yields quantitative estimates which may serve as a point of departure for the full DSGE model. Driving the model specification is the question of how the fiscal authority and the central bank should respond to an unexpected drop in aid.

The model is characterized by the following equations:

$$
\begin{aligned}
& \text { (1) : NDA+FR }: x=M B ; \quad \text { [Central bank balance sheet] } \\
& \text { (2) : } \bar{Y}=C+I(r)+G+N X \cdot x \text {; } \\
& {[\mathrm{GDP}]} \\
& \text { (3) : } G N D Y=C+I(r)+G+N X \cdot x+R m z \cdot x+A i d \cdot x \text {; [Gross national disposable income] } \\
& \text { (4) }: C=c(\bar{Y}+R m z \cdot x-T a) ; \quad S a=(1-c)(\bar{Y}+R m z \cdot x-T a) \text { [Consumption demand] } \\
& \text { (5) }: I(r)=\bar{I}-(r-\bar{r}) v \\
& \text { [Investment demand] } \\
& \text { (6) : } B D=G-T a-A i d \cdot x \\
& \text { [Budget deficit] } \\
& \text { (7) : } P N S=S a(x)-I(r) \text {; } \\
& \text { (8) : } N B S P=B D-\triangle N D A \\
& \text { (9) : } C A=\left(\frac{1}{x}\right)(P N S-B D) \\
& \text { [Private net saving] } \\
& \text { [Net bond sales to the private sector] } \\
& \text { (10) }: \pi=\bar{\pi}+\delta(M B-\overline{M B}) \\
& \text { (11) : } K A=\left(\frac{\bar{Y}}{x}\right)\left(\kappa+\gamma_{x}(x-\bar{x})+\gamma_{r}\left(r-r^{*}\right)\right) \\
& \text { (12) : } \triangle F R=K A+C A \\
& \text { (13) : } \quad C_{N}=\frac{e^{x}}{1+e^{x}} C ; \quad C_{T}=\frac{1}{1+e^{x}} C \\
& \text { (14) }: I_{N}=\frac{e^{x}}{1+e^{x}} I\left(r^{\prime}\right) ; \quad I_{T}=I-I_{N} \\
& \text { (15) }: r=r^{\prime}+\rho(N B S P) \\
& \text { (16) : } G_{N}=G \text {; } \\
& \text { (17) }: \bar{Y}=C_{N}+I_{N}+G_{N} \\
& \text { [Current account] } \\
& \text { [Inflation (money demand)] } \\
& \text { [Capital/financial account] } \\
& \text { [Balance of payments] } \\
& \text { [Nontradeables consumption demand] } \\
& \text { [Nontradeables investment demand] } \\
& \text { [Real interest rate] } \\
& \text { [Nontradeables government demand] } \\
& \text { [Internal balance] }
\end{aligned}
$$


Long-run values $\bar{x}$, for the real exchange rate, and $\bar{r}$, for the real interest rate, are unaffected by current conditions, and function as fixed parameters. The subscript $N$ denotes the single nontradeable good, while $T$ denotes the tradeable good, which is not produced domestically. Greek letters correspond to fixed parameters, calibrated to Haiti's case. All domestic variables (e.g., $C, B D, M B$, etc.) are expressed in real local currency terms.

The price assumptions are as follows. Given fixed output, and to maintain the tractability of the model, money demand is assumed to be invariant, with the result that domestic inflation $\pi$ is determined by the real money base MB. Domestic prices take time to adjust they adjust fully in the long run (implicitly a single period). However the nominal exchange rate, and therefore the real exchange rate $x$, adjusts instantaneously to monetary and other shocks. Consumption and investment demand for nontradeable $N$ and tradeable $T$ goods is a function of the relative prices of the two goods, i.e. the real exchange rate $x$ as shown in equations (13) and (14).

Domestic output is fixed over the horizon of the model, reflecting the low supply elasticity of domestic output. Investment is a negative function of the domestic real interest rate. The real exchange rate $x$ shifts instantaneously, following standard practice, to respond to aid shocks and policy decisions, but the long-run real exchange rate $\bar{x}$ is unaffected by these. The central bank is available to finance the full budget deficit on the margin, but the central bank is also able to conduct open market operations with the private sector (equivalently, the government can sell debt directly to the private sector). Net bond sales to the private sector affect the real interest rate, as expressed in equation (15). The current account $C A$ is determined as the sum of net public savings $(-B D)$ and net private savings $P N S$, as expressed in equation (9). The capital account $K A$ reflects a modified interest parity relationship as expressed in equation (9), such that net capital inflows are determined as a positive function both of domestic interest rates $r$ relative to the long-term equilibrium real interest rate $\bar{r}$, and of expected appreciation $(x-\bar{x})$. Aid is provided as a grant to the government in foreign exchange, deposited by the government in the central bank so that central bank reserves are augmented by the amount of the aid grant, and government deposits at the central bank increase by the equivalent amount in local currency.

Equations $(4-5)$ and $(13-17)$ can be used to obtain a conditions for internal balance:

$$
\bar{Y}=\frac{e^{x}}{1+e^{x}}\left[c(\bar{Y}+R m z \cdot x-T a)+I\left(r^{\prime}\right)+G\right]
$$

Multiplying through by $\frac{1+e^{x}}{e^{x}}$, rearranging terms, and using equation (5) to substitute for $I(r)$ yields:

$$
\left(r^{\prime}-\bar{r}\right) v-\bar{I}=\left[c((\bar{Y}+R m z \cdot x-T a)+G]-\bar{Y}\left(\frac{1+e^{x}}{e^{x}}\right)\right.
$$

This equation is solved for $r^{\prime}$ to yield a closed-form expression for internal balance: 


$$
\left.r^{\prime}=\left(\frac{1}{v}\right)[c \bar{Y}+c R m z \cdot x-c T a+G)-\bar{Y}\left(\frac{1+e^{x}}{e^{x}}\right)+\bar{I}\right]
$$

Substituting in equation (15) to solve for $\mathrm{r}$ :

$$
\left.r=\left(\frac{1}{v}\right)[c \bar{Y}+c R m z \cdot x-c T a+G)-\bar{Y}\left(\frac{1+e^{x}}{e^{x}}\right)+\bar{I}\right]+\rho N B S P
$$

Note that the internal balance line is upward sloping in $(r, x)$ space:

$$
\frac{d r}{d x}=\frac{c}{v} R m z+\frac{1}{e^{x}} \bar{Y}>0
$$

To obtain the condition for external balance, substitute equations (6-7), (9), and (11) into the balance of payments identity (12) .

$$
\begin{aligned}
\Delta F R= & \frac{1}{x}[((1-c)(\bar{Y}+R m z \cdot x-T a)-I(r)-G+T a+\text { Aid } \cdot x)] \\
& +\frac{\bar{Y}}{x}\left[\kappa+\gamma_{x}(x-\bar{x})+\gamma_{r}\left(r-r^{*}\right)\right]
\end{aligned}
$$

Multiplying through by the real exchange rate $x$, and substituting equation (5) yields:

$$
\begin{aligned}
x \Delta F R= & (1-c) \bar{Y}+(1-c) R m z \cdot x-(1-c) T a-(\bar{I}-(r-\bar{r}) v)+\text { Ta }+ \text { Aid } \cdot x-G \\
& +\bar{Y} \kappa+\bar{Y} \gamma_{x} \cdot x-\bar{Y} \gamma_{x} \cdot \bar{x}+\bar{Y} \gamma_{r} \cdot r-\bar{Y} \gamma_{r} r^{*}
\end{aligned}
$$

Collecting terms:

$$
\begin{aligned}
x\left[\Delta F R-(1-c) R m z-A i d+\bar{Y} \gamma_{x}\right]= & (1-c) \bar{Y}-(1-c) T a+T a-G+\bar{Y}\left(\kappa-\gamma_{x} \bar{x}-\gamma_{r} r^{*}\right) \\
& r \cdot v+r \cdot \bar{Y} \gamma_{r}-\bar{I}-\bar{r} v
\end{aligned}
$$

Defining $\Omega=\Delta F R-(1-c) R m z-A i d-\bar{Y} \gamma_{x}$, and $\Psi=\kappa-\gamma_{x} \bar{x}-\gamma_{r} r^{*}$, the expression for external balance becomes:

$$
x \Omega=((1-c) \bar{Y}+c T a-G+\bar{Y} \Psi-\bar{I}-\bar{r} v)+r\left(v+\bar{Y} \gamma_{r}\right)
$$

Dividing through by $\Omega$ yields a closed-form solution for x:

$$
x=\frac{((1-c) \bar{Y}+c T a-G+\bar{Y} \Psi-\bar{I}-\bar{r} v)}{\Omega}+r \frac{\left(v+\bar{Y} \gamma_{r}\right)}{\Omega}
$$

Note that $\Omega$ will be negative as long as the accumulation of foreign reserves does not 
exceed the sum of aid inflows and nonconsumed remittances. Moreover, even if reserve accumulation does exceed this threshold, given a "normal" range of parameters for a lowincome country, the expression will still be positive. (The extreme case in which $\Omega$ becomes negative corresponds to a situation where reserve accumulation is so high that the accounting effect of a weaker currency (i.e. higher $x$ ) in increasing reserves denominated in local currency terms outweighs the positive effect of a weaker currency on the capital and current account balances). The external balance line is then downward-sloping in $(r, x)$ space [Figure 5].

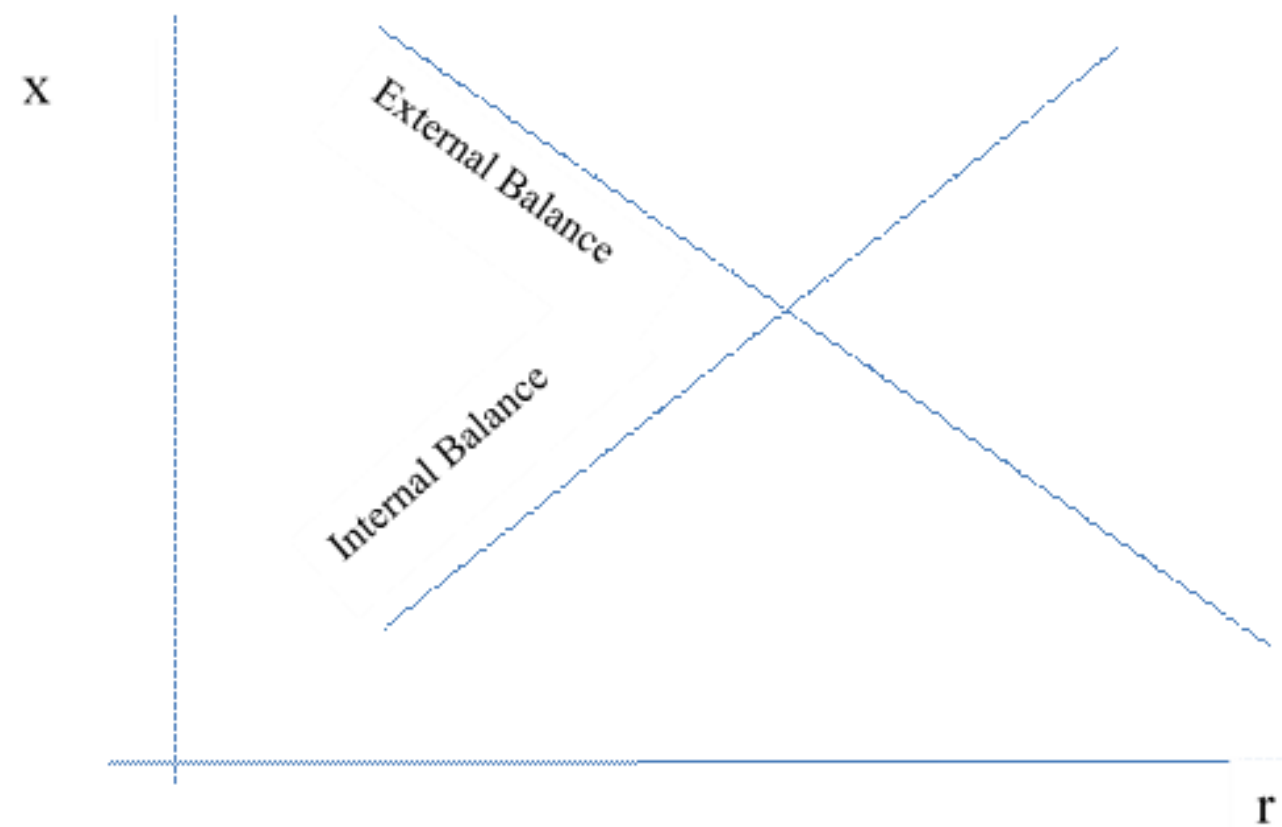

Figure 5: Ex-ante market equilibrium in the $(r, x)$ space, before the aid shock.

The panels in Figure 6 depict the effects of a halt in aid, depending on the policy response. In the first case, if government spending is cut to match the decline in aid, the real interest rate drops and the exchange rate depreciates. The decline in government spending causes the internal balance line IB to move to the left, corresponding to a drop in demand for domestic output. The decline in aid, matched by the decline in government spending, prompts steepening of the external balance line EB, pivoting around the ex ante real exchange rate of 1. The net impact is that the real interest rate drops and the real exchange rate depreciates. Nominal variables move in the same direction, as there is no change in the monetary base.

If the budget deficit is increased, and the central bank finances this, then it has essentially three options, dictated by its balance sheet. To make room for the additional government debt, it may sell debt to the private sector. As depicted in Figure 6-2, the EB line steepens and shifts to the right with the loss of aid. At the same time the IB curve moves to the 
right, reflecting the effect of the net bond sales on the real interest rate. This leads to an increase in the real interest rate, and an indeterminate impact on the real exchange rate, as the weakening impact of the decline in aid flows is counteracted by the impact of the bond sales on the interest rate.

Monetization of the increase in government budget deficit is presented in panel 3 of Figure 6. Here, the central bank monetizes the purchase of the additional government debt, increasing the money supply. With no open market bond sales, the IB line rests unchanged, while the EB line shifts as in panel 2. The real interest rate rises, although not as much as in the case of bond sales to the private sector, while the lack of net bond sales to the private sector allows the real exchange rate to depreciate. With the increase in the money supply (not depicted), the nominal interest rate rises further, while the nominal exchange rate depreciates more sharply than the real exchange rate.

The central bank's third option is to match the increased purchase of government bonds with an equivalent sale of foreign reserves, sterilizing the extension of credit to the government and keeping the monetary base unchanged, but at the cost of losing reserves - as shown in panel 4 of Figure 6. Both IB and EB lines remain unchanged, and the net impact on interest and exchange rates is zero. Of course, partial tradeoffs among these basic alternatives (higher interest rate, exchange rate depreciation, loss of reserves, or budget cuts) are possible (see, for example, the last line of Table 1 for a numerical example).

The implications of each of these policy choices are explored in more detail in numerical simulations of the model, detailed in Table 1 below $^{4}$. The base case, of an uninterrupted inflow of the equivalent of two percent of GDP in aid, is shown as the first row of the table. The second line of the table is included to illustrate the impact of an open market purchase from the public, with no reduction in aid flows. The next four cases correspond to the four panels of Figure 6, while the final line presents a mixed scenario.

\section{A Simple Dynamic Model of Aid Changes}

The static model of Section 3 is useful in elucidating the monetary responses to different policy choices in the wake of an aid cut, but it provides little insight on the behavior of the real economy or on dynamic responses to these shocks. To understand these, we turn to a DSGE modeling framework. This is developed first in the form of a simplified but analytically tractable model, that illustrates the interaction between exchange rate changes and the real economy, before considering simulation results from a more complex model economy, calibrated to capture key features of Haiti.

\footnotetext{
${ }^{4}$ Computations were performed in Matlab using the fsolve nonlinear system solver.
} 


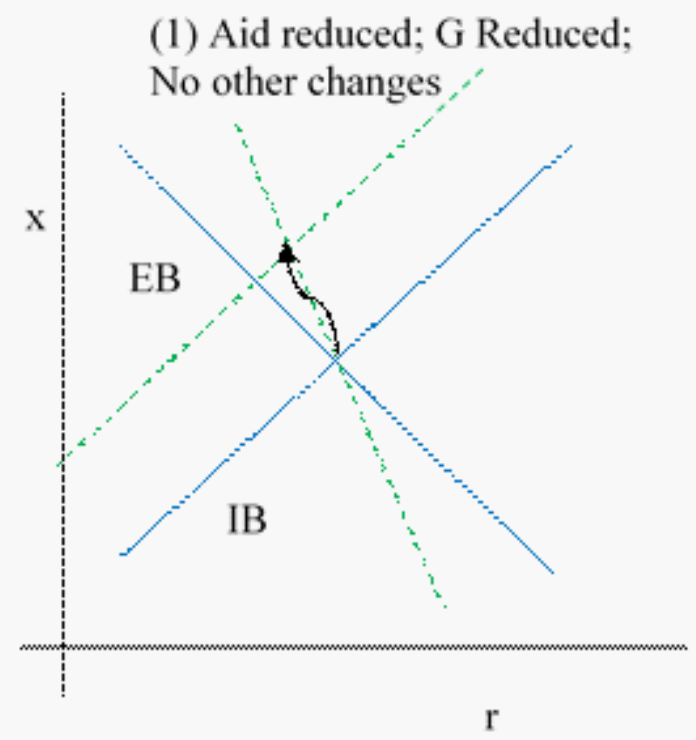

(3) Aid reduced; G Unchanged; MB Up; Debt Monetization

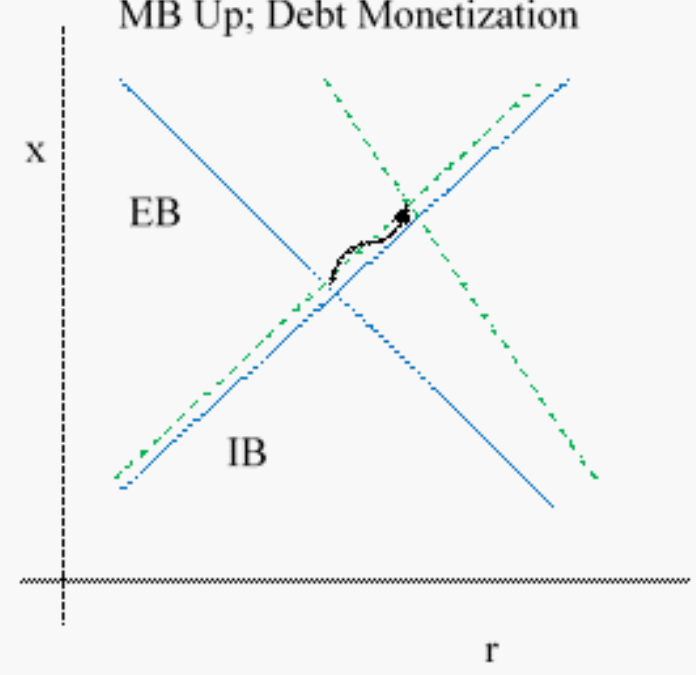

(2) Aid reduced; G Unchanged; MB no change; Debt Sales to PS

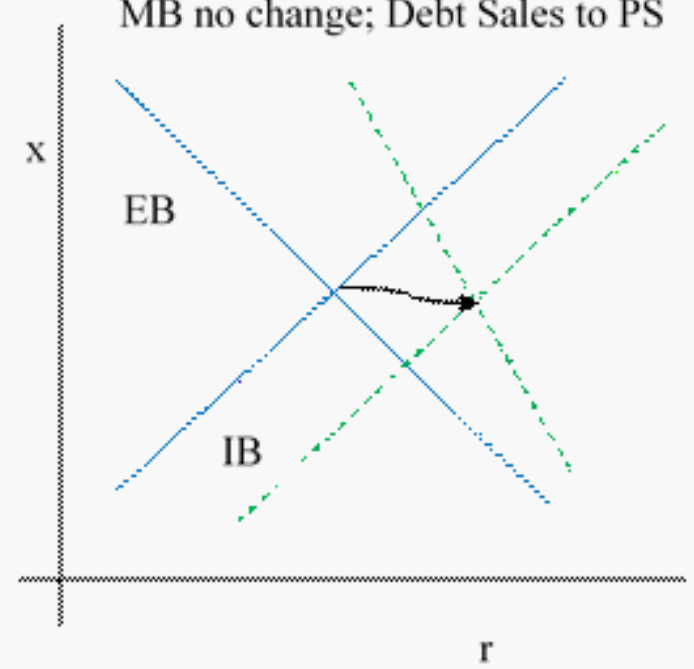

(4) Aid reduced; G Unchanged; MB No Change; F/X Sales

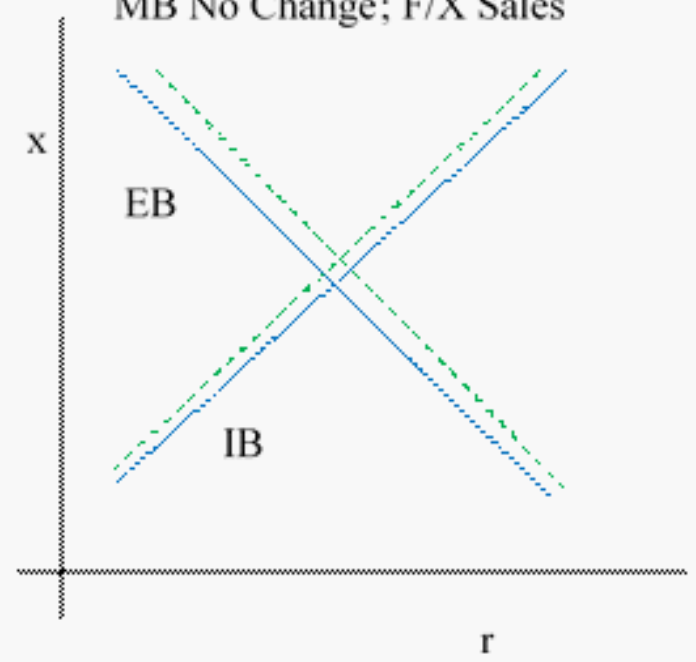

Figure 6: Consequences of the decline in aid, under the four policy scenarios. 


\begin{tabular}{|c|c|c|c|c|c|c|c|c|c|c|c|c|c|c|c|}
\hline & \multicolumn{7}{|c|}{ In percent of GDP } & \multicolumn{4}{|c|}{ In percent } & \multicolumn{4}{|c|}{ In percent of GDP } \\
\hline & \multicolumn{4}{|c|}{ Policy variables } & \multirow[b]{2}{*}{ 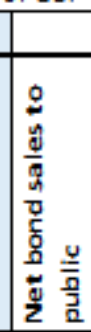 } & \multirow[b]{2}{*}{ 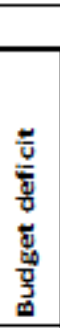 } & \multirow[b]{2}{*}{ 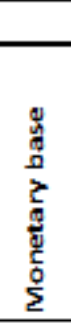 } & \multirow[b]{2}{*}{ 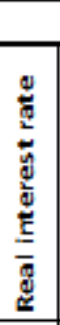 } & \multirow[b]{2}{*}{ 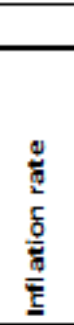 } & \multirow[b]{2}{*}{ 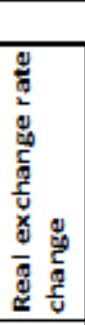 } & \multirow[b]{2}{*}{ 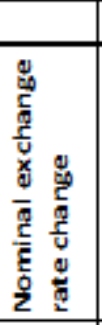 } & \multirow[b]{2}{*}{ _ } & \multirow[b]{2}{*}{$\underline{z}$} & \multirow[b]{2}{*}{$\$$} & \multirow[b]{2}{*}{$\$$} \\
\hline Scenario & $\frac{\pi}{4}$ & 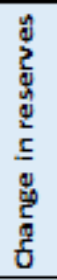 & 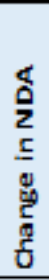 & 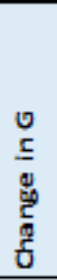 & & & & & & & & & & & \\
\hline \multicolumn{16}{|l|}{ No aid cut } \\
\hline Baseline case & 2 & 0 & 0 & 0 & 0 & 2 & 10.0 & 7.0 & 8.0 & 0.0 & -7.4 & 25.0 & -4.0 & -2.0 & 2.0 \\
\hline Bond purchases from the public & 2 & 0 & 2 & 0 & -2 & 2 & 12.2 & 4.8 & 10.2 & -2.0 & -10.9 & 25.1 & -4.0 & -2.0 & 2.0 \\
\hline \multicolumn{16}{|l|}{\begin{tabular}{|c|} 
Aid cut \\
\end{tabular}} \\
\hline Budget cut & 0 & 0 & 0 & -2 & 0 & 2 & 10.6 & 1.3 & 8.6 & -5.3 & -12.4 & 25.3 & -1.9 & -1.9 & 1.9 \\
\hline Crowding out & 0 & 0 & 0 & 0 & 2 & 4 & 9.9 & 16.3 & 7.9 & 1.2 & -6.2 & 24.5 & -3.7 & -3.7 & 3.7 \\
\hline Monetization & 0 & 0 & 2 & 0 & 0 & 4 & 12.1 & 14.2 & 10.1 & -0.8 & -9.8 & 24.6 & -3.6 & -3.6 & 3.6 \\
\hline Reserves sales & 0 & -2 & 2 & 0 & 0 & 4 & 10.0 & 7.0 & 8.0 & 0.0 & -7.4 & 25.0 & -4.0 & -4.0 & 2.0 \\
\hline Monetization/Reserves sales & 0 & -1 & 2 & 0 & 0 & 4 & 11.0 & 10.6 & 9.0 & -0.4 & -8.6 & 24.8 & -3.8 & -3.8 & 2.8 \\
\hline
\end{tabular}

Table 1: Numerical simulations in the simple static modely.

\subsection{Simple Model Setup}

The model economy includes households, a tradable and a non-tradable production sector, the government and the central bank. Firms use only labor in production and prices are fully flexible. This is similar to the analytical models in Berg et al. (2010) and Shen et al. (2016) and represents a simplified version of the more complex economy discussed in the next section.

Households The representative household chooses consumption $\left(c_{t}\right)$, labor $\left(l_{t}\right)$, real money balances $\left(m_{t}\right)$, and domestic one-period government bonds $\left(b_{t}^{c}\right)$ to maximize the expected utility

$$
E_{0} \sum_{t=0}^{\infty} \beta^{t}\left[\frac{\left(c_{t}\right)^{1-\sigma}}{1-\sigma}-\varkappa^{l} \frac{\left(l_{t}\right)^{1+\psi}}{1+\psi}+\varkappa^{m} \frac{\left(m_{t}\right)^{1-\xi}}{1-\xi}\right]
$$

subject to the budget constraint

$$
c_{t}+m_{t}+b_{t}^{c}=\left(1-\tau_{t}\right) w_{t} l_{t}+\frac{m_{t-1}}{\pi_{t}}+\frac{R_{t-1} b_{t-1}^{c}}{\pi_{t}}+\Omega_{t}+s_{t} r m^{*} .
$$

$\beta$ is the discount factor and $\sigma, \psi$, and $\xi$ are the inverses of the elasticities of intertemporal substitution for consumption, labor, and money. $w_{t}$ is the real wage rate, $R_{t}$ is the gross nominal interest rate on government bonds, $\pi_{t}$ is the rate of inflation, and $\Omega_{t}$ are dividends from firms, rebated to households in lump-sum fashion. $\mathrm{rm}^{*}$ are foreign remittances, assumed 
constant, and $s_{t}$ is the real exchange rate. Labor income is taxed at rate $\tau_{t}$.

The consumption basket, $c_{t}$, is a constant elasticity of substitution (CES) aggregate of nontraded and traded goods, with the intratemporal elasticity of substitution $\chi$ and degree of home bias $\varphi$ :

$$
c_{t}=\left[\varphi^{\frac{1}{\chi}}\left(c_{t}^{N}\right)^{\frac{\chi-1}{\chi}}+(1-\varphi)^{\frac{1}{\chi}}\left(c_{t}^{T}\right)^{\frac{\chi-1}{\chi}}\right]^{\frac{\chi}{\chi-1}} .
$$

The corresponding demand functions are

$$
c_{t}^{N}=\varphi\left(p_{t}^{N}\right)^{-\chi} c_{t} \quad \text { and } \quad c_{t}^{T}=(1-\varphi)\left(s_{t}\right)^{-\chi} c_{t}
$$

where $p_{t}^{N} \equiv \frac{P_{t}^{N}}{P_{t}}$ and $s_{t} \equiv \frac{P_{t}^{T}}{P_{t}}$ are the relative prices of the nontraded and traded goods and $P_{t}=\left[\varphi\left(P_{t}^{N}\right)^{1-\chi}+(1-\varphi)\left(P_{t}^{T}\right)^{1-\chi}\right]^{\frac{1}{1-\chi}}$ is the aggregate price index. All real variables are expressed in terms of this consumption basket. And we have the expenditure relationship, $p_{t}^{N} c_{t}^{N}+s_{t} c_{t}^{T}=c_{t}$.

Firms Firms in the non-tradable sector are monopolistically competitive but prices are flexible. Each firm $i$ employs labor $l_{t}^{N}(i)$ to produce a differentiated good using the technology

$$
y_{t}^{N}(i)=z^{N}\left[l_{t}^{N}(i)\right]^{\alpha^{N}}
$$

where $z^{N}$ is a constant total factor productivity (TFP) term and $\alpha^{N}$ is the labor income share. The differentiated nontraded goods are aggregated into the nontraded goods bundle via the CES aggregator $y_{t}^{N}=\left[\int_{0}^{1} y_{t}^{N}(i)^{\frac{\theta-1}{\theta}} d i\right]^{\frac{\theta}{\theta-1}}$. The demand for each good $i$, coming from household consumption and government expenditures, is given by

$$
y_{t}^{N}(i)=\left[\frac{p_{t}^{N}(i)}{p_{t}^{N}}\right]^{-\theta} y_{t}^{N} .
$$

Each producer chooses the price of its good and the amount of labor input to maximize profits

$$
\Omega_{t}^{N}(i)=p_{t}^{N}(i) y_{t}^{N}(i)-(1-\iota) w_{t} l_{t}^{N}(i)
$$

subject to the production function (6) and the demand constraint (7). The cost subsidy ( $\iota$, financed by lump-sum taxes, helps removes the monopolistic competition distortion in the long-run. Optimally, the price is set at a constant markup over the (subsidised) marginal cost.

Firms in the tradable sector are perfectly competitive and choose labor $l_{t}^{T}$ to maximize period- $t$ profits

$$
\Omega_{t}^{T}=s_{t} y_{t}^{T}-w_{t} l_{t}^{T}
$$


given a similar production technology $y_{t}^{T}=z^{T}\left(l_{t}^{T}\right)^{\alpha^{T}}$.

The Public Sector The public sector consists of the government and the central bank. Each period, the government collects income tax revenues $\left(\tau_{t} w_{t} l_{t}\right)$, receives foreign aid $\left(a_{t}^{*}\right)$, and issues bonds to finance its expenditures $\left(g_{t}\right)$. Government debt is held by the central bank $\left(b_{t}^{c b}\right)$ and by the private sector $\left(b_{t}^{c}\right)$, the latter carrying a gross nominal interest rate of $R_{t}$ (debt held by the central bank is at no cost to the government). The government can also hold part of its revenues as deposits at the central bank $\left(d_{t}\right)$. The government budget constraint is then

$$
p_{t}^{G} g_{t}+\left(d_{t}-\frac{d_{t-1}}{\pi_{t}}\right)=\tau_{t} w_{t} l_{t}+\left(b_{t}^{c}-\frac{R_{t-1} b_{t-1}^{c}}{\pi_{t}}\right)+\left(b_{t}^{c b}-\frac{b_{t-1}^{c b}}{\pi_{t}}\right)+s_{t} a_{t}^{*}
$$

Foreign aid is assumed to be entirely exogenous and follows an $\operatorname{AR}(1)$ process

$$
\log \left(\frac{a_{t}^{*}}{a^{*}}\right)=\rho_{a} \log \left(\frac{a_{t-1}^{*}}{a^{*}}\right)+\varepsilon_{t}, \quad \varepsilon_{t} \sim N\left(0, \sigma_{a}^{2}\right)
$$

with persistence $\rho_{a}$ and standard deviation of the shock, $\sigma_{a}$.

Total government purchases $g_{t}$ are a CES aggregate of traded and nontraded goods, with elasticity of substitution $\chi$ and degree of home bias $\varphi^{G}$ (generally assumed to be higher than that of the private sector, $\varphi$ )

$$
g_{t}=\left[\left(\varphi^{G}\right)^{\frac{1}{\chi}}\left(g_{t}^{N}\right)^{\frac{\chi-1}{\chi}}+\left(1-\varphi^{G}\right)^{\frac{1}{\chi}}\left(g_{t}^{T}\right)^{\frac{\chi-1}{\chi}}\right]^{\frac{\chi}{\chi-1}}
$$

The related demand functions for non-traded and traded goods are:

$$
g_{t}^{N}=\varphi^{G}\left(\frac{p_{t}^{N}}{p_{t}^{G}}\right)^{-\chi} g_{t} \quad \text { and } \quad g_{t}^{T}=\left(1-\varphi^{G}\right)\left(\frac{s_{t}}{p_{t}^{G}}\right)^{-\chi} g_{t}
$$

where $p_{t}^{G}=\left[\varphi^{G}\left(p_{t}^{N}\right)^{1-\chi}+\left(1-\varphi^{G}\right)\left(s_{t}\right)^{1-\chi}\right]^{\frac{1}{1-\chi}}$ is the relative price of the government consumption bundle, in terms of the private consumption good, while total expenditures are $p_{t}^{N} g_{t}^{N}+s_{t} g_{t}^{T}=p_{t}^{G} g_{t}$.

The Central Bank's balance sheet is given by:

$$
m_{t}-\frac{m_{t-1}}{\pi_{t}}+d_{t}-\frac{d_{t-1}}{\pi_{t}}=b_{t}^{c b}-\frac{b_{t-1}^{c b}}{\pi_{t}}+s_{t}\left(r e s_{t}^{*}-\frac{r e s_{t-1}^{*}}{\pi^{*}}\right)
$$

where $m_{t}$ denotes real money balances, $r e s_{t}^{*}$ are foreign exchange reserves, and $d_{t}$ and $b_{t}^{c b}$ are the Central Bank's holdings of government deposits on the liabilities side and government 
bonds on the assets side.

As our analysis does not consider changes in government deposits at the central bank (i.e. $\left.d_{t}=\bar{d}\right)$, it is then useful to consider the consolidated government budget constraint, obtained by combining equations (9) and (13):

$$
p_{t}^{G} g_{t}=\tau_{t} w_{t} l_{t}+s_{t} a_{t}^{*}+\left(b_{t}^{c}-\frac{R_{t-1} b_{t-1}^{c}}{\pi_{t}}\right)+\underbrace{\left[\left(m_{t}-\frac{m_{t-1}}{\pi_{t}}\right)-s_{t}\left(r e s_{t}^{*}-\frac{r e s_{t-1}^{*}}{\pi^{*}}\right)\right]}_{\text {domestic credit }}
$$

\section{Monetary and Fiscal Policies}

We consider the same four policy scenarios discussed above. In response to a reduction in foreign aid inflows, the government could adjust its expenditures, in line with the decline in revenues, such that the government deficit remains unchanged. Alternatively, if the government maintains its level of spending at pre-existing (long-run) levels, it then needs to finance the increased deficit and could do so through: $(i)$ sales of debt to the private sector, $(i i)$ direct monetization, or (iii) sales of foreign exchange reserves. Further details of the policy specification are given in the discussion section below.

Aggregation and market clearing The labor market clearing requires

$$
l_{t}=l_{t}^{N}+l_{t}^{T}
$$

while total output (GDP) is given by

$$
y_{t}=p_{t}^{N} y_{t}^{N}+s_{t} y_{t}^{T}
$$

The market clearing condition for nontraded goods (the internal balance) is given by

$$
\begin{aligned}
y_{t}^{N} & =c_{t}^{N}+g_{t}^{N} \\
& =\left(p_{t}^{N}\right)^{-\chi}\left[\varphi c_{t}+\varphi^{G}\left(p_{t}^{G}\right)^{\chi} g_{t}\right] .
\end{aligned}
$$

and the aggregate resource constraint for the small open economy is

$$
c_{t}+p_{t}^{G} g_{t}=y_{t}+s_{t}\left[a_{t}^{*}-\left(r e s_{t}^{*}-\frac{r e s_{t-1}^{*}}{\pi^{*}}\right)+r m^{*}\right]
$$

Together, they imply an equilibrium in the traded goods market (the external balance),

$$
c_{t}^{T}+g_{t}^{T}=y_{t}^{T}+a_{t}^{*}-\left(r e s_{t}^{*}-\frac{r e s_{t-1}^{*}}{\pi^{*}}\right)+r m^{*}
$$




\subsection{Some Simple Analytical Results}

We adopt a simple calibration of the steady state which allows for an analytical solution to the log-linearized model. Particularly, we assume that the households' holdings of government debt are zero in steady state, $b^{c}=0$, and we set the technology parameters $z^{N}=\varpi^{1-\alpha}$ and $z^{T}=(1-\varpi)^{1-\alpha}$, and the labor disutility parameter $\varkappa^{l}=(1-\tau) \frac{\alpha}{\kappa_{c}}$, where $\varpi$ is the nontraded sector's share of employment and output, and $\kappa_{x}$ represents the share of variable $x$ in GDP. Also, utility is assumed to be logarithmic in consumption and real money balances, $\sigma=\xi=1$. The internal and external balance conditions imply $\varpi=\varphi \kappa_{c}+\varphi^{G} \kappa_{g}$ and $(1-\varpi)=(1-\varphi) \kappa_{c}+\left(1-\varphi^{G}\right) \kappa_{g}-\kappa_{a^{*}}+\kappa_{r e s^{*}}\left(1-\frac{1}{\pi^{*}}\right)-\kappa_{r m^{*}}$. These assumptions support a deterministic steady state where $p^{N}=s=p^{G}=y=l=1$. The cost subsidy is set to $\iota=1 /(\theta-1)$, to offset the effects of monopolistic competition. The labor income tax $\tau$ is such that the government budget constraint is satisfied.

The model is log-linearized around the deterministic steady state. The full list of loglinear conditions is included in the Appendix A. Here, we only present the main equations which, together with the government policy specification, help characterize the dynamics of the economy and in particular those of consumption, the real exchange rate, the real interest rate, and inflation. A hatted variable $\left(\widehat{x}_{t}\right)$ denotes the log-deviation of $x_{t}$ from its steady state value $x, \widehat{x}_{t}=\ln \left(\frac{x_{t}}{x}\right)$, while $\kappa_{x}=x / y$ represents the steady state ratio of variable $x$ in GDP.

The Euler equation in log-linear form is given by

$$
\sigma \widehat{c}_{t}=\sigma E_{t} \widehat{c}_{t+1}-\left(\widehat{R}_{t}-E_{t} \widehat{\pi}_{t+1}\right)
$$

while the money market equilibrium implies a nominal interest rate that satisfies the relationship

$$
\widehat{R}_{t}=(R-1) \sigma \widehat{c}_{t}-(R-1) \xi \widehat{m}_{t}
$$

where changes in real money balances $\widehat{m}_{t}$ are tied to specific policy considerations.

The internal balance (IB) condition, embedding the equilibrium in the non-tradable goods market and the labor market, can be written as (see Appendix A.3 for details of the derivations)

$$
\mathfrak{b}_{s} \widehat{s}_{t}=\mathfrak{b}_{c} \widehat{c}_{t}+\mathfrak{b}_{\tau} \widehat{\tau}_{t}+\varphi^{G}\left(\frac{\kappa_{g}}{\kappa_{y^{N}}}\right) \widehat{g}_{t}
$$

It relates the real exchange rate and consumption and changes in the fiscal stance, as given by adjustments in government spending and taxes. The coefficients $\mathfrak{b}_{s}, \mathfrak{b}_{c}, \mathfrak{b}_{\tau}$ are combi- 
nations of the model's structural parameters and steady state values: $\mathfrak{b}_{s}=\left(\frac{\alpha}{1-\alpha}+\chi\right) \zeta_{1}-$ $\chi \varphi^{G}\left(\kappa_{g} / \kappa_{y^{N}}\right) \zeta_{2}-\frac{\alpha}{1-\alpha} \zeta_{3}, \mathfrak{b}_{c}=\varphi\left(\kappa_{c} / \kappa_{y^{N}}\right)+\left(\frac{\alpha}{1-\alpha+\psi}\right) \sigma$, and $\mathfrak{b}_{\tau}=\left(\frac{\alpha}{1-\alpha+\psi}\right)\left(\frac{\tau}{1-\tau}\right)$, where $\zeta_{1}=(\varphi-1) / \varphi, \quad \zeta_{2}=\left(\varphi-\varphi^{G}\right) / \varphi$, and $\zeta_{3}=\left(\frac{\psi}{1-\alpha+\psi}\right)\left(1-\kappa_{y^{N}} / \varphi\right)$. We note that $\zeta_{1}$, $\zeta_{2}, \zeta_{3}$ are all negative under the model calibration, while $\mathfrak{b}_{s}<0$ and $\mathfrak{b}_{c}>0$ indicating that an increase in consumption requires a real appreciation of the exchange rate (a fall in $s_{t}$ ) to ensure internal balance.

The external balance (EB) condition can be expressed in a similar fashion,

$$
\left.\vartheta_{s} \widehat{s}_{t}=\vartheta_{c} \widehat{c}_{t}+\mathfrak{b}_{\tau} \widehat{\tau}_{t}+\left(1-\varphi^{G}\right)\left(\frac{\kappa_{g}}{\kappa_{y^{T}}}\right) \widehat{g}_{t}-\left(\frac{\kappa_{a^{*}}}{\kappa_{y^{T}}}\right) \widehat{a}_{t}^{*}+\left(\frac{\kappa_{r e s^{*}}}{\kappa_{y^{T}}}\right)\left(\widehat{r e s}_{t}^{*}-\frac{\widehat{r e s}_{t-1}^{*}}{\pi^{*}}\right) 23\right)
$$

where $\vartheta_{s}=\left(\frac{\alpha}{1-\alpha}\right)\left(1-\zeta_{3}\right)+\chi \zeta_{0}-\chi\left(1-\varphi^{G}\right)\left(\kappa_{g} / \kappa_{y^{T}}\right) \zeta_{2}, \vartheta_{c}=(1-\varphi)\left(\kappa_{c} / \kappa_{y T}\right)+\left(\frac{\alpha}{1-\alpha+\psi}\right) \sigma$, and $\zeta_{0}=(1-\varphi)\left(\kappa_{c} / \kappa_{y^{T}}\right)+\left(1-\varphi^{G}\right)\left(\kappa_{g} / \kappa_{y^{T}}\right)$, with the remaining coefficients $\mathfrak{b}_{\tau}$, $\zeta_{2}$, and $\zeta_{3}$, being defined as above. With $\zeta_{0}>0$ and $\zeta_{2}, \zeta_{3}<0$, we then have both $\vartheta_{s}$ and $\vartheta_{c}$ positive, such that a rise in consumption requires a real exchange rate depreciation to achieve balance of payments equilibrium.

Figure 7 provides a graphical representation of the two conditions, in the $(c, s)$ space, with a downward sloping internal balance (IB) schedule and an upward sloping external balance (EB) schedule. Changes in exogenous variables, such as the reduction in foreign aid inflows, and the endogenous policy responses to such changes will cause the two curves to shift.

Finally, we present the government budget constraint in log-linear form ${ }^{5}$

$$
\begin{aligned}
\kappa_{g} \widehat{g}_{t}= & \left(\zeta^{\sharp}-\kappa_{g} \zeta_{2}\right) \widehat{s}_{t}-\frac{\tau w l}{y}\left(\frac{\alpha}{1-\alpha+\psi}\right) \sigma \widehat{c}_{t}+\frac{\tau w l}{y}\left(1-\frac{\alpha}{1-\alpha+\psi} \frac{\tau}{1-\tau}\right) \widehat{\tau}_{t} \\
& +\left(\frac{1}{\pi} \kappa_{m}\right) \widehat{\pi}_{t}+\kappa_{a^{*}} \widehat{a}_{t}^{*}+(1 / \bar{y})\left(d b_{t}^{c}-\frac{R}{\pi} d b_{t-1}^{c}\right) \\
& +\kappa_{m}\left(\widehat{m}_{t}-\frac{1}{\pi} \widehat{m}_{t-1}\right)-\kappa_{r e s^{*}}\left(\widehat{r e s}_{t}^{*}-\frac{1}{\pi^{*}} \widehat{r e s}_{t-1}^{*}\right)
\end{aligned}
$$

where $\zeta^{\sharp}=\frac{\tau w l}{y}\left(\frac{1+\psi}{\psi}\right) \zeta_{3}+\kappa_{a^{*}}-\kappa_{r e s^{*}}\left(1-\frac{1}{\pi^{*}}\right)<0$. Government policies must be such that the budget constraint is satisfied in an intertemporal sense.

\footnotetext{
${ }^{5}$ Note that we have imposed the calibration assumption that government debt is zero in the steady state $\left(b^{c}=0\right)$, and hence short-run changes in debt are expressed as simple deviations from the steady state $d b_{t}^{c}$ (and not log-deviations).
} 


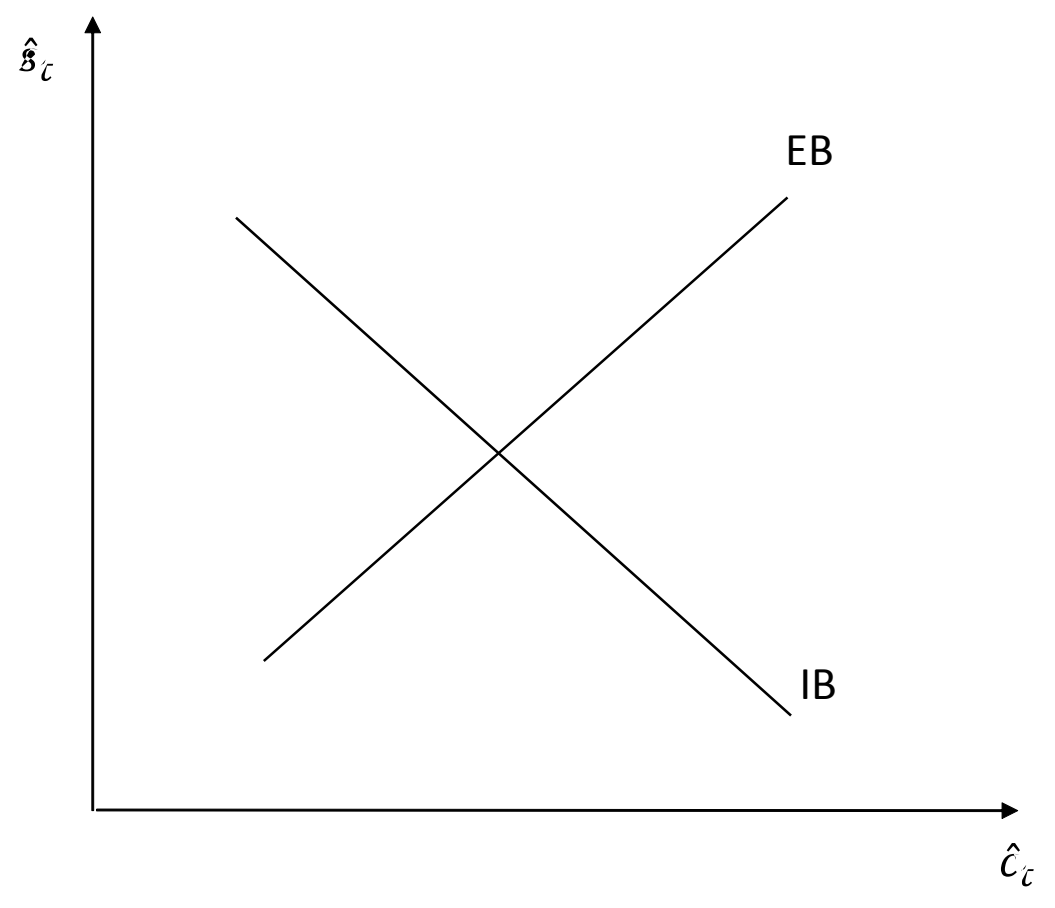

Figure 7: Internal and external balance.

\section{Policy Analysis in the Simple Dynamic Model}

We use this analytical framework to assess the impact of the aid reduction under the four different policy scenarios.

Adjusting Government Expenditures We start the analysis with the case when the government reduces its spending $g_{t}$ in response to the decline in foreign aid revenues, such that the government budget constraint is satisfied, and without further adjustment in other policy instruments. Specifically, changes in $g_{t}$ are determined from the budget constraint (24), government debt held by households, labor income taxes, and the stock of foreign exchange reserves remain unchanged at their steady-state levels (so that $d b_{t}^{c}=0, \widehat{\tau}_{t}=0$, and $\widehat{r e s}_{t}^{*}=0$ ), while reserve nominal money balances grow at a constant rate $\mu$, implying real money balances follow the rule, $\widehat{m}_{t}=\widehat{m}_{t-1}-\widehat{\pi}_{t}$. Equations (20) - (24), together with the policy specification, allow us to obtain an analytical solution of the log-linearized model and to evaluate the economy's dynamics in response to changes in aid. Details of the analytical derivations are provided in Appendix B.

Considering the effects of the shock on consumption and the real exchange rate, equilibrium in Figure 8 moves from point ' $a$ ' to point ' $b$ ', where point ' $a$ ' represents the initial (steady-state) equilibrium. We first notice that the reduction in aid has a direct impact on the balance of payments (shifting the EB curve left in Figure 8) and is associated with 


\begin{tabular}{|l|c|c|c|c|}
\hline & Consumption & Real Exch. Rate & Inflation & Real Int. Rate \\
\hline Expenditure Cut & - & + & + & + \\
\hline Sales of Debt & - & + & + & + \\
\hline Monetization & - & + & ++ & + \\
\hline Reserves Sales & 0 & 0 & 0 & 0 \\
\hline
\end{tabular}

Table 2: Contemporaneous responses to a persistent fall in foreign aid. An increase in the real exchange rate denotes a depreciation of the domestic currency.

a depreciation of the domestic currency. At the same time, the policy response of reducing government expenditures requires a currency depreciation to ensure internal balance (a rightward shift of the IB curve) and a currency appreciation for external balance (moving the EB curve to the right) which goes against and slighly offsets the direct effect of the aid reduction. Overall, we observe an initial real depreciation of the currency and a small decline in private consumption. Table 2 provides a summary of the contemporaneous responses of key macroeconomic variables to the decline in foreign aid, based on the analytical solution and the simple model calibration. Given a very persistent reduction in aid, the real interest rate rises slightly, supporting the relatively low current consumption.

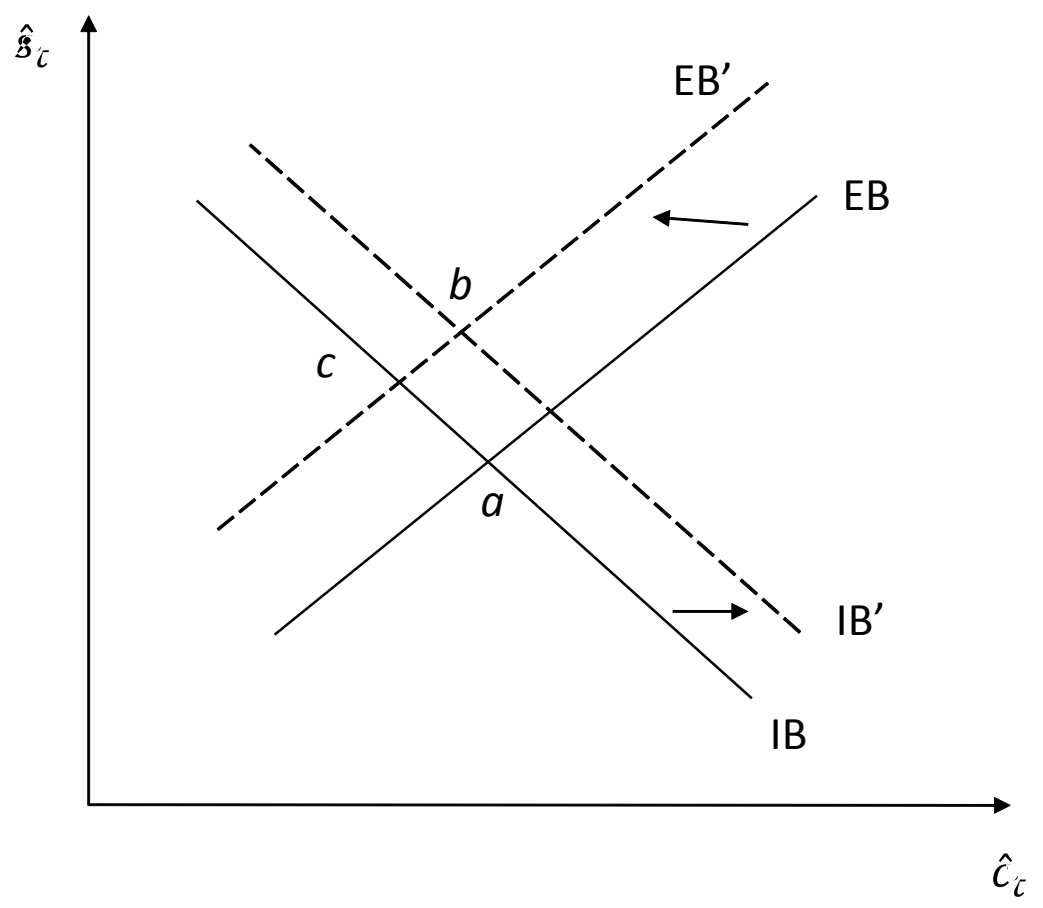

Figure 8: Internal and external balance under alternative policy scenarios. Initial responses to aid reduction: expenditure cuts move the equilibrium from point ' $a$ ' to ' $b$ '. Sales of debt and monetization shift the equilibrum from ' $a$ ' to ' $c$ '. 
Sales of Debt to the Private Sector If the government maintains its spending at pre-existing levels (i.e. $\widehat{g}_{t}=0$ ), the increased deficit could be financed through sales of debt to the private sector ( $b_{t}^{c}$ increases so as to balance the budget). Foreign exchange reserves remain unchanged $\left(\widehat{r e s}_{t}^{*}=0\right)$, while the money supply follows the constant growth rate rule. To ensure the policy is sustainable over the long run, we assume that the government will slightly raise income taxes in the future in response to the increased level of indebtedness, so that $\widehat{\tau}_{t}=\varrho d b_{t-1}^{c}$, where $\varrho>0$ but small.

In this case, consumption and the real exchange rate depend on changes in foreign aid as well as subsequent changes in government debt which lead to higher future taxes. This can be seen from the internal and external balance conditions (22) and (23) which simplify to:

$$
\mathfrak{b}_{s} \widehat{s}_{t}=\mathfrak{b}_{c} \widehat{c}_{t}+\mathfrak{b}_{\tau}\left(\varrho d b_{t-1}^{c}\right)
$$

and

$$
\vartheta_{s} \widehat{s}_{t}=\vartheta_{c} \widehat{c}_{t}-\left(\frac{\kappa_{a^{*}}}{\kappa_{y^{T}}}\right) \widehat{a}_{t}^{*}+\mathfrak{b}_{\tau}\left(\varrho d b_{t-1}^{c}\right)-\left(\frac{\kappa_{r e s^{*}}}{\kappa_{y^{T}}} \frac{1}{\pi^{*}}\right) \widehat{r e s}_{t-1}^{*}
$$

The two equations can be solved for the dynamics of consumption and the real exchange rate

$$
\widehat{s}_{t}=\lambda_{a} \widehat{a}_{t}^{*}+\lambda_{b} d b_{t-1}^{c}
$$

and

$$
\widehat{c}_{t}=\gamma_{a} \widehat{a}_{t}^{*}+\gamma_{b} d b_{t-1}^{c}
$$

where $\lambda_{a}<0, \gamma_{a}>0$, and $\lambda_{b}, \gamma_{b}<0$, and we have set $\widehat{r e s}_{t-1}^{*}=0$ at all $t$ (by assumption in this policy scenario). See Appendix B for details.

The reduction in aid causes a real depreciation of the currency $\left(\widehat{s}_{t}>0\right)$ as the EB curve shifts left and, associated with it, consumption falls to maintain internal balance. In Figure 8 , the equilibrium moves in the short-run from the initial point ' $a$ ' to point ' $c$ '. The fall in consumption is much larger than when the government adjusts expenditures, while the currency depreciation is more muted. Consistent with the rise in government debt and the decline in consumption, the real interest rate increases, as seen in the second row of Table 2.

In subsequent periods, the dynamics of the economy will be affected by the increase in government debt $\left(d b_{t}^{c}>0\right)$ and the rise in taxes that ensures long-run sustainability. These changes will further reduce consumption and the degree of exchange rate appreciation.

Monetization of the Deficit The government could also choose to monetize the deficit that arises when foreign aid declines and help balance the budget, while keeping all other policy instruments unchanged $\left(\widehat{g}_{t}=0, d b_{t}^{c}=0, \widehat{\tau}_{t}=0\right.$, and $\left.\widehat{r e s}_{t}^{*}=0\right)$. The dynamics of consumption and the real exchange rate can be inferred from the internal and external 
balance conditions, which are now given by

$$
\mathfrak{b}_{s} \widehat{s}_{t}=\mathfrak{b}_{c} \widehat{c}_{t}
$$

and

$$
\vartheta_{s} \widehat{s}_{t}=\vartheta_{c} \widehat{c}_{t}-\left(\frac{\kappa_{a^{*}}}{\kappa_{y^{T}}}\right) \widehat{a}_{t}^{*}-\left(\frac{\kappa_{r e s^{*}}}{\kappa_{y^{T}}} \frac{1}{\pi^{*}}\right) \widehat{r e s}_{t-1}^{*}
$$

Imposing $\widehat{r e s}_{t}^{*}=0$, we then obtain the paths for consumption and the real exchange rate as

$$
\widehat{s}_{t}=\lambda_{a} \widehat{a}_{t}^{*}
$$

and

$$
\widehat{c}_{t}=\gamma_{a} \widehat{a}_{t}^{*}
$$

where $\lambda_{a}<0$ and $\gamma_{a}>0$ are the same as above.

So, in this case, the dynamics of the real exchange rate and consumption are entirely determined by the evolution of aid inflows. A persistent decline in aid leads to persistently lower consumption levels and a depreciated currency. In the first period, the effects are the same as in the case of sales of debt. Beyond the first period, consumption under monetization will however remain relatively higher than under the sales of debt policy, where the increased taxation that supports higher debt levels has additional negative effects on consumption.

Compared to the other two policies, inflation increases substantially. As the Central Bank increases the money supply to finance the rising government deficit, prices rise immediately in this flexible price economy.

Sales of Foreign Exchange Reserves Finally, we consider the case when the Central Bank uses its foreign exchange reserves to finance the increased deficit. The money supply follows a constant growth rate rule, while other policy instruments remain unchanged at their initial levels $\left(\widehat{g}_{t}=0, d b_{t}^{c}=0, \widehat{\tau}_{t}=0\right)$. If minimim threshold levels on reserves are not binding, the government could use reserves to fully compensate for the decline in foreign aid and thus insulates the economy from the effects that these revenue losses would otherwise entail. The last row in Table 2 shows such a scenario, with no changes in any of the variables (the analytical solution can be found in the Appendix). When the use of foreign exchange reserves is more restricted, the policy makers could sell reserves up to a given threshold and finance the remaining deficit through alternative means - either through sales of debt to the private sector or through monetization or, possibly, by adjusting expenditures. 


\section{A Full-Scale DSGE Model for Haiti}

The two simple models have highlighted some important effects of the decline in foreign aid on the economy. However, to better gauge the economic and welfare consequences of the policy choices that Haiti faces, we now turn to simulations of a full-scale DSGE model, based on Berg et al. (2015) and Moldovan et al. (2018), which better captures a wide range of economic features characteristic of a developing economy like Haiti. Specifically, the model allows for:

- two types of households - savers and hand-to-mouth consumers, to capture the large share of liquidity-constrained households in less developed economies;

- nominal rigidities in the non-tradable sector;

- investment in private capital and access to international financial markets, as in the static model, which reinstates the main channel linking monetary policy with the balance of payments.

- public infrastructure investment, featuring elements of inefficiency typical in less developed economies.

We provide here the setup of the model. Variables and parameters share the same definitions as in Section 4.

\subsection{Full-Scale Model Setup}

\subsubsection{Households}

The economy has two types of households: a fraction $f$ are asset holders (or savers) - denoted with $(a)$ - and the remaining $1-f$ are hand-to-mouth consumers $(h)$.

Savers Savers have access to capital markets and hold a portfolio of assets, including investment in private capital, domestic government bonds, foreign assets, and money. These households are able to adjust savings to better smooth consumption in response to shocks.

The representative saver chooses consumption $\left(c_{t}^{a}\right)$, labor $\left(l_{t}^{a}\right)$, real money balances $\left(m_{t}^{a}\right)$,

investment $\left(i_{t}^{N, a}\right.$ and $\left.i_{t}^{T, a}\right)$, capital $\left(k_{t}^{N, a}\right.$ and $\left.k_{t}^{T, a}\right)$, domestic government bonds $\left(b_{t}^{c, a}\right)$ and foreign assets $\left(b_{t}^{*, a}\right)$ to maximize the expected utility

$$
E_{0} \sum_{t=0}^{\infty} \beta^{t}\left[\frac{\left(c_{t}^{a}\right)^{1-\sigma}}{1-\sigma}-\varkappa^{l} \frac{\left(l_{t}^{a}\right)^{1+\psi}}{1+\psi}+\varkappa^{m} \frac{\left(m_{t}^{a}\right)^{1-\xi}}{1-\xi}\right]
$$


subject to the budget constraint

$$
\begin{aligned}
& c_{t}^{a}+m_{t}^{a}+i_{t}^{N, a}+i_{t}^{T, a}+b_{t}^{c, a}+s_{t} b_{t}^{*, a}+a c_{t}^{i, a}+s_{t} a c_{t}^{*} \\
= & \left(1-\tau_{t}\right)\left(w_{t} l_{t}^{a}+r_{t}^{N} k_{t-1}^{N, a}+r_{t}^{T} k_{t-1}^{T, a}\right)+\frac{m_{t-1}^{a}}{\pi_{t}}+\frac{R_{t-1} b_{t-1}^{c, a}}{\pi_{t}}+s_{t} \frac{R^{*} b_{t-1}^{a *}}{\pi^{*}}+s_{t} r m^{*}+\Omega_{t}^{a} .
\end{aligned}
$$

Foreign assets pay a constant gross nominal rate $R^{*}$ and depreciate at the rate of foreign inflation $\pi^{*}$, and are subject to portfolio adjustment costs given by $a c_{t}^{*} \equiv \frac{v}{2}\left(b_{t}^{a *}-\bar{b}^{a *}\right)^{2}$, where $\bar{b}^{a *}$ is the steady-state value of real foreign assets and parameter $v$ governs the degree of capital account openness. ${ }^{6}$ Households also receive $\mathrm{rm}^{*}$ in foreign remittances (assumed constant), while labor and capital rental income are taxed at the same rate $\tau_{t}$. We assume that capital is sector specific, so $r_{t}^{N}$ and $r_{t}^{T}$ are the rental rates of capital in the two sectors, while $a c_{t}^{i, a} \equiv$ $\frac{\kappa}{2}\left[\left(\frac{i_{t}^{N, a}}{k_{t-1}^{N, a}}-\delta\right)^{2} k_{t-1}^{N, a}+\left(\frac{i_{t}^{T, a}}{k_{t-1}^{T, a}}-\delta\right)^{2} k_{t-1}^{T, a}\right]$ represent total investment adjustment costs. The law of motion for capital for each sector is

$$
k_{t}^{j, a}=(1-\delta) k_{t-1}^{j, a}+i_{t}^{j, a}, \quad j \in\{N, T\}
$$

where $\delta$ is the depreciation rate. Total investment made by savers is $i_{t}^{a}=i_{t}^{N, a}+i_{t}^{T, a}$. Consumption and investment are CES aggregates of nontraded and traded goods, with elasticity of substitution $\chi$ and degree of home bias $\varphi$, as defined in equation (4). While the nontraded goods are also a CES aggregate of differentiated intermediate goods, with elasticity of substitution $\theta$.

Households supply labor to both sectors of production, so as to maximize wage revenues. The savers' total labor supply is

$$
l_{t}^{a}=\left[\left(\varphi^{l}\right)^{-\frac{1}{\chi^{l}}}\left(l_{t}^{a, N}\right)^{\frac{1+\chi^{l}}{\chi^{l}}}+\left(1-\varphi^{l}\right)^{-\frac{1}{\chi^{l}}}\left(l_{t}^{a, T}\right)^{\frac{1+\chi^{l}}{\chi^{l}}}\right]^{\frac{\chi^{l}}{1+\chi^{l}}}
$$

where $\varphi^{l}$ is the steady-state share of labor in the nontraded goods sector and $\chi^{l}>0$ is the elasticity of substitution between labor supplied to the two sectors. Hence, labor can move between sectors, depending on relative wages, but it is not perfectly mobile. The aggregate real wage index is

$$
w_{t}=\left[\varphi^{l}\left(w_{t}^{N}\right)^{1+\chi^{l}}+\left(1-\varphi^{l}\right)\left(w_{t}^{T}\right)^{1+\chi^{l}}\right]^{\frac{1}{1+\chi^{l}}}
$$

where $w_{t}^{N}$ and $w_{t}^{T}$ are the two real wage rates.

\footnotetext{
${ }^{6}$ Such portfolio adjustment costs help close the small open economy model, as discussed in Schmitt-Grohe and Uribe (2003).
} 
Hand-to-Mouth Households Hand-to-mouth consumers are households who do not have access to capital markets and rely on after-tax labor income and foreign remittances as their only source of income. They consume all available income every period:

$$
c_{t}^{h}=\left(1-\tau_{t}\right) w_{t} l_{t}^{h}+s_{t} r m^{*}
$$

They derive utility from consumption and disutility from labor, with a period utility function given by

$$
U_{t}^{h}=\left[\frac{\left(c_{t}^{h}\right)^{1-\sigma}}{1-\sigma}-\varkappa^{l} \frac{\left(l_{t}^{h}\right)^{1+\psi}}{1+\psi}\right]
$$

They decide on the total labor supply optimally, given preferences and the return to work, and then allocate labor to the two sectors in the same way savers do.

Given the large share of hand-to-mouth households in an economy like Haiti, labor market outcomes will be significantly affected by the labor supply decisions of these consumers. Also, although remittances are held constant, exchange rate fluctuations will matter for these households' income and consumption.

\subsubsection{Firms}

As in the simple model, firms in the non-tradable sector are monopolistically competitive, while those in the tradable sector are perfectly competitive. However, differently from the simple model, production in both sectors now uses both private and public capital, in addition to the labor input, and the nontradable sector is subject to nominal inertia in the form of Rotemberg (1982) price adjustment costs.

Nontraded Goods Sector Monopolistically competitive firm $i \in[0,1]$ in the nontraded goods sector uses labor $l_{t}^{N}(i)$, private capital $k_{t-1}^{N}(i)$, and public capital $k_{t-1}^{G}$ to produce goods using the technology

$$
y_{t}^{N}(i)=z^{N}\left[k_{t-1}^{N}(i)\right]^{1-\alpha^{N}}\left[l_{t}^{N}(i)\right]^{\alpha^{N}}\left(k_{t-1}^{G}\right)^{\alpha^{G}}
$$

where $z^{N}$ is a sector-specific constant total factor productivity (TFP) term and $\alpha^{G}$ is the output elasticity of public capital. The differentiated nontraded goods are aggregated into the nontraded goods bundle via the CES aggregator $y_{t}^{N}=\left[\int_{0}^{1} y_{t}^{N}(i)^{\frac{\theta-1}{\theta}} d i\right]^{\frac{\theta}{\theta-1}}$. The demand for each good $i$, now coming from household consumption, private investment, and government expenditures, is

$$
y_{t}^{N}(i)=\left[\frac{p_{t}^{N}(i)}{p_{t}^{N}}\right]^{-\theta} y_{t}^{N} .
$$


A nontraded good producer $i$ chooses the price, labor, and capital to maximize its net presentvalue of profits, discounted by the stochastic discount factor $\beta^{t}\left(\lambda_{t}^{a} / \lambda_{0}^{a}\right)$, where $\lambda_{t}^{a}$ is the savers' (firm owners') marginal utility of consumption,

$$
E_{0} \sum_{t=0}^{\infty} \beta^{t}\left(\lambda_{t}^{a} / \lambda_{0}^{a}\right) \underbrace{\left[p_{t}^{N}(i) y_{t}^{N}(i)-w_{t}^{N} l_{t}^{N}(i)-r_{t}^{N} k_{t-1}^{N}(i)-a c_{t}^{p}(i)\right]}_{\equiv \Omega_{t}(i), \text { dividends }},
$$

subject to the production function (34) and the demand constraint (35). Firms must pay a price adjustment cost $a c_{t}^{p}(i) \equiv \frac{\zeta}{2}\left[\frac{\pi_{t}^{N}(i)}{\pi^{N}(i)}-1\right]^{2} p_{t}^{N} y_{t}^{N}$, as in Rotemberg (1982), where $\pi_{t}^{N} \equiv$ $\frac{p_{t}^{N}}{p_{t-1}^{N}} \pi_{t}$ represents nontraded goods inflation.

Traded Good Sector The tradable sector is perfectly competitive. Firms choose labor and capital to maximize period- $t$ profits

$$
s_{t} y_{t}^{T}-w_{t}^{T} l_{t}^{T}-r_{t}^{T} k_{t-1}^{T}
$$

given the production technology $y_{t}^{T}=z^{T}\left(k_{t-1}^{T}\right)^{1-\alpha^{T}}\left(l_{t}^{T}\right)^{\alpha^{T}}\left(k_{t-1}^{G}\right)^{\alpha^{G}}$.

Total output produced in the economy in period $t$ is $y_{t}=p_{t}^{N} y_{t}^{N}+s_{t} y_{t}^{T}$.

\subsubsection{The Public Sector}

The public sector functions in a similar way to that described in the simple model of the previous section. However, differently from the simple model, we now allow for a distinction between government consumption $g_{t}^{C}$ and public investment $g_{t}^{I}$, so total goverment expenditures $g_{t}$ are

$$
g_{t}=g_{t}^{C}+g_{t}^{I}
$$

Government investment is a constant share of total expenditures and helps build the stock of public capital. The accumulation of public capital is given by

$$
k_{t}^{G}=\left(1-\delta^{G}\right) k_{t-1}^{G}+\epsilon g_{t}^{I} \quad 0<\epsilon<1
$$

where $\delta^{G}$ is the rate of depreciation of public capital and $\epsilon$ captures public investment efficiency, of the kind highlighted in Section 2 of the paper, such that for a given amount of public investment spending, only a relatively small fraction translates into effective public capital, corresponding to a small $\epsilon$.

Total government purchases $g_{t}$ are, as before, a CES aggregate of traded and nontraded goods, with elasticity of substitution $\chi$ and degree of home bias $\varphi^{G}$, as in (11). While tax revenues are now based on total factor income, $\operatorname{tax}_{t}=\tau_{t}\left(w_{t} l_{t}+r_{t}^{N} k_{t-1}^{N}+r_{t}^{T} k_{t-1}^{T}\right)$. The 
consolidated government budget constraint is then:

$$
p_{t}^{G}\left(g_{t}^{C}+g_{t}^{I}\right)=\operatorname{tax}_{t}+s_{t} a_{t}^{*}+\left(b_{t}^{c}-\frac{R_{t-1} b_{t-1}^{c}}{\pi_{t}}\right)+\underbrace{\left[\left(m_{t}-\frac{m_{t-1}}{\pi_{t}}\right)-s_{t}\left(r e s_{t}^{*}-\frac{r e s_{t-1}^{*}}{\pi^{*}}\right)\right]}_{\text {domestic credit }}
$$

Monetary and Fiscal Policies The policy scenarios considered are the same as described earlier, with one further assumption that any expenditure cuts that the government undertakes are reductions in public investment spending.

\subsubsection{Aggregation and market clearing}

Aggregate consumption and labor are determined as a weighted average across the two househoulds,

$$
x_{t}=f x_{t}^{a}+(1-f) x_{t}^{h}, \quad x \in\left\{c, c^{N}, c^{T}, l, l^{N}, l^{T}\right\} .
$$

Since only savers have access to asset and capital markets, aggregate real money balances, investment, capital, debt, and dividends are determined as

$$
x_{t}=f x_{t}^{a}, \quad x \in\left\{m, i^{N}, i^{T}, k^{N}, k^{T}, b^{c}, b_{t}^{*}, \Omega, a c^{i}, a c^{*}\right\} .
$$

Finally, the market clearing condition of nontraded goods is

$$
y_{t}^{N}=\left(p_{t}^{N}\right)^{-\chi}\left[\varphi\left(c_{t}+i_{t}+a c_{t}^{i}+a c_{t}^{p}\right)+\varphi^{G}\left(p_{t}^{G}\right)^{\chi} g_{t}\right]
$$

while the balance of payment condition is

$$
\underbrace{c_{t}+i_{t}+p_{t}^{G} g_{t}+a c_{t}^{i}+a c_{t}^{p}-y_{t}+s_{t} a c_{t}^{*}-s_{t}\left(R^{*}-1\right) \frac{b_{t-1}^{*}}{\pi^{*}}-s_{t} r m^{*}}=s_{t}\left[a_{t}^{*}-\left(b_{t}^{*}-\frac{b_{t-1}^{*}}{\pi^{*}}\right)-\left(r e s_{t}^{*}-\frac{r e s_{t-1}^{*}}{\pi^{*}}\right)\right]
$$

current account deficits

\subsubsection{Model Calibration}

We use the algorithm of Schmitt-Grohe and Uribe (2004) to obtain a solution of the model and compute welfare measures. The model is at quarterly frequency ${ }^{7}$ and is calibrated to capture key features of the Haitian economy. Table 4 lists the key parameter values and aggregate ratios used in the calibration. In particular, we calibrate the values of consumption, private investment, government consumption, public investment, foreign exchange reserves,

\footnotetext{
${ }^{7}$ Haiti does not publish consumption and private investment data on a quarterly basis; these values are interpolated from annual consumption and private investment, and quarterly variations in GDP.
} 
and foreign aid as a share of GDP to match the data average for Haiti over the period 2005$2015^{8}$. Inflation is set to $8.5 \%$ annually and the share of savers in the economy to about $20 \%$, representing a broad definition of asset-owning households.

Key structural parameters reflecting preferences and technology are set following Berg et al (2015) and Moldovan et al. (2018), and are in line with the literature on aid recipients and developing economies. The discount factor $\beta$ is 0.98 . We assume a risk aversion parameter $\sigma$ of 2.32 , corresponding to an intertemporal elasticity of substitution of 0.43 , as estimated by Ogaki et al. (1996) for Haiti, while $\psi$ (the inverse of the Frisch labor supply elasticity) equals $1 / 0.8$ reflecting a relatively inelastic labor supply. The intratemporal elasticity of substitution of labor between the two sectors is set to $\chi^{l}=0.6$, implying a relatively low degree of labor mobility. For the elasticity of substitution between traded and nontraded goods, we set $\chi=0.44$, following the estimate of Stockman and Tesar (1995) based on a sample of both developing and developed countries, while the elasticity of substitution between varieties of nontraded goods is $\theta=6$, matching a steady-state markup of 20 percent, as calibrated by Gali and Monacelli (2005) for a small open economy.

The degree of home bias in private consumption and investment is set to $\varphi=0.5$, while for government purchases we follow the convention in the literature and assume a higher value of $\varphi^{G}=0.6$, reflecting the relatively higher proportion of government spending on non-traded goods. The labor income shares in nontraded and traded production are set to $\alpha^{N}=0.45$ and $\alpha^{T}=0.6$, based on the estimates of Buffie et al. (2012). Consistent with commonly used values, the depreciation rate of private capital $\delta$ is 0.025 , implying an annual depreciation rate of 10 percent, and the investment adjustment cost parameter $\kappa$ is set to 1.4 , based on the estimate for a developing country with the same specification (Mexico, Aguiar and Gopinath (2007)). The elasticity of output with respect to public capital $\alpha^{G}$ is calibrated at a value of 0.21 , corresponding to a rate of return on public capital of about $20 \%$ (in line with the evidence for developing economies, as discussed in Buffie et al. (2012)). The efficiency of public investment expenditures $\epsilon$ is set to 0.4, following the evidence in Dabla-Norris et al. (2012).

\subsection{Policy Analysis Revisited}

For each of the policy scenarios, we plot a set of impulse responses to convey the dynamics of key variables in response to a persistent decline in foreign aid inflows. We also compute the welfare consequences of the shock. Specifically, for each type of household, we measure welfare as the present discounted value of life-time utility, conditional on the aid decline and

\footnotetext{
${ }^{8}$ The end year of 2015 was the latest date for which data was available at the time the study was prepared.
} 
on government policy. For asset holders, welfare is given by

$$
V_{0}^{a}=E_{0} \sum_{t=0}^{\infty} \beta^{t}\left[\frac{\left(c_{t}^{a}\right)^{1-\sigma}}{1-\sigma}-\varkappa^{l} \frac{\left(l_{t}^{a}\right)^{1+\psi}}{1+\psi}+\varkappa^{m} \frac{\left(m_{t}^{a}\right)^{1-\xi}}{1-\xi}\right]
$$

while for the hand-to-mouth consumers, it is

$$
V_{0}^{h}=E_{0} \sum_{t=0}^{\infty} \beta^{t}\left[\frac{\left(c_{t}^{h}\right)^{1-\sigma}}{1-\sigma}-\varkappa^{l} \frac{\left(l_{t}^{h}\right)^{1+\psi}}{1+\psi}\right]
$$

An aggregate measure of welfare can be obtained as a weighted average of $V_{0}^{a}$ and $V_{0}^{h}$, with weights given by the shares of the two types of households in the economy.

Figures 9 and 10 show the impulse responses of a set of aggregate and household-specific variables to a decrease in aid of $2 \%$ of GDP, under the four policy scenarios - expenditure cuts (dashed red lines), sales of debt to the private sector (solid blue lines), monetization of the increased deficit (black circle lines), and sales of foreign reserves (dash-dot green lines). We first note that, as discussed earlier, through sales of foreign exchange reserves the government could fully offset the effects of the decline in aid inflows, leaving all other variables unchanged, as long as any thresholds on foreign reserves are not binding. Under the remaining policy choices, the fall in aid generally leads to a real depreciation of the exchange rate, a reduction in the trade deficit, and overall reduced GDP levels. However, differences arise when considering the time-paths of these changes, as well as differences across sectors of production and across the two types of consumers, as discussed below.

Adjusting Government Expenditure: If the government responds to lower aid inflows by decreasing its expenditures, this reduces the demand for goods, with a higher propensity for non-tradable goods. Given the nominal inertia present in the non-tradable sector, output in this sector contracts and so does employment, while wages fall as labor demand declines. At the same time, the real depreciation of the currency due to the reduced aid inflows has a positive effect on output and employment in the tradable sector, but also implies a decrease in the trade deficit. Overall, GDP and private consumption fall, but private investment is crowded-in initially, as asset holders attempt to reduce the negative impact of the shock on their consumption.

We assume that the entire reduction in expenditures is in the form of cuts in public investment spending. This translates into lower public capital which has direct negative effects on the production of both traded and non-traded goods over a longer time period (although public investment inefficiencies would, in this case, mute the effects of the reduced spending on the capital stock).

Dynamics in the labor market are intricate, reflecting changes in total demand from the

\section{CInternational Monetary Fund. Not for Redistribution}



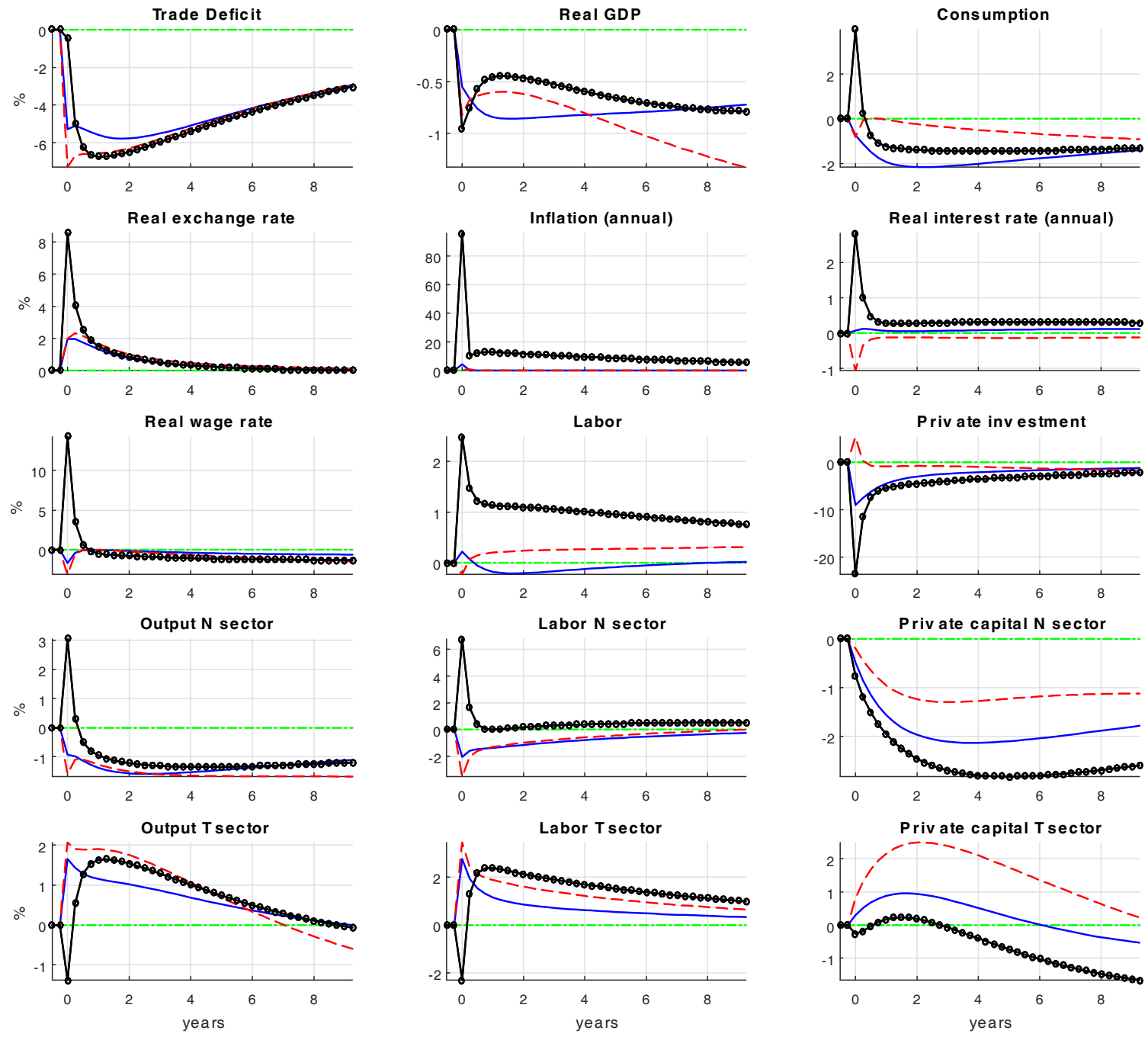

Figure 9: Impulse responses of aggregate variables to a decrease in aid of $2 \%$ of GDP, under the four policy scenenarios: $(i)$ expenditure cuts (red dashed lines); ( $i i$ ) sales of debt (solid blue lines); ( $i i i)$ monetization of the deficit (black circles lines), and ( $i v$ ) sales of reserves (dash-dot green lines). 
two production sectors as well as movements in aggregate labor supply, coming from the two types of households. Overall, we observe a decrease in real wages at least in the short run, reflecting primarily a dominating effect of reduced demand for labor in the non-tradable sector.

The impact of the shock for the two types of households is highlighed in Figure 10. Asset holders face a persistent reduction in their consumption and temporarily reduce labor supply as wages fall. They also draw on their holdings of foreign assets to help support consumption and private investment. For hand-to-mouth households, their consumption is entirely determined by their wage income and the value of foreign remittances. While the currency depreciation raises the latter, this positive effect is in this case outweighed by the decrease in labor income due to lower real wages (despite an initial increase in hours worked). Hence, hand-to-mouth consumers also see a short-run decrease in consumption (and utility), under this policy stance. This is reflected in the welfare numbers in Table 3, which show a decline of $0.11 \%$ in welfare for hand-to-mouth consumers (relative to the steady state), a figure that is about 9 times larger than the welfare loss of asset holders. ${ }^{9}$

Sales of Debt to the Private Sector: If the government finances the increased deficit (due to reduced aid inflows) by issuing new debt, it is effectively drawing resources from the private sector to support existing public expenditures. Asset holders now hold more of their savings as government bonds and reduce investment in private capital (as shown by the solid blue line in Figure 9). Although the decline in demand for investment goods affects both sectors of production, the real depreciation of the currency makes the tradable sector expand, while the non-tradable sector contracts ${ }^{10}$. Dominant effects from the non-tradable sector translate into a decline in overall GDP and in real wages.

The negative wealth effect drives up the savers' labor supply initially, but the higher future taxes, needed to support the expansion of public debt, will reduce labor supply in later periods. Their consumption falls by about $1 \%$. Overall, asset holders are able to smooth consumption relatively well and see only a relatively small decline in welfare. The situation is rather different for the hand-to-mouth consumers, for whom the decline in aftertax wages represents a strong negative income effect. Despite increasing labor supply, they suffer a large decrease in consumption, resulting in an overall much larger decline in welfare relative to asset holders. This policy option hurts hand-to-mouth households most.

Monetization of the Deficit: The policy of monetizing the increased deficit triggers a much larger real depreciation of the currency, compared to the alternative policies considered, as

\footnotetext{
${ }^{9}$ An alternative fiscal response to the loss of aid flows could be to raise taxes. However, all versions of such a policy that reduce after-tax income to hand-to-mouth households have worse welfare outcomes than corresponding reductions in government expenditures.

${ }^{10}$ This effect obtains whatever the initial level of the real exchange rate, and therefore in unrelated to whether the exchange rate is initially "fairly valued".
} 

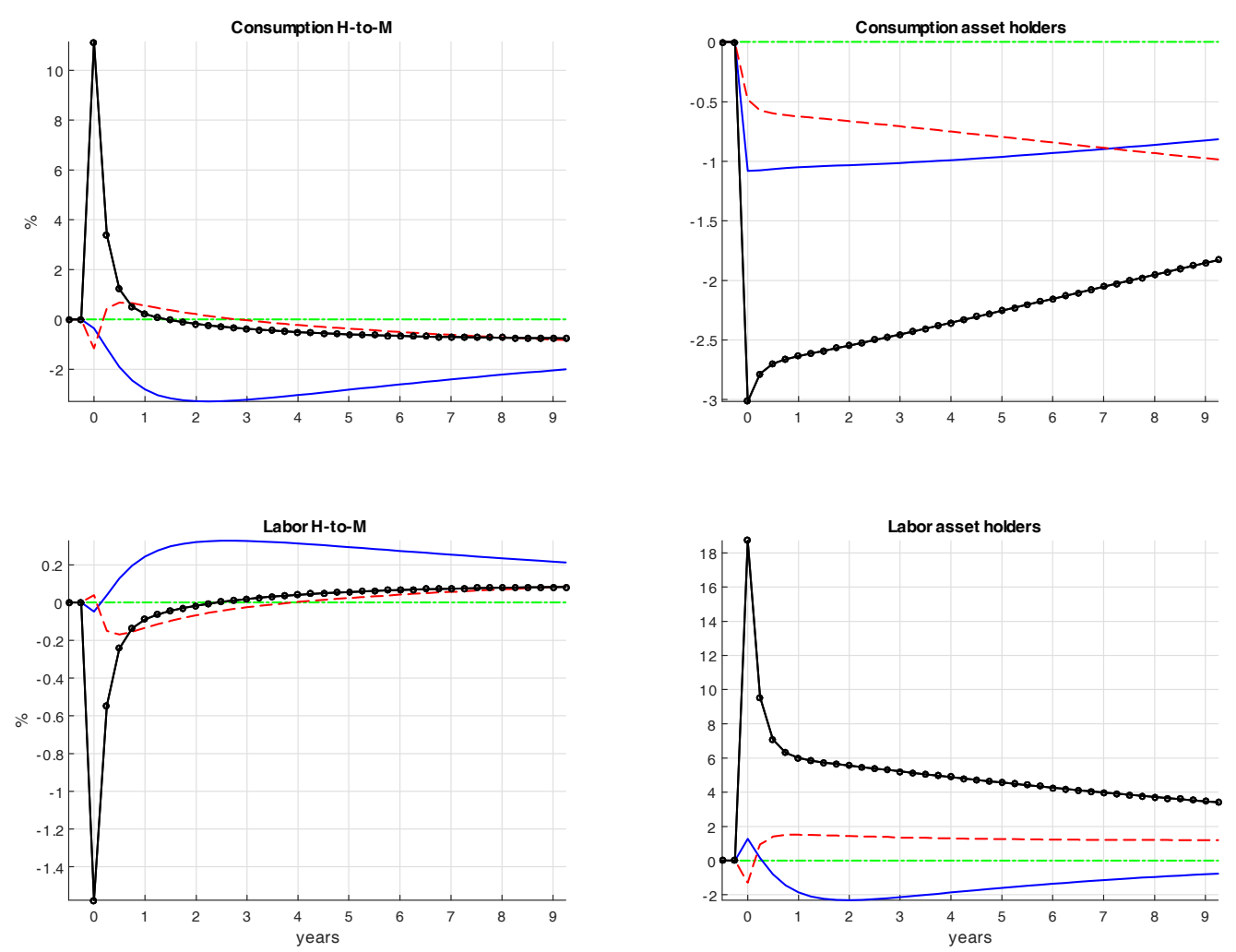

Figure 10: Impulse responses of consumption and labor of the two types of households to a decrease in aid of $2 \%$ of GDP, under the four policy scenenarios: $(i)$ expenditure cuts (red dashed lines); (ii) sales of debt (solid blue lines); ( $i i i$ ) monetization of the deficit (black circles lines), and ( $i v)$ sales of reserves (dash-dot green lines). 


\begin{tabular}{|l|c|c|c|}
\hline & Hand-to-Mouth Consumers & Asset Holders & Aggregate \\
\hline Expenditure Cut & -0.108 & -0.012 & -0.090 \\
\hline Sales of Debt & -0.313 & -0.006 & -0.256 \\
\hline Monetization & -0.024 & -0.029 & -0.025 \\
\hline Reserves Sales & 0 & 0 & 0 \\
\hline
\end{tabular}

Table 3: Welfare implications of aid reductions, as percent changes relative to steady state levels.

the nominal exchange rate jumps significantly. Although the real depreciation increases the competitiveness of the traded goods sector, it also makes traded goods much more expensive for domestic consumers who substitute towards the relatively cheaper non-tradable goods. As a result of this strong shift in demand across sectors, we observe a short-run expansion in the non-tradable sector and a decline in traded goods production ${ }^{11}$. Aggregate consumption rises sharply over the baseline in the first period after the shock, then falls below the baseline, and below that of the expenditure reduction scenario, thereafter.

The significantly higher value of foreign remittances, together with the initial increase in wages, leads to an increase in income for hand-to-mouth consumers who can enjoy more consumption (and leisure) in the short-run. As nominal rigidities dissipate, the real depreciation becomes more muted and wages return towards their long-run level, so the consumption of hand-to-mouth households falls.

Savers in the economy face a large negative wealth effect, as high inflation erodes the value of their assets. Their labor supply increases and remains at higher levels for a long time, while consumption falls significantly and private investment is crowded out. In contrast to the hand-to-mouth households, who see a relatively modest decline in welfare (relative to steady state), asset holders suffer large welfare losses under this policy, larger than under the alternative policies considered.

\section{Conclusion}

Adjustment to an aid reduction represents a complex policy challenge for a low-income country such as Haiti. In the long run, it seems evident that policymakers need to increase resource mobilization and encourage the formation of capital - public and private, human and physical - in an environment of diminishing aid flows. But it is also crucial to understand the implications of the policy responses that are available over the short run. The present study analyzes this issue using three related analytical and numerical models - a static open economy equilibrium model, a simplified analytically-tractable dynamic model, and a full-scale

\footnotetext{
${ }^{11}$ This effect is more muted under the alternative policies considered.
} 
dynamic stochastic general equilibrim model that is solved numerically. It identifies several results that are consistent across these models. While these models are capable of providing detailed analysis of a range of policy scenarios, a important limitation is they are not able to fully account for the long-term costs of reserves sales. The full-scale DSGE model permits a detailed welfare comparison among the four policy options considered.

All three models indicate that an aid cut accompanied by an equivalent reduction in government spending triggers a real exchange rate depreciation, as the price of tradeable goods rises relative to that of nontradeables. In the static model the real interest rate declines to maintain external balance with the real depreciation; the full-scale DSGE model shows a similar dynamic. Aid cuts matched by bond sales to the private sector lead to real interest rate increases in all models through a standard crowding-out effect, while the effect on the real exchange rate is indeterminate in the static model and a depreciation is indicated in the dynamic models. Monetization of the increase in government debt following an aid cut still yields a real interest rate higher than the rate prevailing before the aid reduction. Monetization also triggers real depreciation and sharply higher inflation in all three models, and thus a large nominal depreciation. Reserves sales in all three models substitute fully for the lost aid inflow. The full DSGE model also highlights the welfare implications of these policy choices. Unless foreign reserves can fully compensate for the loss of aid inflows, welfare is reduced. Expenditure cuts and sales of debt create larger welfare losses for liquiditycontrained (hand-to-mouth) households, as they generally imply larger reductions in after-tax wages which directly reduce their consumption. While monetization leads to worst welfare outcomes for those households who own assets, as the very high inflation that arises in this case erodes the value of these assets. Overall, the results suggest that a policy mix of expenditure cuts and depreciation through monetary expansion would be a good option, when sales of foreign reserves are constrained.

This present study advances the line of research into the macroeconomics of aid flows developed by Berg et al, in providing a set of related frameworks for analyzing policy options in the face of an aid cut. Its implications extend beyond aid flows, encompassing, for example, the analysis of policy choices in the wake of commodity price drops. Extensions of the dynamic model employed in the paper would provide for deeper analysis of the implications of reserves sales in response to an aid reduction. as a topic for further research. A subsequent study will compare the models' predictions against empirical measures of the implications of policy choices in Haiti and other low income countries. 


\begin{tabular}{lll}
\hline \hline Parameters & Values & Description \\
\hline$\beta$ & 0.98 & Discount factor \\
$\sigma$ & 2.32 & Inverse of intertemporal elasticity of substitution for consumption \\
$\psi$ & $1 / 0.8$ & Inverse of Frisch labor supply elasticity \\
$\varphi$ & 0.5 & Home bias in private consumption and investment \\
$\varphi^{G}$ & 0.6 & Home bias in government consumption and investment \\
$\chi$ & 0.44 & Elasticity of substitution between traded and nontraded goods \\
$\varphi^{l}$ & 0.54 & Steady-state labor share in nontraded goods sector \\
$\chi^{l}$ & 0.6 & Elasticity of substitution between labor supply to the two sectors \\
$f$ & 0.2 & Fraction of asset holders \\
$\theta$ & 6 & Elasticity of substitution between nontraded goods varieties \\
$\zeta$ & 37.2 & Price adjustment cost parameter \\
$\delta$ & 0.025 & Depreciation rate of private capital \\
$\kappa$ & 1.4 & Investment adjustment cost parameter \\
$\alpha^{N}$ & 0.45 & Labor income share in nontraded output \\
$\alpha^{T}$ & 0.60 & Labor income share in traded output \\
$\alpha^{G}$ & 0.21 & Output elasticity with respect to public capital \\
$\delta^{G}$ & 0.012 & Depreciation rate of public capital \\
$\epsilon$ & 0.4 & Public investment efficiency in steady state. \\
$\pi^{4}$ & 1.085 & CPI inflation (annual rate) \\
$c / y$ & $88 \%$ & Private consumption to GDP ratio \\
$i / y$ & $18 \%$ & Private investment to GDP ratio \\
$g^{C} / y$ & $7.6 \%$ & Government consumption to GDP ratio \\
$g^{I} / y$ & $10.9 \%$ & Public investment to GDP ratio \\
$\left(s \times r e s^{*}\right) / 4 y$ & $19.2 \%$ & Foreign exchange reserves to GDP ratio (annual) \\
$\left(s \times a^{*}\right) / y$ & $5.7 \%$ & Foreign aid to GDP ratio \\
\hline \hline
\end{tabular}

Table 4: Parameterization of the Full-Scale DSGE Model of Section.

\section{References}

[1] Aguiar, M. and G. Gopinath (2007): "Emerging market business cycles: the cycle is in the trend," Journal of Political Economy, Vol. 115(1), 69-101.

[2] Allen, (2005): [paper refered to in Introduction footnote - ]

[3] Berg, Andrew, Jan Gottschalk, Rafael Portillo, and Luis-Felipe Zanna (2010a): "The macroeconomics of medium-term aid scaling-up scenarios," IMF Working Paper No. 10/160, July 2010.

[4] Berg, Andrew, Tokhir Mirzoev, Rafael Portillo, and Luis-Felipe Zanna (2010b): "The short-run macroeconomics of aid inflows: Understanding the interaction of fiscal and reserve policy," IMF Working Paper 10/65, March 2010.

[5] Berg, Andrew, Shu-Chun S. Yang, and Luis-Felipe Zanna (2015): "Modeling African economies: A DSGE approach." Oxford Handbook of Africa and Economics,Oxford University Press, Vol. 1 (July). 
[6] Buffie, E.E, A. Berg, C. Pattillo, R. Portillo, and L.-F. Zanna (2012): "Public investment, growth, and debt sustainability: Putting together the pieces," IMF Working Paper No. $12 / 144$.

[7] Dabla-Norris, Era, Jim Brumby, Annette Kyobe, Zac Mills, and Chris Papageorgiou (2012): "Investing in public investment: an index of public investment efficiency," Journal of Economic Growth, Vol. 17, Issue 3, 235-266.

[8] Gali, J. and T. Monacelli (2005): "Monetary policy and exchange rate volatility in a small open economy", Review of Economic Studies.

[9] Moldovan, Ioana, Shu-Chun S. Yang, and Luis-Felipe Zanna (2018): "Fiscal and reserve accumulation policies under volatile aid", mimeo.

[10] Ogaki, M., J. Ostry, and C. Reinhart (1996): "Saving behavior in low- and middle-income developing countries: A Comparison", IMF Staff Papers, Vol 43 (1), 38-71.

[11] Rotemberg, J. J. (1982): "Monopolistic price adjustment and aggregate output", Review of Economic Studies, Vol. 49, 517-531.

[12] Schmitt-Grohe, S., and M. Uribe (2003): "Closing small open economy models", Journal of International Economics, Vol. 61 (1), 163-185.

[13] Schmitt-Grohe, S., and M. Uribe (2004): "Solving dynamic general equilibrium models using a second-order approximation to the policy function", Journal of Economic Dynamics and Control, Vol. 28, 755-775.

[14] Stockman, A. C., and L.L. Tesar (1995): "Tastes and technology in a two-country model of the business cycle: Explaining international comovements", American Economic Review, Vol. 85(1), 168-185.

[15] World Bank (2015): "Haiti: Towards a new narrative," World Bank Systematic Country Diagnostic Report, May 2015. 


\section{A Appendix - A Simple Dynamic Model}

\section{A.1 System of Nonlinear Equations}

Households:

Consumption Euler equation

$$
c_{t}^{-\sigma}=\beta E_{t}\left[c_{t+1}^{-\sigma}\left(\frac{R_{t}}{\pi_{t+1}}\right)\right]
$$

Money demand

$$
\varkappa^{m} m_{t}^{-\xi}=c_{t}^{-\sigma}\left(\frac{R_{t}-1}{R_{t}}\right)
$$

Labor supply

$$
\varkappa^{l} l_{t}^{\psi}=\left(1-\tau_{t}\right) w_{t} c_{t}^{-\sigma}
$$

Non-traded goods firms:

Production of non-tradables

$$
y_{t}^{N}=z^{N}\left(l_{t}^{N}\right)^{\alpha^{N}}
$$

Pricing condition

$$
p_{t}^{N}=\left[\left(\frac{\theta}{\theta-1}\right)(1-\iota)\right] m c_{t}
$$

Real marginal cost

$$
m c_{t}=\frac{w_{t}}{\alpha^{N} z^{N}\left(l_{t}^{N}\right)^{\alpha^{N}-1}}
$$

Traded goods firms:

Production of tradables

$$
y_{t}^{T}=z^{T}\left(l_{t}^{T}\right)^{\alpha^{T}}
$$

Labor demand

$$
w_{t}=\alpha^{T}\left(\frac{s_{t} y_{t}^{T}}{l_{t}^{T}}\right)
$$

The government

Consolidated budget constraint

$$
p_{t}^{G} g_{t}=\tau_{t} w_{t} l_{t}+s_{t} a_{t}^{*}+\left(b_{t}^{c}-\frac{R_{t-1} b_{t-1}^{c}}{\pi_{t}}\right)+\underbrace{\left[\left(m_{t}-\frac{m_{t-1}}{\pi_{t}}\right)-s_{t}\left(r e s_{t}^{*}-\frac{r e s_{t-1}^{*}}{\pi^{*}}\right)\right]}_{\text {domestic credit }}
$$


Monetary and fiscal policy rules:

Scenario (1): Adjustment in expenditures - $g_{t}$ satisfies (51)

$$
b_{t}^{c}=\overline{b^{c}} ; \quad \tau_{t}=\bar{\tau} ; \quad r e s_{t}^{*}=\overline{r e s}^{*} ; \quad m_{t}=\mu \frac{m_{t-1}}{\pi_{t}}
$$

Scenario (2): Debt sales to the private sector - $b_{t}^{c}$ satisfies (51)

$$
g_{t}=\bar{g} ; \quad r e s_{t}^{*}=\overline{r e s}^{*} ; \quad m_{t}=\mu \frac{m_{t-1}}{\pi_{t}} ; \quad \ln \left(\tau_{t} / \bar{\tau}\right)=\varrho \ln \left(b_{t-1}^{c} / \bar{b}^{c}\right)
$$

Scenario (3): Monetization of the deficit $-m_{t}$ satisfies (51)

$$
g_{t}=\bar{g} ; \quad b_{t}^{c}=\overline{b^{c}} ; \quad \tau_{t}=\bar{\tau} ; \quad r e s_{t}^{*}=\overline{r e s}^{*}
$$

Scenario (4): Sales of foreign exchange reserves - res* satisfies (51)

$$
g_{t}=\bar{g} ; \quad b_{t}^{c}=\overline{b^{c}} ; \quad \tau_{t}=\bar{\tau} ; \quad m_{t}=\mu \frac{m_{t-1}}{\pi_{t}}
$$

Aggregate constraints and definitions:

Aggregate labor

$$
l_{t}=l_{t}^{N}+l_{t}^{T}
$$

GDP

$$
y_{t}=p_{t}^{N} y_{t}^{N}+s_{t} y_{t}^{T}
$$

Internal balance condition

$$
\begin{aligned}
y_{t}^{N} & =c_{t}^{N}+g_{t}^{N} \\
& =\left(p_{t}^{N}\right)^{-\chi}\left[\varphi c_{t}+\varphi^{G}\left(p_{t}^{G}\right)^{\chi} g_{t}\right]
\end{aligned}
$$

External balance condition

$$
\begin{aligned}
y_{t}^{T}+a_{t}^{*}-\left(r e s_{t}^{*}-\frac{r e s_{t-1}^{*}}{\pi^{*}}\right) & =c_{t}^{T}+g_{t}^{T} \\
& =\left(s_{t}^{-\chi}\right)\left[(1-\varphi) c_{t}+\left(1-\varphi^{G}\right)\left(p_{t}^{G}\right)^{\chi} g_{t}\right]
\end{aligned}
$$

Definition of the CPI

$$
1=\left[\varphi\left(p_{t}^{N}\right)^{1-\chi}+(1-\varphi) s_{t}^{1-\chi}\right]^{\frac{1}{1-\chi}}
$$


Definition of government price index

$$
p_{t}^{G}=\left[\varphi^{G}\left(p_{t}^{N}\right)^{1-\chi}+\left(1-\varphi^{G}\right) s_{t}^{1-\chi}\right]^{\frac{1}{1-\chi}}
$$

Exogenous foreign aid process

$$
\log \left(\frac{a_{t}^{*}}{\bar{a}^{*}}\right)=\rho_{a} \log \left(\frac{a_{t-1}^{*}}{\bar{a}^{*}}\right)+\varepsilon_{t}
$$

\section{A.2 System of Log-Linearized Equations}

We denote with $\widehat{x}_{t}$ the log-deviation of variable $x_{t}$ from its deterministic steady state value $x, \widehat{x}_{t}=\ln \left(\frac{x_{t}}{x}\right)$.

Households:

Consumption Euler equation

$$
\sigma \widehat{c}_{t}=\sigma E_{t} \widehat{c}_{t+1}-\left(\widehat{R}_{t}-E_{t} \widehat{\pi}_{t+1}\right)
$$

Money demand

$$
\xi \widehat{m}_{t}=\sigma \widehat{c}_{t}-\left(\frac{1}{R-1}\right) \widehat{R}_{t}
$$

Labor supply

$$
\psi \widehat{l}_{t}=\widehat{w}_{t}-\sigma \widehat{c}_{t}-\left(\frac{\tau}{1-\tau}\right) \widehat{\tau}_{t}
$$

Non-traded goods firms:

Production of non-tradables

$$
\widehat{y}_{t}^{N}=\alpha^{N} \widehat{l}_{t}^{N}
$$

Pricing condition

$$
\widehat{p}_{t}^{N}=\widehat{m c}_{t}
$$

Real marginal cost

$$
\widehat{m c}_{t}=\widehat{w}_{t}+\left(1-\alpha^{N}\right) \widehat{l}_{t}^{N}
$$

Traded goods firms:

Production of tradables

$$
\widehat{y}_{t}^{T}=\alpha^{T} \widehat{l}_{t}^{T}
$$


Labor demand T sector

$$
\widehat{w}_{t}=\widehat{s}_{t}+\widehat{y}_{t}^{T}-\widehat{l}_{t}^{T}
$$

The government:

Consolidated government budget

$$
\kappa_{g}\left(\widehat{p}_{t}^{G}+\widehat{g}_{t}\right)=\left[\begin{array}{c}
\left(\frac{\tau w l}{y}\right)\left(\widehat{\tau}_{t}+\widehat{w}_{t}+\widehat{l}_{t}\right)+\kappa_{a^{*}}\left(\widehat{s}_{t}+\widehat{a}_{t}^{*}\right)+\kappa_{b^{c}}\left(\widehat{b}_{t}^{c}-\frac{R}{\pi} \widehat{b}_{t-1}^{c}\right) \\
+\kappa_{m}\left(\widehat{m}_{t}-\frac{1}{\pi} \widehat{m}_{t-1}\right)-\kappa_{r e s^{*}}\left(\widehat{r e s}_{t}^{*}-\frac{1}{\pi^{*}} \widehat{r e s}_{t-1}^{*}\right) \\
+\left(\frac{R}{\pi} \kappa_{b^{c}}+\frac{1}{\pi} \kappa_{m}\right) \widehat{\pi}_{t}-\kappa_{r e s^{*}}\left(1-\frac{1}{\pi^{*}}\right) \widehat{s}_{t}-\left(\frac{R}{\pi} \kappa_{b^{c}}\right) \widehat{R}_{t-1}
\end{array}\right]
$$

Monetary and fiscal policies

Scenario (1): Adjustment in expenditures $-\widehat{g}_{t}$ satisfies (67)

$$
\widehat{b}_{t}^{c}=0 ; \quad \widehat{\tau}_{t}=0 ; \quad \widehat{r e s}_{t}^{*}=0 ; \quad \widehat{m}_{t}=\widehat{m}_{t-1}-\widehat{\pi}_{t}
$$

Scenario (2): Debt sales to the private sector $-\widehat{b}_{t}^{c}$ satisfies (67)

$$
\widehat{g}_{t}=0 ; \quad \widehat{r e s}_{t}^{*}=0 ; \quad \widehat{m}_{t}=\widehat{m}_{t-1}-\widehat{\pi}_{t} ; \quad \widehat{\tau}_{t}=\varrho d b_{t-1}^{c}
$$

Scenario (3): Monetization - $\widehat{m}_{t}$ satisfies (67)

$$
\widehat{g}_{t}=0 ; \quad \widehat{b}_{t}^{c}=0 ; \quad \widehat{\tau}_{t}=0 ; \quad \widehat{r e s}_{t}^{*}=0
$$

Scenario (4): Sales of foreign exchange reserves $-\widehat{r e s}_{t}^{*}$ satisfies (67)

$$
\widehat{g}_{t}=0 ; \quad \widehat{b}_{t}^{c}=0 ; \quad \widehat{\tau}_{t}=0 ; \quad \widehat{m}_{t}=\widehat{m}_{t-1}-\widehat{\pi}_{t}
$$

Aggregate constraints and definitions

Aggregate labor:

$$
\widehat{l}_{t}=\left(\frac{l^{N}}{l}\right) \widehat{l}_{t}^{N}+\left(\frac{l^{T}}{l}\right) \widehat{l}_{t}^{T}
$$

Real GDP:

$$
\widehat{y}_{t}=\kappa_{y^{N}}\left(\widehat{p}_{t}^{N}+\widehat{y}_{t}^{N}\right)+\kappa_{y^{T}}\left(\widehat{s}_{t}+\widehat{y}_{t}^{T}\right)
$$


Internal balance condition

$$
\widehat{y}_{t}^{N}=(-\chi) \widehat{p}_{t}^{N}+\varphi\left(\frac{\kappa_{c}}{\kappa_{y^{N}}}\right) \widehat{c}_{t}+\varphi^{G}\left(\frac{\kappa_{g}}{\kappa_{y^{N}}}\right)\left(\chi \widehat{p}_{t}^{G}+\widehat{g}_{t}\right)
$$

External balance condition

$$
\begin{aligned}
\widehat{y}_{t}^{T} & =(-\chi) \zeta_{0} \widehat{s}_{t}+(1-\varphi)\left(\frac{\kappa_{c}}{\kappa_{y^{T}}}\right) \widehat{c}_{t}+\left(1-\varphi^{G}\right)\left(\frac{\kappa_{g}}{\kappa_{y^{T}}}\right)\left(\chi \widehat{p}_{t}^{G}+\widehat{g}_{t}\right) \\
& -\left(\frac{\kappa_{a^{*}}}{\kappa_{y^{T}}}\right) \widehat{a}_{t}^{*}+\left(\frac{\kappa_{r e s^{*}}}{\kappa_{y^{T}}}\right)\left(\widehat{r e s}_{t}^{*}-\frac{\widehat{r e s}_{t-1}^{*}}{\pi^{*}}\right) \\
\text { where } & : \zeta_{0} \equiv(1-\varphi)\left(\frac{\kappa_{c}}{\kappa_{y^{T}}}\right)+\left(1-\varphi^{G}\right)\left(\frac{\kappa_{g}}{\kappa_{y^{T}}}\right)
\end{aligned}
$$

Definition of the CPI

$$
\widehat{p}_{t}^{N}=\underbrace{\left[-\left(\frac{1-\varphi}{\varphi}\right)\right]}_{\equiv \zeta_{1}} \widehat{s}_{t}=\zeta_{1} \widehat{s}_{t}
$$

Definition of government price index, accounting for $p_{t}^{N}$ changes as in (72) above

$$
\widehat{p}_{t}^{G}=\underbrace{\left(\frac{\varphi-\varphi^{G}}{\varphi}\right)}_{\equiv \zeta_{2}} \widehat{s}_{t}=\zeta_{2} \widehat{s}_{t}
$$

Exogenous foreign aid process

$$
\widehat{a}_{t}^{*}=\rho_{a} \widehat{a}_{t-1}^{*}+\epsilon_{t}^{a}
$$




\section{A.3 Further Manipulations}

The Labor Market

- Non-tradable sector labor demand - combine equations (63), (64), and (72):

$$
\widehat{l}_{t}^{N}=\left(\frac{1}{1-\alpha^{N}}\right)\left(\widehat{p}_{t}^{N}-\widehat{w}_{t}\right)=\left(\frac{1}{1-\alpha^{N}}\right)\left(\zeta_{1} \widehat{s}_{t}-\widehat{w}_{t}\right)
$$

- Tradable sector labor demand - combine equations (66) and (65):

$$
\widehat{l}_{t}^{T}=\left(\frac{1}{1-\alpha^{T}}\right)\left(\widehat{s}_{t}-\widehat{w}_{t}\right)
$$

- Aggregate labor - using the aggregate labor condition (68), substitute for $\widehat{l}_{t}^{N}$ and $\widehat{l}_{t}^{T}$ from above, and further impose the calibration assumption that $\alpha^{N}=\alpha^{T}=\alpha$ :

$$
\widehat{l}_{t}=\left(\frac{1}{1-\alpha}\right)\left[1-\frac{l^{N}}{l}\left(1-\zeta_{1}\right)\right] \widehat{s}_{t}-\left(\frac{1}{1-\alpha}\right) \widehat{w}_{t}
$$

- Equilibrium real wage rate - the households' FOC for labor (61) relates labor supply changes to changes in (after-tax) wages and consumption. Combining this equation with (77) yields an expression for the real wage:

$$
\begin{aligned}
& \qquad \widehat{w}_{t}=\zeta_{3} \widehat{s}_{t}+\left(\frac{1-\alpha}{1-\alpha+\psi}\right) \sigma \widehat{c}_{t}+\left(\frac{1-\alpha}{1-\alpha+\psi}\right)\left(\frac{\tau}{1-\tau}\right) \widehat{\tau}_{t} \\
& \text { where }: \quad \zeta_{3} \equiv\left(\frac{\psi}{1-\alpha+\psi}\right)\left[1-\frac{l^{N}}{l}\left(1-\zeta_{1}\right)\right]
\end{aligned}
$$

- Equilibrium labor - substitute for the real wage back into (77) to obtain an expression for the total labor supply in terms of consumption, the real exchange rate, and the income tax:

$$
\widehat{l}_{t}=\left(\frac{1}{1-\alpha+\psi}\right)\left\{\left[1-\frac{l^{N}}{l}\left(1-\zeta_{1}\right)\right] \widehat{s}_{t}-\sigma \widehat{c}_{t}-\left(\frac{\tau}{1-\tau}\right) \widehat{\tau}_{t}\right\}
$$

- Wage income - a measure of wage income (changes) is then obtained by combining equations (78) and (79):

$$
\left(\widehat{w}_{t}+\widehat{l}_{t}\right)=\left[\left(\frac{1+\psi}{\psi}\right) \zeta_{3}\right] \widehat{s}_{t}-\left(\frac{\alpha}{1-\alpha+\psi}\right) \sigma \widehat{c}_{t}-\left(\frac{\alpha}{1-\alpha+\psi}\right)\left(\frac{\tau}{1-\tau}\right) \widehat{\tau}_{t}
$$




\section{Aggregate Output}

- NT sector output - combine the production function (62) with the labor condition (75) and the real wage expression in (78):

$$
\widehat{y}_{t}^{N}=\left(\frac{\alpha}{1-\alpha}\right)\left(\zeta_{1}-\zeta_{3}\right) \widehat{s}_{t}-\left(\frac{\alpha}{1-\alpha+\psi}\right) \sigma \widehat{c}_{t}-\left(\frac{\alpha}{1-\alpha+\psi}\right)\left(\frac{\tau}{1-\tau}\right) \widehat{\tau}_{t}
$$

- T sector output - similarly, combine the production function (65) with the labor condition (76) and the real wage expression in (78):

$$
\widehat{y}_{t}^{T}=\left(\frac{\alpha}{1-\alpha}\right)\left(1-\zeta_{3}\right) \widehat{s}_{t}-\left(\frac{\alpha}{1-\alpha+\psi}\right) \sigma \widehat{c}_{t}-\left(\frac{\alpha}{1-\alpha+\psi}\right)\left(\frac{\tau}{1-\tau}\right) \widehat{\tau}_{t}
$$

- Aggregate output - using the GDP definition (69) and the expressions for $\widehat{y}_{t}^{N}$ and $\widehat{y}_{t}^{T}$ from above, we obtain:

$$
\begin{aligned}
\widehat{y}_{t} & =\zeta_{4} \widehat{s}_{t}-\left(\frac{\alpha}{1-\alpha+\psi}\right) \sigma \widehat{c}_{t}-\left(\frac{\alpha}{1-\alpha+\psi}\right)\left(\frac{\tau}{1-\tau}\right) \widehat{\tau}_{t} \\
\text { where } & : \quad \zeta_{4} \equiv \frac{1}{1-\alpha}\left[1-\kappa_{y^{N}}\left(1-\zeta_{1}\right)\right]-\frac{\alpha}{1-\alpha} \zeta_{3}
\end{aligned}
$$

The government budget constraint:

- Starting with equation (67), substitute for $\widehat{p}_{t}^{G}$ using (73) and for wage income using (80) and, under the calibration assumption that government debt is zero in steady state $\left(\bar{b}^{c}=0\right)$, we obtain the following expression: ${ }^{12}$

$$
\begin{aligned}
\kappa_{g} \widehat{g}_{t}= & \left(\zeta^{\sharp}-\kappa_{g} \zeta_{2}\right) \widehat{s}_{t}-\left[\frac{\tau w l}{y}\left(\frac{\alpha}{1-\alpha+\psi}\right) \sigma\right] \widehat{c}_{t}+\left[\frac{\tau w l}{y}\left(1-\frac{\alpha}{1-\alpha+\psi} \frac{\tau}{1-\tau}\right)\right] \widehat{\tau}_{t}+ \\
& +\left(\kappa_{m} \frac{1}{\pi}\right) \widehat{\pi}_{t}+\kappa_{a^{*}} \widehat{a}_{t}^{*}+(1 / \bar{y})\left(d b_{t}^{c}-\frac{R}{\pi} d b_{t-1}^{c}\right) \\
& +\kappa_{m}\left(\widehat{m}_{t}-\frac{1}{\pi} \widehat{m}_{t-1}\right)-\kappa_{r e s^{*}}\left(\widehat{r e s}_{t}^{*}-\frac{1}{\pi^{*}} \widehat{r e s}_{t-1}^{*}\right) \\
\text { where }: & \zeta^{\sharp} \equiv \frac{\tau w l}{y}\left(\frac{1+\psi}{\psi}\right) \zeta_{3}+\kappa_{a^{*}}-\kappa_{r e s^{*}}\left(1-\frac{1}{\pi^{*}}\right)
\end{aligned}
$$

\footnotetext{
${ }^{12}$ Note that changes in government debt are measured as simple deviations from the steady-state value, $d b_{t}^{c}$ (and not as log-deviations).
} 
The money market:

- The money market equilibrium implies a nominal interest rate that satisfies the relationship

$$
\widehat{R}_{t}=(R-1) \sigma \widehat{c}_{t}-(R-1) \xi \widehat{m}_{t}
$$

where changes in real money balances $\widehat{m}_{t}$ are tied to specific policy considerations, as described in the different policy scenarios discussed.

\section{Internal balance condition:}

- Starting with equation (70), substitute for prices $\widehat{p}_{t}^{N}$ and $\widehat{p}_{t}^{G}$ using (72) and (73) and for $\widehat{y}_{t}^{N}$ using (81), and collect terms to obtain the following expression relating the real exchange rate, consumption, and adjustments in fiscal policy (as given by possible changes in government expenditures and/or taxes)

$$
\mathfrak{b}_{s} \widehat{s}_{t}=\mathfrak{b}_{c} \widehat{c}_{t}+\mathfrak{b}_{\tau} \widehat{\tau}_{t}+\varphi^{G}\left(\frac{\kappa_{g}}{\kappa_{y^{N}}}\right) \widehat{g}_{t}
$$

where

$$
\left\{\begin{array}{l}
\mathfrak{b}_{s} \equiv\left(\frac{\alpha}{1-\alpha}+\chi\right) \zeta_{1}-\chi \varphi^{G}\left(\frac{\kappa_{g}}{\kappa_{y^{N}}}\right) \zeta_{2}-\frac{\alpha}{1-\alpha} \zeta_{3} \\
\mathfrak{b}_{c} \equiv \varphi\left(\frac{\kappa_{c}}{\kappa_{y^{N}}}\right)+\left(\frac{\alpha}{1-\alpha+\psi}\right) \sigma \\
\mathfrak{b}_{\tau} \equiv\left(\frac{\alpha}{1-\alpha+\psi}\right)\left(\frac{\tau}{1-\tau}\right)
\end{array}\right.
$$

\section{External balance condition:}

- Starting with equation (71), substitute for $\widehat{p}_{t}^{G}$ using (73) and for tradable-sector output $\widehat{y}_{t}^{T}$ using (82), and collect terms to obtain a similar expression, which now also includes foreign aid and foreign exchange reserves:

$$
\vartheta_{s} \widehat{s}_{t}=\vartheta_{c} \widehat{c}_{t}+\mathfrak{b}_{\tau} \widehat{\tau}+\left(1-\varphi^{G}\right)\left(\frac{\kappa_{g}}{\kappa_{y^{T}}}\right) \widehat{g}_{t}-\left(\frac{\kappa_{a^{*}}}{\kappa_{y^{T}}}\right) \widehat{a}_{t}^{*}+\left(\frac{\kappa_{r e s^{*}}}{\kappa_{y^{T}}}\right)\left(\widehat{r e s}_{t}^{*}-\frac{\widehat{r e s}_{t-1}^{*}}{\pi^{*}}\right)
$$

where

$$
\left\{\begin{array}{l}
\vartheta_{s} \equiv\left(\frac{\alpha}{1-\alpha}\right)\left(1-\zeta_{3}\right)+\chi \zeta_{0}-\chi\left(1-\varphi^{G}\right)\left(\frac{\kappa_{g}}{\kappa_{y} T}\right) \zeta_{2} \\
\vartheta_{c} \equiv(1-\varphi)\left(\frac{\kappa_{c}}{\kappa_{y} T}\right)+\left(\frac{\alpha}{1-\alpha+\psi}\right) \sigma
\end{array}\right.
$$

List of the $\zeta$ coefficients: 


$$
\left\{\begin{array}{l}
\zeta_{0} \equiv\left(\frac{\kappa_{c}}{\kappa_{y^{T}}}\right)(1-\varphi)+\left(\frac{\kappa_{g}}{\kappa_{y^{T}}}\right)\left(1-\varphi^{G}\right) \\
\zeta_{1} \equiv-\left(\frac{1-\varphi}{\varphi}\right) \\
\zeta_{2} \equiv\left(\frac{\varphi-\varphi^{G}}{\varphi}\right) \\
\zeta_{3} \equiv\left(\frac{\psi}{1-\alpha+\psi}\right)\left[1-\frac{l^{N}}{l}\left(1-\zeta_{1}\right)\right] \\
\zeta_{4} \equiv \frac{1}{1-\alpha}\left[1-\kappa_{y^{N}}\left(1-\zeta_{1}\right)\right]-\frac{\alpha}{1-\alpha} \zeta_{3} \\
\zeta^{\sharp} \equiv \frac{\tau w l}{y}\left(\frac{1+\psi}{\psi}\right) \zeta_{3}+\kappa_{a^{*}}-\kappa_{r e s^{*}}\left(1-\frac{1}{\pi^{*}}\right)
\end{array}\right.
$$




\section{B Policy Analysis in the Simple Dynamic Model - Analytical Details}

In this section of the Appendix, we provide further details on the analytical derivations in the simple dynamic model discussed in Section 4 of the paper. We consider, in turn, each of the four policy scenarios.

\section{B.1 Adjusting Government Expenditures}

In this case, the government reduces its spending $g_{t}$ in response to the decline in aid, such that the government budget constraint is satisfied, without further adjustments in other policy instruments. Specifically, government debt held by households, labor income taxes, and the stock of foreign exchange reserves remain unchanged at their steady-state levels (so that $d b_{t}^{c}=0, \widehat{\tau}_{t}=0$, and $\widehat{r e s}_{t}^{*}=0$ ), while reserve nominal money balances grow at a constant rate $\mu$, implying $\widehat{m}_{t}=\widehat{m}_{t-1}-\widehat{\pi}_{t}$.

\section{Government expenditures:}

From the government budget constraint (84) and given the policy specification, we obtain an expression for real government expenditures as,

$$
\begin{aligned}
\kappa_{g} \widehat{g}_{t}= & \left(\zeta^{\sharp}-\kappa_{g} \zeta_{2}\right) \widehat{s}_{t}-\left[\frac{\tau w l}{y}\left(\frac{\alpha}{1-\alpha+\psi}\right) \sigma\right] \widehat{c}_{t}+\kappa_{a^{*}} \widehat{a}_{t}^{*}-\left(\frac{R}{\pi y}\right) d b_{t-1}^{c}+ \\
& +\kappa_{m}\left(1-\frac{1}{\pi}\right)\left(\widehat{m}_{t-1}-\widehat{\pi}_{t}\right)+\left(\frac{\kappa_{r e s^{*}}}{\pi^{*}}\right) \widehat{r e s}_{t-1}^{*}
\end{aligned}
$$

Internal and External Balance Conditions: Substituting for government expenditures in the internal and external balance conditions (86) and (87) and given $\widehat{\tau}_{t}=0$, we can express $\widehat{s}_{t}$ and $\widehat{c}_{t}$ in terms of inflation $\widehat{\pi}_{t}$ and state variables.

Internal balance: starting with the internal balance condition (86), substitute for government expenditures $\kappa_{g} \widehat{g}_{t}$ from above, impose $\widehat{\tau}_{t}=0$, and collect terms to obtain the following expression in $\widehat{s}_{t}, \widehat{c}_{t}, \widehat{\pi}_{t}$ and state variables $\left\{\widehat{a}_{t}^{*}, d b_{t-1}^{c}, \widehat{m}_{t-1}, \widehat{r e s}_{t-1}^{*}\right\}$ :

$$
\begin{aligned}
\mathfrak{b}_{s}^{(g)} \widehat{s}_{t}= & \mathfrak{b}_{c}^{(g)} \widehat{c}_{t}+\left[\varphi^{G} \frac{\kappa_{a^{*}}}{\kappa_{y^{N}}}\right] \widehat{a}_{t}^{*}-\left[\varphi^{G} \frac{1}{\kappa_{y^{N}}} \frac{R}{\pi y}\right] d b_{t-1}^{c} \\
& +\left[\varphi^{G} \frac{\kappa_{m}}{\kappa_{y^{N}}}\left(1-\frac{1}{\pi}\right)\right]\left(\widehat{m}_{t-1}-\widehat{\pi}_{t}\right)+\left[\varphi^{G} \frac{\kappa_{r e s^{*}}}{\kappa_{y^{N}}} \frac{1}{\pi^{*}}\right] \widehat{r e s}_{t-1}^{*}
\end{aligned}
$$


where

$$
\left\{\begin{array}{l}
\mathfrak{b}_{s}^{(g)} \equiv\left(\frac{\alpha}{1-\alpha}\right)\left(\zeta_{1}-\zeta_{3}\right)+\chi \zeta_{1}-\varphi^{G} \frac{\kappa_{g}}{\kappa_{y^{N}}}(\chi-1) \zeta_{2}-\varphi^{G} \frac{1}{\kappa_{y^{N}}} \zeta^{\sharp} \\
\mathfrak{b}_{c}^{(g)} \equiv \varphi \frac{\kappa_{c}}{\kappa_{y^{N}}}+\left(\frac{\alpha}{1-\alpha+\psi}\right) \sigma\left(1-\varphi^{G} \frac{1}{\kappa_{y^{N}}} \frac{\tau w l}{y}\right)
\end{array}\right.
$$

External balance: Similarly, starting with the external balance condition in (87), substitute for government expenditures, set $\widehat{\tau}_{t}=0$ and collect terms to obtain the expression

$$
\begin{aligned}
\vartheta_{s}^{(g)} \widehat{s}_{t}= & \vartheta_{c}^{(g)} \widehat{c}_{t}-\left[\varphi^{G} \frac{\kappa_{a^{*}}}{\kappa_{y^{T}}}\right] \widehat{a}_{t}^{*}-\left[\left(1-\varphi^{G}\right) \frac{1}{\kappa_{y^{T}}} \frac{R}{\pi y}\right] d b_{t-1}^{c} \\
& +\left[\left(1-\varphi^{G}\right) \frac{\kappa_{m}}{\kappa_{y^{T}}}\left(1-\frac{1}{\pi}\right)\right]\left(\widehat{m}_{t-1}-\widehat{\pi}_{t}\right)-\left[\varphi^{G} \frac{\kappa_{r e s^{*}}}{\kappa_{y^{T}}} \frac{1}{\pi^{*}}\right] \widehat{r e s}_{t-1}^{*}
\end{aligned}
$$

where

$$
\left\{\begin{array}{l}
\vartheta_{s}^{(g)} \equiv\left(\frac{\alpha}{1-\alpha}\right)\left(1-\zeta_{3}\right)+\chi \zeta_{0}-\left(1-\varphi^{G}\right) \frac{\kappa_{g}}{\kappa_{y^{T}}}(\chi-1) \zeta_{2}-\left(1-\varphi^{G}\right) \frac{1}{\kappa_{y} T} \zeta^{\sharp} \\
\vartheta_{c}^{(g)} \equiv(1-\varphi) \frac{\kappa_{c}}{\kappa_{y^{T}}}+\left(\frac{\alpha}{1-\alpha+\psi}\right) \sigma\left[1-\left(1-\varphi^{G}\right) \frac{1}{\kappa_{y^{T}}} \frac{\tau w l}{y}\right]
\end{array}\right.
$$

Then, using the two conditions (89) and (90), $\widehat{s}_{t}$ and $\widehat{c}_{t}$ can be expressed in terms of inflation $\widehat{\pi}_{t}$ and state variables:

$$
\begin{aligned}
\widehat{s}_{t} & =\lambda_{a}^{(g)} \widehat{a}_{t}^{*}+\lambda_{b}^{(g)} d b_{t-1}^{c}+\lambda_{m}^{(g)}\left(\widehat{m}_{t-1}-\widehat{\pi}_{t}\right)+\lambda_{\text {res }}^{(g)} \widehat{r e s}_{t-1}^{*} \\
\widehat{c}_{t} & =\gamma_{a}^{(g)} \widehat{a}_{t}^{*}+\gamma_{b}^{(g)} d b_{t-1}^{c}+\gamma_{m}^{(g)}\left(\widehat{m}_{t-1}-\widehat{\pi}_{t}\right)+\gamma_{\text {res }}^{(g)} \widehat{r e s}_{t-1}^{*}
\end{aligned}
$$


where:

$$
\left\{\begin{array}{l}
\lambda_{a}^{(g)} \equiv-\left[\vartheta_{s}^{(g)}-\frac{\mathfrak{b}_{s}^{(g)}}{\mathfrak{b}_{c}^{(g)}} \vartheta_{c}^{(g)}\right]^{-1} \Gamma^{*} \kappa_{a^{*}} \\
\lambda_{b}^{(g)} \equiv\left[\vartheta_{s}^{(g)}-\frac{\mathfrak{b}_{s}^{(g)}}{\mathfrak{b}_{c}^{(g)}} \vartheta_{c}^{(g)}\right]^{-1} \Gamma \frac{R}{\pi y} \\
\lambda_{m}^{(g)} \equiv-\left[\vartheta_{s}^{(g)}-\frac{\mathfrak{b}_{s}^{(g)}}{\mathfrak{b}_{c}^{(g)}} \vartheta_{c}^{(g)}\right]^{-1} \Gamma \kappa_{m}\left(1-\frac{1}{\pi}\right) \\
\lambda_{r e s}^{(g)} \equiv-\left[\vartheta_{s}^{(g)}-\frac{\mathfrak{b}_{s}^{(g)}}{\mathfrak{b}_{c}^{(g)}} \vartheta_{c}^{(g)}\right]^{-1} \Gamma^{*} \kappa_{r e s^{*}} \frac{1}{\pi^{*}} \\
\Gamma \equiv\left[\frac{\vartheta_{c}^{(g)}}{\mathfrak{b}_{c}^{(g)}} \frac{1}{\kappa_{y^{N}}} \varphi^{G}+\frac{1}{\kappa_{y^{T}}}\left(1-\varphi^{G}\right)\right] \\
\Gamma^{*} \equiv\left[\frac{\vartheta_{c}^{(g)}}{\mathfrak{b}_{c}^{(g)}} \frac{1}{\kappa_{y^{N}}}+\frac{1}{\kappa_{y^{T}}}\right] \varphi^{G}
\end{array}\right.
$$

and

$$
\left\{\begin{array}{l}
\gamma_{a}^{(g)} \equiv \frac{\mathfrak{b}_{s}^{(g)}}{\mathfrak{b}_{c}^{(g)}} \lambda_{a}^{(g)}-\frac{1}{\mathfrak{b}_{c}^{(g)}} \varphi^{G} \frac{\kappa_{a^{*}}}{\kappa_{y^{N}}} \\
\gamma_{b}^{(g)} \equiv \frac{\mathfrak{b}_{s}^{(g)}}{\mathfrak{b}_{c}^{(g)}} \lambda_{b}^{(g)}+\frac{1}{\mathfrak{b}_{c}^{(g)}} \varphi^{G} \frac{1}{\kappa_{y^{N}}} \frac{R}{\pi y} \\
\gamma_{m}^{(g)} \equiv \frac{\mathfrak{b}_{s}^{(g)}}{\mathfrak{b}_{c}^{(g)}} \lambda_{m}^{(g)}-\frac{1}{\mathfrak{b}_{c}^{(g)}} \varphi^{G} \frac{\kappa_{m}}{\kappa_{y^{N}}}\left(1-\frac{1}{\pi}\right) \\
\gamma_{\text {res }}^{(g)} \equiv \frac{\mathfrak{b}_{s}^{(g)}}{\mathfrak{b}_{c}^{(g)}} \lambda_{r e s}^{(g)}-\frac{1}{\mathfrak{b}_{c}^{(g)}} \varphi^{G} \frac{\kappa_{r e s^{*}}}{\kappa_{y^{N}}} \frac{1}{\pi^{*}}
\end{array}\right.
$$

Note that a solution for $\widehat{s}_{t}$ and $\widehat{c}_{t}$ can only be obtained once we have a solution for inflation $\widehat{\pi}_{t}$, which is shown below.

Inflation dynamics: Using the nominal interest rate in (85), the Euler equation (59) can be re-written as

$$
(R-1) \xi \widehat{\pi}_{t}=E_{t} \widehat{\pi}_{t+1}+\sigma\left(E_{t} \widehat{c}_{t+1}-R \widehat{c}_{t}\right)+(R-1) \xi \widehat{m}_{t-1}
$$

The expression for consumption in (92), together with the rest of the policy specification, then allows us to obtain an expression for $\left(E_{t} \widehat{c}_{t+1}-R \widehat{c}_{t}\right)$ as

$\left(E_{t} \widehat{c}_{t+1}-R \widehat{c}_{t}\right)=\left[\gamma_{a}^{(g)}\left(\rho_{a}-R\right)\right] \widehat{a}_{t}^{*}-\gamma_{b}^{(g)} R d b_{t-1}^{c}-\gamma_{m}^{(g)}(R-1)\left(\widehat{m}_{t-1}-\widehat{\pi}_{t}\right)-\gamma_{m}^{(g)} E_{t} \widehat{\pi}_{t+1}-\gamma_{r e s}^{(g)} R \widehat{r e s}_{t-1}^{*}$ 
which, upon substitution back into the Euler equation, gives the following relationship between inflation $\widehat{\pi}_{t}$, expected inflation $E_{t} \widehat{\pi}_{t+1}$, and state variables:

$$
\widehat{\pi}_{t}=\Upsilon E_{t} \widehat{\pi}_{t+1}+\Upsilon_{a} \widehat{a}_{t}^{*}+\Upsilon_{b} d b_{t-1}^{c}+\widehat{m}_{t-1}+\Upsilon_{r e s} \widehat{r e s}_{t-1}^{*}
$$

where

$$
\left\{\begin{array}{l}
\Upsilon \equiv \frac{1-\gamma_{m}^{(g)} \sigma}{(R-1)\left(\xi-\gamma_{m}^{(g)} \sigma\right)} \\
\Upsilon_{a} \equiv \frac{\gamma_{a}^{(g)}\left(\rho_{a}-R\right) \sigma}{(R-1)\left(\xi-\gamma_{m}^{(g)} \sigma\right)} \\
\Upsilon_{b} \equiv-\frac{\gamma_{b}^{(g)} R \sigma}{(R-1)\left(\xi-\gamma_{m}^{(g)} \sigma\right)} \\
\Upsilon_{r e s} \equiv-\frac{\gamma_{r e s}^{(g)} R \sigma}{(R-1)\left(\xi-\gamma_{m}^{(g)} \sigma\right)}
\end{array}\right.
$$

\section{A Solution for Inflation:}

Using the minimum state variable method, we can solve for inflation as a function of state variables only. We posit a linear solution of the general form,

$$
\widehat{\pi}_{t}=\varkappa_{a} \widehat{a}_{t}^{*}+\varkappa_{b} d b_{t-1}^{c}+\varkappa_{m} \widehat{m}_{t-1}+\varkappa_{r e s} \widehat{r e s}_{t-1}^{*}
$$

Given the stationary process for aid in (74) and that, in this policy scenario, $d b_{t}^{c}=0$ and $\widehat{r e s}_{t}^{*}=0$, this implies

$$
\begin{aligned}
E_{t} \widehat{\pi}_{t+1} & =\varkappa_{a} E_{t} \widehat{a}_{t+1}^{*}+\varkappa_{b} d b_{t}^{c}+\varkappa_{m} \widehat{m}_{t}+\varkappa_{\text {res }} \widehat{r e s}_{t}^{*} \\
& =\varkappa_{a} \rho_{a} \widehat{a}_{t}^{*}+\varkappa_{m}\left(\widehat{m}_{t-1}-\widehat{\pi}_{t}\right)
\end{aligned}
$$

where in the second line we have substituted for $\widehat{m}_{t}$ using the policy rule for money balances.

Substituting back into (93) and re-arranging terms, we then obtain

$$
\left(1+\Upsilon \varkappa_{m}\right) \widehat{\pi}_{t}=\left[\Upsilon \rho_{a} \varkappa_{a}+\Upsilon_{a}\right] \widehat{a}_{t}^{*}-\Upsilon_{b} d b_{t-1}^{c}+\left(1+\Upsilon \varkappa_{m}\right) \widehat{m}_{t-1}-\Upsilon_{r e s} \widehat{r e s}_{t-1}^{*}
$$

where the LHS of the equation can further be written as

$$
\left[1+\Upsilon \varkappa_{m}\right]\left(\varkappa_{a} \widehat{a}_{t}^{*}+\varkappa_{b} d b_{t-1}^{c}+\varkappa_{m} \widehat{m}_{t-1}+\varkappa_{r e s} \widehat{r e s}_{t-1}^{*}\right)
$$

Then, equating coefficients, we have the following system of four equations in four un-

\section{(C)International Monetary Fund. Not for Redistribution}


knowns $\left\{\varkappa_{a}, \varkappa_{r e s}, \varkappa_{m}, \varkappa_{b}\right\}$ :

$$
\begin{cases}(i): & \left(1+\Upsilon_{m}\right) \varkappa_{a}=\Upsilon_{\rho_{a}} \varkappa_{a}+\Upsilon_{a} \\ (i i): & \left(1+\Upsilon_{\varkappa_{m}}\right) \varkappa_{b}=-\Upsilon_{b} \\ (i i i): & \left(1+\Upsilon_{\varkappa_{m}}\right) \varkappa_{m}=1+\Upsilon_{\varkappa_{m}} \\ (i v): & \left(1+\Upsilon_{\varkappa_{m}}\right) \varkappa_{r e s}=-\Upsilon_{\text {res }}\end{cases}
$$

The third equation in (94) is quadratic in $\varkappa_{m}$, with solutions $\varkappa_{m}=1$ and $\varkappa_{m}=-1 / \Upsilon$. With $\Upsilon>0$, the latter would however lead to non-stationary real money balances and so the stationary solution is $\varkappa_{m}=1 .{ }^{13}$ The remaining equations can then be solved for $\varkappa_{a}$, $\varkappa_{b}$, and $\varkappa_{\text {res }}$. Inflation dynamics are therefore given by the expression in (93), where the coefficients are (Note: we use the superscript ' $g$ ' to denote this policy scenario):

$$
\left\{\begin{array}{l}
\varkappa_{a}^{(g)}=\left[1+\Upsilon\left(1-\rho_{a}\right)\right]^{-1} \Upsilon_{a} \\
\varkappa_{b}^{(g)}=-(1+\Upsilon)^{-1} \Upsilon_{b} \\
\varkappa_{m}^{(g)}=1 \\
\varkappa_{\text {res }}^{(g)}=-(1+\Upsilon)^{-1} \Upsilon_{\text {res }}
\end{array}\right.
$$

The real exchange rate and consumption: Given the solution for inflation, the dynamics of the real exchange rate and consumption can be obtained from (91) and (92) as

$$
\begin{aligned}
& \widehat{s}_{t}=\left(\lambda_{a}-\lambda_{m} \varkappa_{a}\right) \widehat{a}_{t}^{*}+\left(\lambda_{b}-\lambda_{m} \varkappa_{b}\right) d b_{t-1}^{c}+\left(\lambda_{\text {res }}-\lambda_{m} \varkappa_{r e s}\right) \widehat{r e s}_{t-1}^{*} \\
& \widehat{c}_{t}=\left(\gamma_{a}-\gamma_{m} \varkappa_{a}\right) \widehat{a}_{t}^{*}+\left(\gamma_{b}-\gamma_{m} \varkappa_{b}\right) d b_{t-1}^{c}+\left(\gamma_{\text {res }}-\gamma_{m} \varkappa_{r e s}\right) \widehat{r e s}_{t-1}^{*}
\end{aligned}
$$

\footnotetext{
${ }^{13} \Upsilon$ can be shown to be positive. This can be easily seen when utility is logarithmic in real money balances (i.e. $\xi=1$ ), as in our benchmark calibration, which yields $\Upsilon=1 /(R-1)>0$. However, the condition holds in the more general case as well.
} 
The real interest rate: The real interest rate can be inferred from the Euler equation (59) and the dynamics of consumption. Specifically,

$$
\widehat{r}_{t}=\sigma\left(E_{t} \widehat{c}_{t+1}-\widehat{c}_{t}\right)
$$

where $\widehat{r}_{t}=\widehat{R}_{t}-E_{t} \widehat{\pi}_{t+1}$. Given the solution for consumption in (96), we then have

$$
\widehat{r}_{t}=\sigma\left[\left(\gamma_{a}-\gamma_{m} \varkappa_{a}\right)\left(\rho_{a}-1\right)\right] \widehat{a}_{t}^{*}-\sigma\left(\gamma_{b}-\gamma_{m} \varkappa_{b}\right) d b_{t-1}^{c}-\sigma\left(\gamma_{r e s}-\gamma_{m} \varkappa_{r e s}\right) \widehat{r e s}_{t-1}^{*}
$$




\section{B.2 Sales of Debt to the Private Sector}

In the second policy scenario, the government maintains its spending at pre-existing levels (implying $\widehat{g}_{t}=0$ ), but issues more domestic debt ( $b_{t}^{c}$ increases) to finance the increased deficit and balance its budget, while foreign exchange reserves remain unchanged $\left(\widehat{r e s}_{t}^{*}=0\right)$ and the money supply follows a constant growth rate rule (implying $\widehat{m}_{t}=\widehat{m}_{t-1}-\widehat{\pi}_{t}$ ). To ensure this policy is sustainable over the long run, we assume that the government will slightly raise income taxes in the future, $\widehat{\tau}_{t}=\varrho d b_{t-1}^{c}$, where $\varrho>0$ but small.

Internal Balance Condition: Starting with the expression in (70), and imposing the policy setup $\widehat{g}_{t}=0$ and $\widehat{\tau}_{t}=\varrho d b_{t-1}^{c}$ we obtain the following expression in $\widehat{s}_{t}, \widehat{c}_{t}$, and $d b_{t-1}^{c}$

$$
\mathfrak{b}_{s} \widehat{s}_{t}=\mathfrak{b}_{c} \widehat{c}_{t}+\mathfrak{b}_{\tau}\left(\varrho d b_{t-1}^{c}\right)
$$

where

$$
\left\{\begin{array}{l}
\mathfrak{b}_{s} \equiv\left(\frac{\alpha}{1-\alpha}+\chi\right) \zeta_{1}-\chi \varphi^{G}\left(\frac{\kappa_{g}}{\kappa_{y^{N}}}\right) \zeta_{2}-\frac{\alpha}{1-\alpha} \zeta_{3} \\
\mathfrak{b}_{c} \equiv \varphi \frac{\kappa_{c}}{\kappa_{y^{N}}}+\left(\frac{\alpha}{1-\alpha+\psi}\right) \sigma \\
\mathfrak{b}_{\tau} \equiv\left(\frac{\alpha}{1-\alpha+\psi}\right)\left(\frac{\tau}{1-\tau}\right)
\end{array}\right.
$$

External Balance Condition: The external balance condition is given by (71), where we set $\widehat{g}_{t}$ and $\widehat{r e s}_{t}^{*}$ to 0 , and $\widehat{\tau}_{t}=\varrho d b_{t-1}^{c}$, and obtain the following simplified relationship

$$
\vartheta_{s} \widehat{s}_{t}=\vartheta_{c} \widehat{c}_{t}-\left(\frac{\kappa_{a^{*}}}{\kappa_{y^{T}}}\right) \widehat{a}_{t}^{*}-\left(\frac{\kappa_{r e s^{*}}}{\kappa_{y^{T}}} \frac{1}{\pi^{*}}\right) \widehat{r e s}_{t-1}^{*}+\mathfrak{b}_{\tau}\left(\varrho d b_{t-1}^{c}\right)
$$

where

$$
\left\{\begin{array}{l}
\vartheta_{s} \equiv \frac{\alpha}{1-\alpha}\left(1-\zeta_{3}\right)+\chi \zeta_{0}-\chi\left(1-\varphi^{G}\right)\left(\frac{\kappa_{g}}{\kappa_{y^{T}}}\right) \zeta_{2} \\
\vartheta_{c} \equiv(1-\varphi) \frac{\kappa_{c}}{\kappa_{y} T}+\left(\frac{\alpha}{1-\alpha+\psi}\right) \sigma
\end{array}\right.
$$


Consumption and the real exchange rate: The dynamics of the real exchange rate and consumption can be obtained directly from the internal and external balance conditions (97) and (98), which give the following solutions for $\widehat{s}_{t}$ and $\widehat{c}_{t}$ as functions of $\widehat{a}_{t}^{*}, d b_{t-1}^{c}$ and $\widehat{r e s}_{t-1}^{*}$ :

$$
\begin{aligned}
& \widehat{s}_{t}=\lambda_{a}^{(b)} \widehat{a}_{t}^{*}+\lambda_{b}^{(b)} d b_{t-1}^{c}+\lambda_{\text {res }}^{(b)} \widehat{r e s}_{t-1}^{*} \\
& \widehat{c}_{t}=\gamma_{a}^{(b)} \widehat{a}_{t}^{*}+\gamma_{b}^{(b)} d b_{t-1}^{c}+\gamma_{\text {res }}^{(b)} \widehat{r e s}_{t-1}^{*}
\end{aligned}
$$

where:

$$
\left\{\begin{array}{l}
\lambda_{a}^{(b)} \equiv-\left(\vartheta_{s}-\frac{\mathfrak{b}_{s}}{\mathfrak{b}_{c}} \vartheta_{c}\right)^{-1}\left(\frac{\kappa_{a^{*}}}{\kappa_{y^{T}}}\right) \\
\lambda_{r e s}^{(b)} \equiv-\left(\vartheta_{s}-\frac{\mathfrak{b}_{s}}{\mathfrak{b}_{c}} \vartheta_{c}\right)^{-1}\left(\frac{\kappa_{r e s^{*}}}{\kappa_{y} T} \frac{1}{\pi^{*}}\right) \\
\lambda_{b}^{(b)} \equiv\left(\vartheta_{s}-\frac{\mathfrak{b}_{s}}{\mathfrak{b}_{c}} \vartheta_{c}\right)^{-1}\left(1-\frac{1}{\mathfrak{b}_{c}} \vartheta_{c}\right) \mathfrak{b}_{\tau} \varrho
\end{array}\right.
$$

and

$$
\left\{\begin{array}{l}
\gamma_{a}^{(b)} \equiv \frac{\mathfrak{b}_{s}}{\mathfrak{b}_{c}} \lambda_{a}^{(b)} \\
\gamma_{r e s}^{(b)} \equiv \frac{\mathfrak{b}_{s}}{\mathfrak{b}_{c}} \lambda_{r e s}^{(b)} \\
\gamma_{b}^{(b)} \equiv \frac{\mathfrak{b}_{s}}{\mathfrak{b}_{c}} \lambda_{b}^{(b)}-\frac{1}{\mathfrak{b}_{c}} \mathfrak{b}_{\tau} \varrho
\end{array}\right.
$$

Inflation dynamics: As before, given the nominal interest rate in (85), the Euler equation (59) can be written as

$$
(R-1) \xi \widehat{\pi}_{t}=E_{t} \widehat{\pi}_{t+1}+\sigma\left(E_{t} \widehat{c}_{t+1}-R \widehat{c}_{t}\right)+(R-1) \xi \widehat{m}_{t-1}
$$

An expression for $\left(E_{t} \widehat{c}_{t+1}-R \widehat{c}_{t}\right)$ is needed:

Firstly, the solution for consumption dynamics in (100), together with the exogenous aid process (74) and the fact that $\widehat{r e s}_{t}^{*}=0$ (as in this case the government does not adjust its foreign exchange reserves), allows us to find an expression for $E_{t} \widehat{c}_{t+1}$

$$
\begin{aligned}
E_{t} \widehat{c}_{t+1} & =\gamma_{a}^{(b)} E_{t} \widehat{a}_{t+1}^{*}+\gamma_{r e s}^{(b)} \widehat{r e s}_{t}^{*}+\gamma_{b}^{(b)} d b_{t}^{c} \\
& =\gamma_{a}^{(b)} \rho_{a} \widehat{a}_{t}^{*}+\gamma_{b}^{(b)} d b_{t}^{c}
\end{aligned}
$$


This depends, however, on the current period sales of debt to the private sector $d b_{t}^{c}$ which, in this scenario, is the policy instrument that adjusts endogenously in response to the decline in aid revenues.

Sales of debt to the private sector are such that the government budget constraint is satisfied. Hence, starting with the consolidated government budget (84), set $\widehat{g}_{t}$ and $\widehat{r e s}_{t}^{*}$ to 0 , impose the constant money growth rate rule and the tax rule, and re-arrange terms to get

$$
\begin{aligned}
\frac{1}{y} d b_{t}^{c}= & \left(\kappa_{g} \zeta_{2}-\zeta^{\sharp}\right) \widehat{s}_{t}+\frac{\tau w l}{y}\left(\frac{\alpha}{1-\alpha+\psi}\right) \sigma \widehat{c}_{t}-\kappa_{a^{*}} \widehat{a}_{t}^{*}-\kappa_{m}\left(1-\frac{1}{\pi}\right)\left(\widehat{m}_{t-1}-\widehat{\pi}_{t}\right) \\
& -\left[\frac{\tau w l}{y}\left(1-\frac{\alpha}{1-\alpha+\psi} \frac{\tau}{1-\tau}\right) \varrho-\frac{R}{\pi y}\right] d b_{t-1}^{c}-\frac{\kappa_{r e s^{*}}}{\pi^{*}} \widehat{r e s}_{t-1}^{*}
\end{aligned}
$$

Then substituting for $\widehat{s}_{t}$ and $\widehat{c}_{t}$ using the solutions in (99) and (100), we obtain an expression for debt dynamics which depends on inflation $\widehat{\pi}_{t}$ and state variables only:

$$
\frac{1}{y} d b_{t}^{c}=\Delta_{a}^{(b)} \widehat{a}_{t}^{*}+\Delta_{b}^{(b)} d b_{t-1}^{c}+\Delta_{m}^{(b)}\left(\widehat{m}_{t-1}-\widehat{\pi}_{t}\right)+\Delta_{\text {res }}^{(b)} \widehat{r e s}_{t-1}^{*}
$$

where

$$
\left\{\begin{array}{l}
\Delta_{a}^{(b)} \equiv\left(\kappa_{g} \zeta_{2}-\zeta^{\sharp}\right) \lambda_{a}^{(b)}+\frac{\tau w l}{y}\left(\frac{\alpha}{1-\alpha+\psi}\right) \sigma \gamma_{a}^{(b)}-\kappa_{a^{*}} \\
\Delta_{b}^{(b)} \equiv\left(\kappa_{g} \zeta_{2}-\zeta^{\sharp}\right) \lambda_{b}^{(b)}+\frac{\tau w l}{y}\left(\frac{\alpha}{1-\alpha+\psi}\right) \sigma \gamma_{b}^{(b)}-\frac{\tau w l}{y}\left(1-\frac{\alpha}{1-\alpha+\psi} \frac{\tau}{1-\tau}\right) \varrho+\frac{R}{\pi y} \\
\Delta_{m}^{(b)} \equiv-\kappa_{m}\left(1-\frac{1}{\pi}\right) \\
\Delta_{\text {res }}^{(b)} \equiv\left(\kappa_{g} \zeta_{2}-\zeta^{\sharp}\right) \lambda_{\text {res }}^{(b)}+\frac{\tau w l}{y}\left(\frac{\alpha}{1-\alpha+\psi}\right) \sigma \gamma_{\text {res }}^{(b)}-\frac{\kappa_{r e s^{*}}}{\pi^{*}}
\end{array}\right.
$$

An expression for $\left(E_{t} \widehat{c}_{t+1}-R \widehat{c}_{t}\right)$ can then be derived as,

$$
\begin{aligned}
\left(E_{t} \widehat{c}_{t+1}-R \widehat{c}_{t}\right)= & {\left[\gamma_{a}^{(b)}\left(\rho_{a}-R\right)+\gamma_{b}^{(b)} \Delta_{a}^{(b)} y\right] \widehat{a}_{t}^{*}+\left[\gamma_{b}^{(b)} \Delta_{\text {res }}^{(b)} y-\gamma_{\text {res }}^{(b)} R\right] \widehat{r e s}_{t-1}^{*} } \\
& +\left[\gamma_{b}^{(b)}\left(\Delta_{b}^{(b)} y-R\right)\right] d b_{t-1}^{c}+\gamma_{b}^{(b)} \Delta_{m}^{(b)} y\left(\widehat{m}_{t-1}-\widehat{\pi}_{t}\right)
\end{aligned}
$$

Finally, substituting for $\left(E_{t} \widehat{c}_{t+1}-R \widehat{c}_{t}\right)$ in the Euler equation above, we obtain an equation in inflation $\widehat{\pi}_{t}$, expected inflation $E_{t} \widehat{\pi}_{t+1}$, and state variables 


$$
\widehat{\pi}_{t}=\Upsilon E_{t} \widehat{\pi}_{t+1}+\Upsilon_{a} \widehat{a}_{t}^{*}+\Upsilon_{b} d b_{t-1}^{c}+\widehat{m}_{t-1}+\Upsilon_{r e s} \widehat{r e s}_{t-1}^{*}
$$

where

$$
\left\{\begin{array}{l}
\Upsilon \equiv\left[(R-1) \xi+\sigma \gamma_{b}^{(b)} \Delta_{m}^{(b)} y\right]^{-1} \\
\Upsilon_{a} \equiv \Upsilon \sigma\left[\gamma_{b}^{(b)} \Delta_{a}^{(b)} y+\gamma_{a}^{(b)}\left(\rho_{a}-R\right)\right] \\
\Upsilon_{b} \equiv \Upsilon \sigma\left[\gamma_{b}^{(b)} \Delta_{b}^{(b)} y-\gamma_{b}^{(b)} R\right] \\
\Upsilon_{\text {res }} \equiv \Upsilon \sigma\left[\gamma_{b}^{(b)} \Delta_{\text {res }}^{(b)} y-\gamma_{\text {res }}^{(b)} R\right]
\end{array}\right.
$$

\section{A Solution for Inflation:}

As before, we can solve for inflation by using the minimum state variable method. Given a linear solution of the general form

$$
\widehat{\pi}_{t}=\varkappa_{a} \widehat{a}_{t}^{*}+\varkappa_{b} d b_{t-1}^{c}+\varkappa_{m} \widehat{m}_{t-1}+\varkappa_{r e s} \widehat{r e s}_{t-1}^{*}
$$

we then write expected inflation as

$$
\begin{aligned}
E_{t} \widehat{\pi}_{t+1}= & \varkappa_{a} E_{t} \widehat{a}_{t+1}^{*}+\varkappa_{b} d b_{t}^{c}+\varkappa_{m} \widehat{m}_{t}+\varkappa_{r e s} \widehat{r e s}_{t}^{*} \\
= & \left(\rho_{a} \varkappa_{a}+y \Delta_{a}^{(b)} \varkappa_{b}\right) \widehat{a}_{t}^{*}+\left(y \Delta_{r e s}^{(b)} \varkappa_{b}\right) \widehat{r e s}_{t-1}^{*}+\left(y \Delta_{b}^{(b)} \varkappa_{b}\right) d b_{t-1}^{c} \\
& +\left[\varkappa_{m}+y \Delta_{m}^{(b)} \varkappa_{b}\right]\left(\widehat{m}_{t-1}-\widehat{\pi}_{t}\right)
\end{aligned}
$$

where, in the second line, we have substituted for money supply rule and for debt dynamics using the expression in (101).

Substituting back into the Euler equation (102) and collecting terms, we then have

$$
\begin{aligned}
{\left[1+\Upsilon \varkappa_{m}+\Upsilon y \Delta_{m}^{(b)} \varkappa_{b}\right] \widehat{\pi}_{t}=} & {\left[\Upsilon \rho_{a} \varkappa_{a}+\Upsilon y \Delta_{a}^{(b)} \varkappa_{b}+\Upsilon_{a}\right] \widehat{a}_{t}^{*} } \\
& +\left[\Upsilon y \Delta_{r e s}^{(b)} \varkappa_{b}+\Upsilon_{r e s}\right] \widehat{r e s}_{t-1}^{*} \\
& +\left[\Upsilon y \Delta_{b}^{(b)} \varkappa_{b}+\Upsilon_{b}\right] d b_{t-1}^{c} \\
& +\left[1+\Upsilon \varkappa_{m}+\Upsilon y \Delta_{m}^{(b)} \varkappa_{b}\right] \widehat{m}_{t-1}
\end{aligned}
$$


where the LHS of the above equation can be further written as

$$
\left[1+\Upsilon \varkappa_{m}+\Upsilon y \Delta_{m}^{(b)} \varkappa_{b}\right]\left(\varkappa_{a} \widehat{a}_{t}^{*}+\varkappa_{b} d b_{t-1}^{c}+\varkappa_{m} \widehat{m}_{t-1}+\varkappa_{r e s} \widehat{\operatorname{res}}_{t-1}^{*}\right)
$$

Then, equating coefficients, we have the following system of four equations in $\left\{\varkappa_{a}, \varkappa_{r e s}, \varkappa_{m}, \varkappa_{b}\right\}$ :

$$
\begin{cases}(i): & {\left[1+\Upsilon \varkappa_{m}+\Upsilon y \Delta_{m}^{(b)} \varkappa_{b}\right] \varkappa_{a}=\Upsilon \rho_{a} \varkappa_{a}+\Upsilon y \Delta_{a}^{(b)} \varkappa_{b}+\Upsilon_{a}} \\ (i i): & {\left[1+\varkappa_{m}+\Upsilon y \Delta_{m}^{(b)} \varkappa_{b}\right] \varkappa_{b}=\Upsilon y \Delta_{b}^{(b)} \varkappa_{b}+\Upsilon_{b}} \\ (i i i): & {\left[1+\varkappa_{m}+\Upsilon y \Delta_{m}^{(b)} \varkappa_{b}\right] \varkappa_{m}=\left[1+\Upsilon \varkappa_{m}+\Upsilon_{y} \Delta_{m}^{(b)} \varkappa_{b}\right]} \\ (i v): & {\left[1+\varkappa_{m}+\Upsilon y \Delta_{m}^{(b)} \varkappa_{b}\right] \varkappa_{r e s}=\Upsilon y \Delta_{r e s}^{(b)} \varkappa_{b}+\Upsilon_{r e s}}\end{cases}
$$

The second and third equations in (103) can be solved jointly for $\varkappa_{b}$ and $\varkappa_{m}$. The two solutions for $\varkappa_{m}$ from eqn. (iii) are $\varkappa_{m}=1$ and $\varkappa_{m}=-1 / \Upsilon-y \Delta_{m}^{(b)} \varkappa_{b}$. The latter depends on $\varkappa_{b}$, but from eqn. $(i i)$ we obtain $\varkappa_{b}=\left(\Upsilon_{y} \Delta_{b}^{(b)}\right)^{-1}\left(-\Upsilon_{b}\right)$, which then implies $\varkappa_{m}=(-1 / \Upsilon)\left[1+\left(\Upsilon_{b} / \Delta_{b}^{(b)}\right) \kappa_{m}\left(1-\frac{1}{\pi}\right)\right]$. Under the model calibration, this solution is negative, which leads to a non-stationary path for real money balances. Then, the stationary solution is

$$
\varkappa_{m}^{(b)}=1
$$

while $\varkappa_{b}$ must solve the quadratic equation in $(i i)$

$$
\left[1+\Upsilon+\Upsilon y \Delta_{m}^{(b)} \varkappa_{b}\right] \varkappa_{b}=\Upsilon y \Delta_{b}^{(b)} \varkappa_{b}+\Upsilon_{b}
$$

A solution is obtained numerically, using the assumed parameter values.

Given these solutions, the remaining two equations can then be solved for $\varkappa_{a}$ and $\varkappa_{\text {res }}$ yielding:

$$
\begin{aligned}
& \varkappa_{a}^{(b)}=\left[1+\Upsilon \varkappa_{m}+\Upsilon y \Delta_{m}^{(b)} \varkappa_{b}-\Upsilon \rho_{a}\right]^{-1}\left(\Upsilon y \Delta_{a}^{(b)} \varkappa_{b}+\Upsilon_{a}\right) \\
& \varkappa_{\text {res }}^{(b)}=\left[1+\Upsilon \varkappa_{m}+\Upsilon y \Delta_{m}^{(b)} \varkappa_{b}\right]^{-1}\left(\Upsilon y \Delta_{\text {res }}^{(b)} \varkappa_{b}+\Upsilon_{\text {res }}\right)
\end{aligned}
$$

The real interest rate: The real interest rate dynamics can be inferred from the Euler equation (59), given the solution for consumption,

$$
\widehat{r}_{t}=\sigma\left(E_{t} \widehat{c}_{t+1}-\widehat{c}_{t}\right)
$$




\section{B.3 Monetization}

The third option we consider is one where the government monetizes the deficit that arises when foreign aid inflows decline and balances the budget, while keeping all other policy instruments unchanged $\left(\widehat{g}_{t}=0, d b_{t}^{c}=0, \widehat{\tau}_{t}=0\right.$, and $\left.\widehat{r e s}_{t}^{*}=0\right)$.

Internal Balance Condition: In this case, the internal and external balance schedules simplify greatly. For the internal balance condition, set $\widehat{g}_{t}$ and $\widehat{\tau}_{t}$ to 0 in (86) to get an expression in $\widehat{s}_{t}$ and $\widehat{c}_{t}$ only,

$$
\mathfrak{b}_{s} \widehat{s}_{t}=\mathfrak{b}_{c} \widehat{c}_{t}
$$

where $\mathfrak{b}_{s}$ and $\mathfrak{b}_{c}$ are defined as before,

$$
\left\{\begin{array}{l}
\mathfrak{b}_{s} \equiv\left(\frac{\alpha}{1-\alpha}+\chi\right) \zeta_{1}-\chi \varphi^{G}\left(\frac{\kappa_{g}}{\kappa_{y^{N}}}\right) \zeta_{2}-\frac{\alpha}{1-\alpha} \zeta_{3} \\
\mathfrak{b}_{c} \equiv \varphi \frac{\kappa_{c}}{\kappa_{y^{N}}}+\left(\frac{\alpha}{1-\alpha+\psi}\right) \sigma
\end{array}\right.
$$

External Balance Condition: For the external balance condition, set $\widehat{g}_{t}, \widehat{\tau}_{t}$ and $\widehat{r e s}_{t}^{*}$ to 0 in (87) and re-arrange to obtain an expression in $\widehat{s}_{t}, \widehat{c}_{t}$, $\widehat{a}_{t}^{*}$ and $\widehat{r e s}_{t-1}^{*}$ :

$$
\vartheta_{s} \widehat{s}_{t}=\vartheta_{c} \widehat{c}_{t}-\left(\frac{\kappa_{a^{*}}}{\kappa_{y^{T}}}\right) \widehat{a}_{t}^{*}-\left(\frac{\kappa_{r e s^{*}}}{\kappa_{y^{T}}} \frac{1}{\pi^{*}}\right) \widehat{r e s}_{t-1}^{*}
$$

where

$$
\left\{\begin{array}{l}
\vartheta_{s} \equiv \frac{\alpha}{1-\alpha}\left(1-\zeta_{3}\right)+\chi \zeta_{0}-\chi\left(1-\varphi^{G}\right)\left(\frac{\kappa_{g}}{\kappa_{y^{T}}}\right) \zeta_{2} \\
\vartheta_{c} \equiv(1-\varphi) \frac{\kappa_{c}}{\kappa_{y^{T}}}+\left(\frac{\alpha}{1-\alpha+\psi}\right) \sigma
\end{array}\right.
$$

Consumption and the real exchange rate: The internal and external balance conditions in (104) and (105) help characterize the dynamics of consumption and the real exchange rate. Solving the two equations, we obtain $\widehat{s}_{t}$ and $\widehat{c}_{t}$ as functions of state variables,

$$
\begin{aligned}
\widehat{s}_{t} & =\lambda_{a}^{(m)} \widehat{a}_{t}^{*}+\lambda_{\text {res }}^{(m)} \widehat{\operatorname{ess}}_{t-1}^{*} \\
\widehat{c}_{t} & =\gamma_{a}^{(m)} \widehat{a}_{t}^{*}+\gamma_{\text {res }}^{(m)} \widehat{\operatorname{res}}_{t-1}^{*}
\end{aligned}
$$


where

$$
\left\{\begin{array}{l}
\lambda_{a}^{(m)} \equiv-\left(\vartheta_{s}-\frac{\mathfrak{b}_{s}}{\mathfrak{b}_{c}} \vartheta_{c}\right)^{-1}\left(\frac{\kappa_{a^{*}}}{\kappa_{y^{T}}}\right) \\
\lambda_{\text {res }}^{(m)} \equiv-\left(\vartheta_{s}-\frac{\mathfrak{b}_{s}}{\mathfrak{b}_{c}} \vartheta_{c}\right)^{-1}\left(\frac{\kappa_{r e s^{*}}}{\kappa_{y^{T}}} \frac{1}{\pi^{*}}\right)
\end{array}\right.
$$

and

$$
\left\{\begin{array}{c}
\gamma_{a}^{(m)} \equiv \frac{\mathfrak{b}_{s}}{\mathfrak{b}_{c}} \lambda_{a}^{(m)} \\
\gamma_{r e s}^{(m)} \equiv \frac{\mathfrak{b}_{s}}{\mathfrak{b}_{c}} \lambda_{r e s}^{(m)}
\end{array}\right.
$$

We note that these coefficients are the same as in the case when the government uses debt to finance the increased deficit. Hence, the initial (contemporaneous) responses of the real exchange rate and consumption to a decline in aid would be the same under the two policy scenarios. However, their paths beyond the first period would be different, given the role of debt dynamics.

The real interest rate: The real interest rate dynamics are given by

$$
\widehat{r}_{t}=\sigma\left(E_{t} \widehat{c}_{t+1}-\widehat{c}_{t}\right)
$$

The solution for consumption in (107), together with the exogenous aid process (74) and the fact that $\widehat{r e s}_{t}^{*}=0$ (as in this case the government does not adjust its foreign exchange reserves) allow us to find

$$
E_{t} \widehat{c}_{t+1}=\gamma_{a}^{(m)} E_{t} \widehat{a}_{t+1}^{*}+\gamma_{r e s}^{(m)} \widehat{r e s}_{t}^{*}=\gamma_{a}^{(m)} \rho_{a} \widehat{a}_{t}^{*}
$$

which then implies

$$
\widehat{r}_{t}=\left[\gamma_{a}^{(m)}\left(\rho_{a}-1\right) \sigma\right] \widehat{a}_{t}^{*}-\left[\gamma_{\text {res }}^{(m)} \sigma\right] \widehat{r e s}_{t-1}^{*}
$$

Monetary policy setting: The government adjusts the money supply so as to finance the increased deficit that arises when foreign aid declines. Implicitly, changes in real money balances are such that the government budget constraint is satisfied. Starting with the budget constraint (84), set $\widehat{g}_{t}, \widehat{\tau}_{t}, \widehat{r e s}_{t}^{*}$, and $d b_{t}^{c}$ to 0 , and re-arrange terms to get: 


$$
\begin{aligned}
\kappa_{m} \widehat{m}_{t}= & \left(\kappa_{g} \zeta_{2}-\zeta^{\sharp}\right) \widehat{s}_{t}+\frac{\tau w l}{y}\left(\frac{\alpha}{1-\alpha+\psi}\right) \sigma \widehat{c}_{t} \\
& -\kappa_{a^{*}} \widehat{a}_{t}^{*}+\frac{R}{\pi y} d b_{t-1}^{c}+\frac{\kappa_{m}}{\pi}\left(\widehat{m}_{t-1}-\widehat{\pi}_{t}\right)+-\frac{\kappa_{r e s^{*}}}{\pi^{*}} \widehat{r e s}_{t-1}^{*}
\end{aligned}
$$

Then substituting for $\widehat{s}_{t}$ and $\widehat{c}_{t}$, using the solutions in (106) and (107), and collecting terms, changes in real money balances are as given by,

$$
\widehat{m}_{t}=\Delta_{a}^{(m)} \widehat{a}_{t}^{*}+\Delta_{b}^{(m)} d b_{t-1}^{c}+\frac{1}{\pi}\left(\widehat{m}_{t-1}-\widehat{\pi}_{t}\right)+\Delta_{r e s}^{(m)} \widehat{r e s}_{t-1}^{*}
$$

where

$$
\left\{\begin{array}{l}
\Delta_{a}^{(m)} \equiv\left(\frac{1}{\kappa_{m}}\right)\left[\left(\kappa_{g} \zeta_{2}-\zeta^{\sharp}\right) \lambda_{a}+\frac{\tau w l}{y}\left(\frac{\alpha}{1-\alpha+\psi}\right) \sigma \gamma_{a}-\kappa_{a^{*}}\right] \\
\Delta_{b}^{(m)} \equiv\left(\frac{1}{\kappa_{m}}\right) \frac{R}{\pi y} \\
\Delta_{r e s}^{(m)} \equiv\left(\frac{1}{\kappa_{m}}\right)\left[\left(\kappa_{g} \zeta_{2}-\zeta^{\sharp}\right) \lambda_{r e s}+\frac{\tau w l}{y}\left(\frac{\alpha}{1-\alpha+\psi}\right) \sigma \gamma_{r e s}-\frac{\kappa_{r e e^{*}}}{\pi^{*}}\right]
\end{array}\right.
$$

Inflation dynamics: The solution for inflation can be obtained from the Euler equation (59), where nominal interest rate changes are given by (85) and $\widehat{m}_{t}$ follows the path in (109) above. Making these substitutions, the Euler equation becomes,

$$
\begin{aligned}
(R-1) \xi \frac{1}{\pi} \widehat{\pi}_{t}= & E_{t} \widehat{\pi}_{t+1}+\sigma\left(E_{t} \widehat{c}_{t+1}-R \widehat{c}_{t}\right)+ \\
& +(R-1) \xi\left[\Delta_{a}^{(m)} \widehat{a}_{t}^{*}+\Delta_{b}^{(m)} d b_{t-1}^{c}+\frac{1}{\pi} \widehat{m}_{t-1}+\Delta_{\text {res }}^{(m)} \widehat{r e s}_{t-1}^{*}\right]
\end{aligned}
$$

Using the solution for consumption, we can first write the consumption term as

$$
\sigma\left(E_{t} \widehat{c}_{t+1}-R \widehat{c}_{t}\right)=\sigma\left[\gamma_{a}^{(m)}\left(\rho_{a}-R\right)\right] \widehat{a}_{t}^{*}-\sigma R \gamma_{r e s}^{(m)} \widehat{r e s}_{t-1}^{*}
$$

which then gives us the Euler equation in terms of inflation $\widehat{\pi}_{t}$, expected inflation $E_{t} \widehat{\pi}_{t+1}$, and state variables only:

$$
\widehat{\pi}_{t}=\Upsilon E_{t} \widehat{\pi}_{t+1}+\Upsilon_{a}^{(m)} \widehat{a}_{t}^{*}+\Upsilon_{b}^{(m)} d b_{t-1}^{c}+\widehat{m}_{t-1}+\Upsilon_{r e s}^{(m)} \widehat{r e s}_{t-1}^{*}
$$


where

$$
\left\{\begin{array}{l}
\Upsilon \equiv \frac{\pi}{(R-1) \xi} \\
\Upsilon_{a} \equiv \frac{\sigma \pi}{(R-1) \xi} \gamma_{a}^{(m)}\left(\rho_{a}-R\right)+\pi \Delta_{a}^{(m)} \\
\Upsilon_{b} \equiv \pi \Delta_{b}^{(m)} \\
\Upsilon_{r e s} \equiv-\frac{\sigma \pi R}{(R-1) \xi} \gamma_{r e s}^{(m)}+\pi \Delta_{r e s}^{(m)}
\end{array}\right.
$$

Given a linear solution of the general form,

$$
\widehat{\pi}_{t}=\varkappa_{a} \widehat{a}_{t}^{*}+\varkappa_{d} d b_{t-1}^{c}+\varkappa_{m} \widehat{m}_{t-1}+\varkappa_{r e s} \widehat{r e s}_{t-1}^{*}
$$

expected inflation is then given by,

$E_{t} \widehat{\pi}_{t+1}=\left(-\frac{1}{\pi} \varkappa_{m}\right) \widehat{\pi}_{t}+\left[\varkappa_{a} \rho_{a}+\varkappa_{m} \Delta_{a}^{(m)}\right] \widehat{a}_{t}^{*}+\frac{1}{\pi} \varkappa_{m} \widehat{m}_{t-1}+\varkappa_{m} \Delta_{b}^{(m)} d b_{t-1}^{c}+\varkappa_{m} \Delta_{r e s}^{(m)} \widehat{r e s}_{t-1}^{*}$

Substituting back into the Euler equation and re-arranging terms, we obtain:

$$
\begin{aligned}
\left(1+\Upsilon \frac{1}{\pi} \varkappa_{m}\right) \widehat{\pi}_{t}=\left[\Upsilon \rho_{a} \varkappa_{a}+\right. & \left.\Upsilon \Delta_{a}^{(m)} \varkappa_{m}+\Upsilon_{a}^{(m)}\right] \widehat{a}_{t}^{*}+\left[\left(\Upsilon \frac{1}{\pi} \varkappa_{m}+1\right) \Upsilon_{b}\right] d b_{t-1}^{c} \\
& +\left(\Upsilon \frac{1}{\pi} \varkappa_{m}+1\right) \widehat{m}_{t-1}+\left[\Upsilon \Delta_{\text {res }}^{(m)} \varkappa_{m}+\Upsilon_{\text {res }}^{(m)}\right] \widehat{r e s}_{t-1}^{*}
\end{aligned}
$$

where the LHS can be further written as,

$$
\left[1+\Upsilon \frac{1}{\pi} \varkappa_{m}\right]\left(\varkappa_{a} \widehat{a}_{t}^{*}+\varkappa_{b} d b_{t-1}^{c}+\varkappa_{m} \widehat{m}_{t-1}+\varkappa_{r e s} \widehat{r e s}_{t-1}^{*}\right)
$$

Then equating coefficients, we have the following system of four equations in $\left\{\varkappa_{a}, \varkappa_{r e s}, \varkappa_{m}, \varkappa_{d}\right\}$ :

$$
\begin{cases}(i): \quad\left(1+\Upsilon \frac{1}{\pi} \varkappa_{m}\right) \varkappa_{a}=\Upsilon \rho_{a} \varkappa_{a}+\Upsilon \Delta_{a}^{(m)} \varkappa_{m}+\Upsilon_{a}^{(m)} \\ (i i): \quad\left(1+\Upsilon \frac{1}{\pi} \varkappa_{m}\right) \varkappa_{b}=\left(\Upsilon \frac{1}{\pi} \varkappa_{m}+1\right) \Upsilon_{b} \\ (i i i): \quad\left(1+\Upsilon \frac{1}{\pi} \varkappa_{m}\right) \varkappa_{m}=\Upsilon \frac{1}{\pi} \varkappa_{m}+1 \\ (i v): \quad\left(1+\Upsilon \frac{1}{\pi} \varkappa_{m}\right) \varkappa_{r e s}=\Upsilon \Delta_{\text {res }}^{(m)} \varkappa_{m}+\Upsilon_{\text {res }}^{(m)}\end{cases}
$$

The stationary solution to the quadratic equation in $\varkappa_{m}$ is $\varkappa_{m}=1$ (the other root, 
$\varkappa_{m}=-\pi / \Upsilon$, is negative and would lead to non-stationary real money balances). The remaining equations can then be solved for $\varkappa_{a}, \varkappa_{b}$ and $\varkappa_{r e s}$. The solutions are:

$$
\left\{\begin{array}{l}
\varkappa_{a}^{(m)}=\left(1+\Upsilon \frac{1}{\pi}-\Upsilon \rho_{a}\right)^{-1}\left(\Upsilon \Delta_{a}+\Upsilon_{a}\right) \\
\varkappa_{b}^{(m)}=\Upsilon_{b} \\
\varkappa_{m}^{(m)}=1 \\
\varkappa_{r e s}^{(m)}=\left(1+\Upsilon \frac{1}{\pi}\right)^{-1}\left(\Upsilon \Delta_{r e s}+\Upsilon_{r e s}\right)
\end{array}\right.
$$




\section{B.4 Sales of Foreign Exchange Reserves}

The last policy scenario assumes that the Central Bank sells some of its existing foreign exchange reserves in order to finance the deficit. Total money supply follows the constant growth rate rule $\left(\widehat{m}_{t}=\widehat{m}_{t-1}-\widehat{\pi}_{t}\right)$, while other policy instruments remain unchanged $\left(\widehat{g}_{t}=\right.$ $\left.0, d b_{t}^{c}=0, \widehat{\tau}_{t}=0\right)$.

Internal Balance Condition: The internal balance condition is the same as in the monetization scenario in the previous section,

$$
\mathfrak{b}_{s} \widehat{s}_{t}=\mathfrak{b}_{c} \widehat{c}_{t}
$$

where $\mathfrak{b}_{s}$ and $\mathfrak{b}_{c}$ are as before.

External Balance Condition: The external balance condition is slightly different, due to the changes in foreign exchange reserves. Hence, starting with the expression in (87), set $\widehat{g}_{t}$ and $\widehat{\tau}_{t}$ to 0 , and re-arrange terms to obtain an expression in $\widehat{s}_{t}, \widehat{c}_{t}, \widehat{a}_{t}^{*}, \widehat{r e s}_{t}^{*}$ and $\widehat{r e s}_{t-1}^{*}$,

$$
\vartheta_{s} \widehat{s}_{t}=\vartheta_{c} \widehat{c}_{t}-\left(\frac{\kappa_{a^{*}}}{\kappa_{y^{T}}}\right) \widehat{a}_{t}^{*}+\left(\frac{\kappa_{r e s^{*}}}{\kappa_{y^{T}}}\right)\left(\widehat{r e s}_{t}^{*}-\frac{\widehat{r e s}_{t-1}^{*}}{\pi^{*}}\right)
$$

where the $\vartheta_{s}$ and $\vartheta_{c}$ coefficients are the same as in the monetization case.

Foreign exchange reserves: The government uses foreign exchange reserves (sales) to compensate for the decline in foreign aid and finance existing expenditures. The path of foreign exchange reserves is then determined by the government budget constraint in (84), which gives an expression for the change in reserves net of aid,

$$
\kappa_{r e s^{*}}\left(\widehat{r e s}_{t}^{*}-\frac{1}{\pi^{*}} \widehat{r e s}_{t-1}^{*}\right)-\kappa_{a^{*}} \widehat{a}_{t}^{*}=\left[\begin{array}{c}
\left(\zeta^{\sharp}-\kappa_{g} \zeta_{2}\right) \widehat{s}_{t}-\frac{\tau w l}{y}\left(\frac{\alpha}{1-\alpha+\psi}\right) \sigma \widehat{c}_{t}-\frac{R}{\pi y} d b_{t-1}^{c} \\
+\kappa_{m}\left(1-\frac{1}{\pi}\right)\left(\widehat{m}_{t-1}-\widehat{\pi}_{t}\right)
\end{array}\right]
$$

The external balance condition then becomes,

$$
\vartheta_{s}^{(r e s)} \widehat{s}_{t}=\vartheta_{c}^{(r e s)} \widehat{c}_{t}+\left(\frac{\kappa_{m}}{\kappa_{y^{T}}}\right)\left(1-\frac{1}{\pi}\right)\left(\widehat{m}_{t-1}-\widehat{\pi}_{t}\right)-\left(\frac{1}{\kappa_{y^{T}}}\right) \frac{R}{\pi y} d b_{t-1}^{c}
$$


where

$$
\left\{\begin{array}{l}
\vartheta_{s}^{(r e s)} \equiv \vartheta_{s}-\frac{\zeta^{\sharp}-\kappa_{g} \zeta_{2}}{\kappa_{y} T} \\
\vartheta_{c}^{(r e s)} \equiv \vartheta_{c}-\left(\frac{1}{\kappa_{y^{T}}}\right) \frac{\tau w l}{y}\left(\frac{\alpha}{1-\alpha+\psi}\right) \sigma
\end{array}\right.
$$

Note that changes in foreign aid are no longer having an effect on the external balance.

From the internal and external balance conditions in (111) and (113), we first express $\widehat{s}_{t}$ and $\widehat{c}_{t}$ in terms of inflation $\widehat{\pi}_{t}$ and state variables,

$$
\begin{aligned}
\widehat{s}_{t} & =\lambda_{m}^{(r e s)}\left(\widehat{m}_{t-1}-\widehat{\pi}_{t}\right)+\lambda_{b}^{(r e s)} d b_{t-1}^{c} \\
\widehat{c}_{t} & =\left(\mathfrak{b}_{s} / \mathfrak{b}_{c}\right) \widehat{s}_{t} \\
& =\gamma_{m}^{(r e s)}\left(\widehat{m}_{t-1}-\widehat{\pi}_{t}\right)+\gamma_{b}^{(r e s)} d b_{t-1}^{c}
\end{aligned}
$$

where:

$$
\left\{\begin{array}{l}
\lambda_{m}^{(r e s)} \equiv\left(\vartheta_{s}^{(r e s)}-\frac{\mathfrak{b}_{s}}{\mathfrak{b}_{c}} \vartheta_{c}^{(r e s)}\right)^{-1}\left(\frac{\kappa_{m}}{\kappa_{y} T}\right)\left(1-\frac{1}{\pi}\right) \\
\lambda_{b}^{(r e s)} \equiv-\left(\vartheta_{s}^{(r e s)}-\frac{\mathfrak{b}_{s}}{\mathfrak{b}_{c}} \vartheta_{c}^{(r e s)}\right)^{-1}\left(\frac{1}{\kappa_{y} T}\right) \frac{R}{\pi y} \\
\gamma_{m}^{(r e s)} \equiv \frac{\mathfrak{b}_{s}}{\mathfrak{b}_{c}} \lambda_{m}^{(r e s)} \\
\gamma_{b}^{(r e s)} \equiv \frac{\mathfrak{b}_{s}}{\mathfrak{b}_{c}} \lambda_{b}^{(r e s)}
\end{array}\right.
$$

Inflation dynamics: Using the nominal interest rate in (85), the Euler equation (59) can be re-written as

$$
(R-1) \xi \widehat{\pi}_{t}=E_{t} \widehat{\pi}_{t+1}+\sigma\left(E_{t} \widehat{c}_{t+1}-R \widehat{c}_{t}\right)+(R-1) \xi \widehat{m}_{t-1}
$$

The expression for consumption in (115), together with the rest of the policy specification, then allows us to obtain an expression for $\left(E_{t} \widehat{c}_{t+1}-R \widehat{c}_{t}\right)$ as

$$
\begin{aligned}
\left(E_{t} \widehat{c}_{t+1}-R \widehat{c}_{t}\right) & =\left[\gamma_{m}^{(r e s)}\left(\widehat{m}_{t-1}-\widehat{\pi}_{t}\right)-\gamma_{m}^{(r e s)} E_{t} \widehat{\pi}_{t+1}\right]-R\left[\gamma_{m}^{(r e s)}\left(\widehat{m}_{t-1}-\widehat{\pi}_{t}\right)+\gamma_{b}^{(r e s)} d b_{t-1}^{c}\right] \\
& =-\gamma_{m}^{(r e s)} E_{t} \widehat{\pi}_{t+1}-\gamma_{m}^{(r e s)}(R-1)\left(\widehat{m}_{t-1}-\widehat{\pi}_{t}\right)-R \gamma_{b}^{(r e s)} d b_{t-1}^{c}
\end{aligned}
$$


Substituting back into the Euler equation, we obtain an expression involving inflation $\widehat{\pi}_{t}$, expected inflation $E_{t} \widehat{\pi}_{t+1}$ and pre-determined variables, $d b_{t-1}^{c}$ and $\widehat{m}_{t-1}$

$$
\widehat{\pi}_{t}=\Upsilon E_{t} \widehat{\pi}_{t+1}+\widehat{m}_{t-1}+\Upsilon_{b}^{(r e s)} d b_{t-1}^{c}
$$

where

$$
\left\{\begin{array}{l}
\Upsilon \equiv \frac{1-\sigma \gamma_{m}^{(r e s)}}{(R-1)\left(\xi-\sigma \gamma_{m}^{(\text {res })}\right)} \\
\Upsilon_{b} \equiv \frac{-\sigma R \gamma_{b}^{(r e s)}}{(R-1)\left(\xi-\sigma \gamma_{m}^{(r e s)}\right)}
\end{array}\right.
$$

\section{A Solution for Inflation}

In this case, inflation is entirely pre-determined, depending only on lagged variables,

$$
\widehat{\pi}_{t}=\varkappa_{b}^{(r e s)} d b_{t-1}^{c}+\varkappa_{m}^{(r e s)} \widehat{m}_{t-1}
$$

where, following the same procedure as before, we find

$$
\begin{aligned}
& \varkappa_{b}^{(\text {res })}=(1+\Upsilon)^{-1} \Upsilon_{b}^{(r e s)} \\
& \varkappa_{m}^{(\text {res })}=1
\end{aligned}
$$

Consumption, the real exchange rate and the real interest rate: Given the nature of inflation, the dynamics of consumption, the real exchange rate and the real interest rate are all predetermined and independent of the foreign aid shock. Formally, using equations (114), (115), and the Euler equation, we have:

$$
\begin{aligned}
\widehat{s}_{t} & =\left(\lambda_{b}^{(\text {res })}-\lambda_{m}^{(\text {res })} \varkappa_{b}^{(r e s)}\right) d b_{t-1}^{c} \\
\widehat{c}_{t} & =\left(\gamma_{b}^{(r e s)}-\gamma_{m}^{(\text {res })} \varkappa_{b}^{(r e s)}\right) d b_{t-1}^{c} \\
\widehat{r}_{t} & =-\sigma\left(\gamma_{b}^{(\text {res })}-\gamma_{m}^{(\text {res })} \varkappa_{b}^{(r e s)}\right) d b_{t-1}^{c}
\end{aligned}
$$

